\title{
Energy metabolism in pediatric obesity
}

Citation for published version (APA):

van Mil, E. G. A. H. (2000). Energy metabolism in pediatric obesity. [Doctoral Thesis, Maastricht University]. UM. https://doi.org/10.26481/dis.20000414em

Document status and date:

Published: 01/01/2000

DOI:

10.26481/dis.20000414em

Document Version:

Publisher's PDF, also known as Version of record

\section{Please check the document version of this publication:}

- A submitted manuscript is the version of the article upon submission and before peer-review. There can be important differences between the submitted version and the official published version of record.

People interested in the research are advised to contact the author for the final version of the publication, or visit the DOI to the publisher's website.

- The final author version and the galley proof are versions of the publication after peer review.

- The final published version features the final layout of the paper including the volume, issue and page numbers.

Link to publication

\footnotetext{
General rights rights.

- You may freely distribute the URL identifying the publication in the public portal. please follow below link for the End User Agreement:

www.umlib.nl/taverne-license

Take down policy

If you believe that this document breaches copyright please contact us at:

repository@maastrichtuniversity.nl

providing details and we will investigate your claim.
}

Copyright and moral rights for the publications made accessible in the public portal are retained by the authors and/or other copyright owners and it is a condition of accessing publications that users recognise and abide by the legal requirements associated with these

- Users may download and print one copy of any publication from the public portal for the purpose of private study or research.

- You may not further distribute the material or use it for any profit-making activity or commercial gain

If the publication is distributed under the terms of Article $25 \mathrm{fa}$ of the Dutch Copyright Act, indicated by the "Taverne" license above, 
Energy metabolism in paediatric obesity 
(C) Edgar G.A.H van Mil, Maastricht 2000 ISBN 90-5681-071-5

Omslag illustratie: Guus van Rooy

Vormgeving en druk: Unigraphic, Universiteit Maastricht 


\section{Energy metabolism in paediatric obesity}

\section{Proefschrift}

ter verkrijging van de graad van doctor

aan de Universiteit Maastricht,

op gezag van de Rector Magnificus,

Prof. dr. A.C. Nieuwenhuijzen Kruseman,

volgens het besluit van het College van Dekanen,

in het openbaar te verdedigen

op vrijdag 14 april 2000 om 12.00 uur

door

Edgar Gerardus Antonius Henricus van Mil geboren te Waalwijk 


\section{Promotores:}

Prof. dr.W.H.M. Saris

Prof. dr. K.R. Westerterp (Katholieke Universiteit Leuven)

Prof. dr. C.E. Blanco

Beoordelingscommissie:

Prof. dr. H. Kuipers (voorzitter)

Prof. dr. T.W.A. de Bruin

Prof. dr. J.P.M. Geraedts

Dr. M.B.E. Livingstone (University of Ulster, Coleraine, Northern Ireland)

Dr. B. Otten (Katholieke Universiteit Nijmegen)

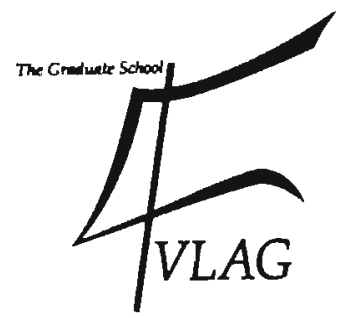

ntưtim
Performed at the Nutrition and Toxicology Research Institute Maastricht (NUTRIM) which participates in the Graduate School VLAG (Food Technology, Agrobiotechnology, Nutrition and Health Sciences), accredited by the Royal Netherlands Academy of Arts and Sciences. www-nutrim.unimaas.nl

Financial support by Knoll B.V. for the publication of this thesis is gratefully acknowledged

Additional support was granted by: Stichting ter bevordering Kindergeneeskunde, Pharmacia \& Upjohn, Friesland Nutrition, Mead Johnson Nutritionals, Roche Nederland BV, Eli Lilly Nederland 
dankzij mijn vader en moeder voor Sandra 


\section{Contents}

Chapter 1

Introduction 19

Chapter 2

Energy expenditure at rest and during sleep in children with Prader-Willi syndrome explained by body composition $\mid 49$

\section{Chapter 3}

Activity related energy expenditure in children and adolescents with Prader-Willi syndrome | 63

\section{Chapter 4}

Body composition in Prader-Willi syndrome $\mid 77$

\section{Chapter 5}

Energy expenditure in adolescence: a multicentre analysis of the effect of gender and body composition $\mid 95$

\section{Chapter 6}

Obesity management in adolescence: Sibutramine prevents the decrease in basal metabolic rate associated with restriction of energy intake | 115

\section{Chapter 7}

General discussion and conclusions | 137

Summary $\mid 157$

Samenvatting | 161

Nawoord 165

Curriculum Vitae | 169

Publications | 17 

Chapter 1

Introduction 


\section{An introduction to paediatric obesity}

Defining paediatric obesity

Increasing prevalence of paediatric obesity

Risks and consequences of paediatric obesity

The aetiology of paediatric obesity

A population perspective

Evidence for an increase in energy intake

Evidence for a decrease in energy expenditure

An individual perspective

Individual susceptibility to obesity

Critical periods for the development of paediatric obesity

\section{An introduction to energy metabolism}

The concept of energy balance

Measurement of energy intake

Measurement of energy expenditure

Energy metabolism in Prader-Willi syndrome

An introduction to Prader-Willi syndrome

Energy metabolism studies in Prader-Willi syndrome

Treatment strategies in paediatric obesity

Outline of the thesis 


\section{An introduction to paediatric obesity}

\section{Defining paediatric obesity}

The term's obesity and overweight are often used interchangeably, but they are distinct conditions. Obesity indicates excess adipose tissue, whereas overweight indicates excess weight for height, regardless of the composition of the weight. The definition of obesity is, however, often based on measures of weight relative to height. In adults, obesity is defined in terms of body mass index (BMI) or Quetelet Index, referring to the mathematician Lambert Adolphe Jacques Quetelet (1), and is calculated as weight in kilograms $(\mathrm{kg})$ divided by the square of the height in meters. The reason for the use of BMI instead of a more direct measurement of adiposity, such as skinfold thickness, is that weight and height can be obtained in a variety of clinical and field settings, with reasonable precision, using instruments that are relatively inexpensive. Recently, an expert consultation on obesity, convened by the world health organization (WHO), reported that obesity in adults is defined as BMI $\geq 30 \mathrm{~kg} / \mathrm{m}^{2}(2)$. This definition is based on longevity and morbidity associations with various levels of weight $(2,3)$. Indeed, for non-growing individuals, BMl is almost independent of height and has a J-shaped relation with mortality risk (4). In children and adolescents, however, BMI changes markedly with age, dependent of the gender, race and maturation, which strongly co-varies with height (5). For example, disproportionate accumulation of adipose tissue occurs during female adolescence, whereas male adolescence is characterized by accumulation of fat-free mass (6). Consequently, the differences in body composition during growth result in a relationship between weight-for-height measures and adiposity, that is age-dependent and varies by race and gender $(5,7,8)$. Nonetheless, comparing children and adolescents of the same age, race and gender, BMI comes close to presenting the least height bias (9), which makes it the preferred measure of adiposity for routine clinical and public health purposes. Another difference between children and adults is that the development of cutoff levels, based on mortality or morbidity, is currently not possible. Childhood mortality is unlikely to be related to increased adiposity, while sparse data on childhood morbidity, adult morbidity, adult mortality, and adult obesity $(10,11,12$, $13,14,15,16,17)$, do not support a classification (6).

Therefore, in the absence of outcome-based criteria for children, the likelihood that obesity will persist in adulthood with related risk of adult morbidity and death following childhood-onset obesity, represents the best criterion by which to judge the clinical validity of BMI in the paediatric age group. This integration of obesity assessment in children and adults has led to a definition based on the agreement that the paediatric percentiles identified in late adolescence by a BMI 
of 30 , should constitute the cutoff point for identification of childhood obesity (18, $19,20)$. Furthermore, because of the great concern associated with the diagnosis, together with the high prevalence of eating disorders among adolescent girls, specificity in the diagnosis of childhood obesity is considered of greater importance than sensitivity. Therefore, a cut-off that minimizes false positives, will be more appropriate, even if it does not detect all children who are obese (21). The combination of these factors has led to a definition of paediatric obesity for children ( 6 - 10 years) and adolescents (22) as BMI $>95^{\text {th }}$ percentile in age and gender related reference curves $(6,23,24,25,26)$. Generally, these curves can also be used for the calculation of a child's standard deviation score (SDS), which is a combined adjustment for age and gender. Although this definition can only serve as a proxy for the degree of obesity $(5,20,27,28)$, changes in BMI SDS over time are helpful to monitor changes in body size in order to evaluate therapeutic interventions. Efforts are underway to develop an international reference population to compare the prevalence of obesity among countries (20).

\section{Increasing prevalence of paediatric obesity}

As a result of the lack of an international reference population, the present global reports of the prevalence of paediatric obesity should be interpreted with care. Nevertheless, large-scale studies have shown that during the last decades, the adiposity of the paediatric population has grown (29). The first alarming reports came from the United States of America (USA), where paediatric obesity is considered the most pressing nutritional problem of recent time (30). From about 1980 until 1990, the number of obese children with BMI in excess of the $95^{\text {th }}$ percentile rose from approximately 7.5 to $10.7 \%$ for children aged 6 - 11 years, and from 5.7 to $10.8 \%$ for adolescents aged $12-17$ years (29). Some epidemiological surveys even estimated a current prevalence of $13 \%$ (26). Generally, the prevalence of obesity in children and adults in the USA has increased by more than $30 \%$ over the past decade (31). Similar trends are provided by the National Studies of Health and Growth of English and Scottish children from the 1970's to the 1990's $(32,33)$. In the Netherlands, initially, weight for height indices for children and young adults had not increased from the 1950's to the 1980's (34), however, the last decade has also showed an increase in obesity $(35,36)$. These data are in agreement with surveys in Dutch adults, which initially showed a fairly stable prevalence of obesity during the 1980's, but recently demonstrated an increase in prevalence $(37,38)$. Other smaller studies $(39,40,41,42,43,44,45)$ have indicated an increasing prevalence throughout Europe, North America and the Middle East. Even several developing countries now have witnessed their century old problem of under-nutrition change into the problem of obesity $(46,47,48,49,50)$. Besides a general increase 
in adiposity in the paediatric population, there is also evidence of an increasing degree of obesity, mainly in older children and adolescents (44), which suggests that the likelihood of persistence from childhood into adulthood will increase in the future (30).

\section{Risks and consequences of paediatric obesity}

The way in which obesity affects health is assessed by examining its effects on the duration of life and the presence or onset of premature disease. This epidemiological approach has associated increased BMI (starting above BMI 25) in adults, with excess morbidity and higher mortality rates $(2,51)$. More specifically, the detrimental effects of obesity include an increased risk for insulin resistance, hypertension, dyslipidemia, cardiovascular disease, non-insulin-dependent diabetes mellitus, gallstones and cholecystitis, respiratory dysfunction, and certain forms of cancer $(52,53,54)$.

Although for most children, complications of childhood obesity do not become apparent for decades, the metabolic consequences may already be evident in young children. Even a young child, if severely obese, can suffer serious morbidity. Prior to adulthood, the obese child may develop hypertension $(55,56,57,58,59)$ gallstones $(60)$, liver steatosis $(61,62)$, sleep apnea $(63,64)$, and increased intracranial pressure (65). In fact, there are few organ systems that obesity does not affect in childhood. The most ominous finding is that one-third of the newly diagnosed diabetics in the USA, between 10 - 19 years of age, are type 2 diabetics, especially poignant when considering that this condition was once called 'adultonset diabetes' (66).

Of equal concern are the teasing, discrimination and victimization of obese children (30). In fact, teasing is among the most frequent complaints in the paediatric age group. To avoid teasing many obese children choose younger children as friends (67). Studies of children as young as 6 years of age suggest that overweight individuals are most likely to be described as lazy, lying, cheating, sloppy, dirty, ugly and stupid $(68,69)$. Consequently, obese children are uniformly ranked by other children as the least desired friends $(70)$ and even physicians describe obese individuals as weak willed, ugly and awkward ( 7$)$. A longitudinal study of self-esteem among obese children (72), demonstrated that self-esteem and body fatness were inversely related, while middle childhood is known as a critical period for the development of body image. Consequently, it has been suggested that women who became obese during childhood are likely to have persistent severe disturbances in body image (73). Discrimination against overweight adolescents, as well as low self-esteem and low confidence, may contribute to the lower academic achievements observed among obese adolescents $(74,75)$. A combination of 
these factors probably contribute to the finding that adolescent obesity is associated with less schooling, lower rates of marriage, lower income and higher rates of poverty, even after adjusting for baseline family income, education and ethnicity $(76,7)$.

Few data are available from children and adolescents regarding the intermediate and long-term consequences of obesity. Associations have been shown between $\mathrm{BMI}$ or changes in BMI in the paediatric age range and increased adult blood pressure $(78,79,80,81)$, adverse lipoprotein profiles $(82,83,84,85,86,87)$, non-insulindependent diabetes mellitus $(88,89)$, and early atherosclerotic lesions $(90)$.

Furthermore, excessive weight during adolescence predicts a number of adverse effects on health later in life, including increased all-cause mortality and mortality from cardiovascular disease and colon cancer among men (13, 14, 16, 91, 92, 93). Additionally, adult mortality is significantly increased among men who were obese as adolescents $(13,21)$. In a follow-up study of young Dutch men, recorded at military registration, elevated adolescent $\mathrm{BMI}$ was associated with a relative risk of 1.5 for all-cause and 2.5 for coronary heart disease mortality after 20 years (12). Despite these associations, the strongest risk factors come from longitudinal data, indicating that BMI tracks from childhood to young adulthood for boys as well as girls $(19,94)$. Up to $80 \%$ of overweight $\left(85^{\text {th }}\right.$ percentile of BMI curve) children become obese adults $(17,19,95,96)$. The risk of adult obesity is greater for children who are at higher levels of obesity and for children who are obese at older ages (15). After adjustment for parental obesity, the odds ratios for obesity in adulthood associated with childhood obesity ranged from 1.3 for obesity at 1 or 2 years of age, to 17.5 for obesity at 15 to 17 years of age. That is, obese children under three years of age without obese parents are at low risk for obesity in adulthood, whereas, among older children, obesity is an increasingly important predictor for adult obesity, regardless of whether the parents are obese. After six years of age, the probability of obesity in adulthood exceeds $50 \%$ for obese children, compared with about $10 \%$ in non-obese children (97). This finding appears to be in agreement with the BMI curve, that shows, on average, a nadir at about 5 to 6 years of age. An early nadir or rebound (less than 6 years) is associated with high BMI and high skinfold thickness at the age of 21 years (98). 


\title{
The aetiology of paediatric obesity
}

\author{
A population perspective
}

What is the reason for this sudden increase in paediatric obesity? The first law of thermodynamics dictates that high energy intake or low energy expenditure, or these factors combined, ultimately explains weight gain. Surprisingly little, however, is known about the factors that cause the high energy intake and low energy expenditure.

\section{Evidence for an increase in energy intake}

In western, affluent societies increased energy intake is often seen as the most obvious reason for weight gain. In contradiction, there is evidence that in recent decades the average energy intake of children in many countries has declined (29, $31,32,52,99)$. Surveys in young children in the UK have indicated a reduction of energy intake of around $15 \%(100,101)$.

Analysis of economic and food availability data for $1962-1994$, however, revealed a major shift in the structure of the global diet in all ages, marked by an uncoupling of the classic relationship between incomes and fat intake, and accelerated further by high urbanization rates. Thus, large parts of the world have changed their traditional food habits (i.e. consisting of a high percentage of carbohydrates and low in fat), towards a more palatable diet (i.e. lower amounts of carbohydrates and higher amounts of fat). Whereas this, so called, nutritional transition, has led to improved food security and health, the availability of cheap vegetable oils and fats has resulted in greatly increased fat consumption particularly among low-income populations (102). Furthermore, the increased palatability of this more energy dense food is likely to result in an increased energy intake, easily leading to a positive energy balance (103). Childhood obesity seems one of the particular implications of these trends $(47,104)$, as take-away and ready-prepared energy dense foods make increasingly large contributions to the energy intake of children around the world $(2,105,106)$. These findings seem to be in contrast with the data that the average energy intake in children is declining, which may indicate selective underreporting of these high fat foods. A possible explanation for this potential confounding factor in the measurement of habitual food intake, is that generally, the child's intake is recollected by the parent, while the parent's capacity to accurately complete the questionnaire is affected by memory failure, level of nutritional knowledge, and motivation. The amount of error is augmented further by the inability of the parent to correctly appraise serving size, the degree of 
the perceived value of the food items to be recalled, and the fact that parents and children tend to better remember preferred foods, than non-preferred foods (107, 108).

\section{Evidence for a decrease in energy expenditure}

Concurrent with the changes in diet structure are equally dramatic shifts in activity patterns among all age groups (109). While studies differ, several reports mentioned that the average child in the USA watches approximately 24 hours of television per week $(109,110,11,112)$. Furthermore, the number of high school students enrolled in physical education classes in the USA decreased between 1984 and 1990 and, consequently, fitness levels as measured by endurance tests have declined, although the latter seems in contrast with the stable measures of aerobic power ( $\mathrm{VO}_{2 \text { max }}$ as a proxy variable of the physical activity level) that have been found in Dutch children (113), and the comparable fitness levels in USA (114) and Italian $(115,116)$ overweight and non-overweight prepubertal children.

Nonetheless, the use of the computer with video games, internet and other similar sedentary activities is increasing $(109,112)$ and many reports have correlated decreased physical activity with obesity in children $(110,112,117,118,119,120,121)$ as well as adults $(122,123)$, suggesting that physical inactivity may explain the development of the current epidemic of obesity. Some studies indicate that the decrease in physical activity has led to such a strong decrease in total energy expenditure, that the energy prescriptions, based on data of children and adolescents measured several decades ago $(124,125)$, are overestimating the current energy needs in growing children, which may enhance a positive energy balance in childhood $(101,126,127,128,129)$. These suggestions, however, are not supported by the results of the Dutch Voedingsraad ('Nutrition Council') that re-calculated the energy requirements from infancy to adulthood from data reported until 1987 and found results that were comparable with previous prescriptions (130).

As with nutrition, activity reflects a strong familial component. $A$ lot of the adult activities, such as jogging, are individual activities, but not social or group activities designed to engage youth. This might be a reason why tracking of physical activity is generally low to moderate during early childhood (131), and during adolescence into adulthood (132). Saris et al. (113) studied the tracking of physical activity variables in a large group of boys and girls between the ages 6 and 12 years, and found only in girls was there a tendency for a reduction in physical fitness (expressed per kg body weight) (32). The strongest decrease in physical activity, or best adherence to sedentary activities (133), therefore, seems to occur just before puberty, with a high risk of maintaining this behaviour into adulthood. 
Summarizing, evidence exists that on a population level, the composition of the diet has changed, which, although not supported by data, has possibly led to an increased energy intake, while the industrialization has resulted in sedentary societies.

\section{An individual perspective}

\section{Individual susceptibility to obesity}

Despite the fact that westernized societies offer an obesity encouraging environment, not all children develop obesity. Probably, some individuals are more obesity prone than others. A popular explanation is the theory of the 'thrifty genes' (134, 135). Since the energy stores in the human body are important for survival and reproduction, the possibility to store energy in tissues, e.g. fat, must have had an important role in the chances of survival of our ancestors in the environments of food shortage, in which they evolved. For this reason, genes were selected that promote energy intake and storage and minimize energy expenditure (136). This is a popular theory to explain the idea that relevant genes mediate susceptibility to obesity in a specific environmental context. The genes may affect energy intake, energy expenditure, and partitioning of stored energy between lean tissues and fat.

Related evidence comes from studies in twins, adoptees, and families $(137,138)$ that indicate that possibly as much as $80 \%$ of the variance in $\mathrm{BMI}$ is attributable to genetic factors. Epidemiological data demonstrates, that before three years of age, the primary predictor of obesity in adulthood is the parents' obesity status, however, as the child grows, the child's obesity status itself becomes a more important predictor, regardless of whether the parents are obese. Especially before six years of age, obesity in both parents substantially increases the odds of the child becoming an obese adult (97) (13). Parental obesity more than doubles the risk of adult obesity among both obese and non-obese children under 10 years of age (97). Familial resemblance, however, is not simple to interpret since it may also be due to shared environmental factors.

The observation that the prevalence of obesity increased substantially over a single decade, a period much too brief for any significant change to have occurred in the genetic make-up of the population in the western societies, indicates that the current relative adiposity is a product of the interaction between genetic predisposition with regard to the storage of body fat, and an environment that is extremely permissive to the expression of that genetic tendency. The physiologi- 
cal determinants (energy intake, energy output, or partitioning of energy stores) that interact with these genetic factors, are not yet known. Small changes in any of the many physiological systems (endocrine, gastrointestinal, central nervous, peripheral nervous and cardiovascular) that affect these functions can, over time, result in substantial changes in body weight (136). In any individual - and in the same individual at different times in life - the relative influence of these environmental and genetic factors may vary (136). Since the susceptibility to obesity is likely to surface during childhood, the study of paediatric obesity is of great importance in relation to the health problem.

\section{Critical periods for the development of paediatric obesity}

Generally, adiposity in boys increases in the prepubertal stage and declines following the growth spurt, whereas in girls, the percentage of fat mass remains relatively constant prior to adolescence and increases during the adolescent growth spurt $(21,139)$. Increase in adiposity can be caused by an increase in adipocyte size or number (21). Cross-sectional and longitudinal studies of adipocyte numbers indicate a modest increase throughout childhood with a pronounced increase after age 10 years $(140,141)$. Adipocyte size, however, increases to adult levels in late infancy, resulting in an average fat mass of $15-25 \%(130,142)$, and then decreases back to the level observed at early infancy (143). This fattening in infancy coincides with the need of the newborn to survive periods of fasting by mobilizing adipose triacylglycerol reserves (144). Thereafter, fat cell size diminishes and remains constant until early adolescence (21). During childhood the adiposity varies between $12-15 \%$ in boys and $15-20 \%$ in girls (145), whereas during puberty, boys often decrease in adiposity, while girls increase to $20-25 \%(146,147,148)$. Fat deposition prior to puberty in boys has physiological importance as a reserve of energy to support lean tissue growth at puberty. In girls, fat deposition is thought to act as energy storage for the nutritional demands of pregnancy and lactation (9). Obese children have increased numbers of fat cells regardless of age, as well as increased adipocyte size, while weight reduction only reduces adipocyte size (149).

Apart from changes in the fat content in the body, the period around puberty also is characterized by changes in body fat distribution. Immediately prior to adolescence, body fat shifts from mainly peripheral distribution to central distribution, in both genders, with the most rapid increase in visceral fat occurring during late adolescence (21).

Recent data suggest that the likelihood of persistence of obesity, and therefore the likelihood of adverse consequences of obesity in adulthood, may be related to the age of onset (150). During early life, such distinct critical periods for subse- 
quent weight regulation seem to occur during prenatal life, childhood, and adolescence. Such a 'critical period' indicates that during this period, underlying biological systems are influenced irreversibly. These periods differ from 'high-risk' periods that mostly occur later in life, such as pregnancy or menopause in women. Evidence that obesity, developing at each of these periods, is associated with an increased risk of persistence and subsequent disease, comes from epidemiological data $(150,151,152,153,154,155)$. The mechanisms that promote this increased risk of persistence of obesity, however, are poorly understood (21). Evidence that the prenatal environment 'programmes' a range of physiological and metabolic parameters, first came from studies in which low birth weight and disproportionate body size at birth (thinness or shortness) have been related to later disease (154). In a later study, males born during or just after the Dutch 'Hunger Winter' (1944 - 1945) were shown to have a slightly higher prevalence of overweight at 19 years of age if maternal under-nutrition occurred during the first two trimesters, and a slightly reduced incidence if maternal under-nutrition occurred during the last trimester of pregnancy or if the infant was exposed to famine conditions in the first 3 to 5 month of extra-uterine life (156). A more recent study describing children of diabetic mothers, demonstrated that the prevalence of obesity was increased at later ages, and extended through adolescence (152). According to Barker (157), underlying mechanisms include setting of the hypothalamus and sensitivity to hormones (i.e., endocrine pancreas). The second critical period is the period of adiposity rebound during prepubertal growth (153). As was mentioned earlier, early acceleration of the BMI after its nadir at 5-6 years of age is associated with an increased risk of later obesity $(98,158)$. The final developmental stage with increased risk for adult obesity appears to be the period of adolescence (21). Together with early infancy, the period of adolescence, especially during the growth spurt, is characterized by rapid changes in body composition. This dynamic period therefore seems an optimal moment for studying the aetiology of paediatric obesity (159). Approximately $30 \%$ of obesity in 36-year-old women is related to obesity at this time, whereas in males, only approximately $10 \%$ of obesity present at 36 years of age begins at adolescence (160).

\section{The concept of energy balance}

The concept of energy balance arises from the law of conservation of energy. One of the earliest reports studying the principle of energy conservation was written in 1894 by Rubner (161), who demonstrated that an animal's heat balance is consistent with the first principle of thermodynamics; namely, energy can neither be created nor destroyed, but can only be exchanged between the body and its envi- 
ronment. Like all living organisms, humans engage in a constant energy exchange with the environment. The energy balance of the body is maintained only if the energy equivalent of the food absorbed from the diet is equal to the energy value of the work and heat generated. Although daily variations in food consumption and bodily energy demands may produce short-term imbalances, it is clear that the long-term maintenance of a stable body weight depends on a tight coupling of energy intake and expenditure $(162,163)$.

Consequently, independent of genetic, developmental or environmental factors involved, obesity can only develop as a result of a prolonged positive energy balance.

The last decade many studies on aetiology of obesity were focussed on the search for the phenotypic expression of the genetically susceptible individual. As discussed earlier, the phenotypic expression can be studied in several fields of research. Eventually, each new finding, must relate to an effect on the energy balance. Whether this effect can be detected depends on the sensitivity of the methods to measure energy balance and the timing on which they are used.

\section{An introduction to energy metabolism}

The various chemical processes, which underlie the functions of the body, require the continuous provision of energy (32). All the energy intake of humans is derived from the chemical energy contained in the nutrients that are absorbed from the diet. Quantitatively, the major source of this energy is that which is stored in the $\mathrm{C}-\mathrm{H}$ bonds of carbohydrates and lipids, and to a lesser extent, proteins. This chemical energy is liberated in the body through oxidative pathways that convert these $\mathrm{C}-\mathrm{H}$ bonds to $\mathrm{CO}_{2}$ and $\mathrm{HO}_{2}\left({ }^{262}\right)$. The heat generated by biological combustion is utilized to maintain body temperature. Furthermore, the chemical energy of substrates is transferred to high energy bonds, mainly within adenosine triphosphate (ATP). Chemical (biosynthesis), osmotic (active transport), and mechanical (muscular contraction) work is thus made possible (164). Therefore, energy metabolism can be defined as the oxidation of fuels producing carbon dioxide, water, heat and external work. This overall process is referred to as energy expenditure or metabolic rate, and represents the utilization of food energy to maintain the functions of the body (32). The ratio of the volume of oxygen used $\left(\mathrm{VO}_{2}\right)$ and carbon dioxide released $\left(\mathrm{VCO}_{2}\right)$ depends on the substrate being metabolized, and is described by the respiratory quotient or respiratory exchange ratio (RER), calculated as $\mathrm{VCO}_{2} / \mathrm{VO}_{2}$. 


\section{Measurement of energy intake}

Most studies show that obese children and adolescents do not have higher energy intakes or even lower intakes than their non-obese peers do $(165,166,167)$. The validity of this data, however, is questionable.

The problem is, that energy intake, in the free living situation, cannot be validly measured. The main reason for this is, that the measurement of energy intake relies on self report, either by dietary interview or food questionnaire, placing all the responsibility for an accurate measurement of food intake with the subjects themselves. It may not be surprising, that this technique is prone to bias, with under-recording particularly found in the obese $(168,169)$. On the other hand, children appear quite capable of self-regulating dietary intake under unsupervised settings (21). While meal-to-meal variation in energy intake is large, the day-to-day variation is much lower ( 170 ), although outcomes have been reported up to $22 \%$ $(171,172)$. The capacity to regulate their own intake appears to be negatively affected by the degree of parental control and attitude towards the child's intake (173, 174).

\section{Measurement of whole body energy expenditure}

The expenditure of energy by the body requires the consumption of oxygen and leads to the production of carbon dioxide and release of heat. Thus, whole-body energy expenditure can be assessed by making calorimetric measurements, i.e., measuring heat released (direct calorimetry). Because of practical implications, however, an alternative, more widely used approach is to assess energy expenditure using indirect calorimetry, calculating energy expenditure from the rates of oxygen use and carbon dioxide production (32). Most studies have used Weir's equation (175): $\mathrm{EE}=3.941 \mathrm{VO}_{2}+1.106 \mathrm{VCO}_{2}-2.17 \mathrm{U}_{\mathrm{n}}$ where $U_{n}$ is measured from urinary nitrogen production. Weir showed that the error from neglecting the protein correction is negligible and shows little variation between individuals. Energy expenditure can therefore be estimated with sufficient accuracy from $\mathrm{VO}_{2}$ and $\mathrm{VCO}_{2}$ alone.

The major components contributing to total energy expenditure or average daily metabolic rate (ADMR) are sleeping metabolic rate (SMR), the energy cost of arousal, the thermic effect of food or diet induced energy expenditure (DEE) and the energy cost of physical activity or activity induced energy expenditure (AEE), as was described by Ravussin (176). Often SMR and the energy cost of arousal are taken together as energy expenditure for maintenance or basal metabolic rate (BMR). BMR is normally the main component of ADMR. Therefore, ADMR is often 
simply divided into resting and non-resting energy expenditure. In adults, $B M R$, DEE and AEE account for approximately $65-70 \%, 10-15 \%$ and $20-30 \%$ of ADMR, respectively (32). Low energy expenditure in any of these components, however, can contribute to the development of obesity or maintenance of the obese state.

\section{Sleeping and basal metabolic rate}

BMR is the energy required to maintain essential body functions under standard conditions: lying awake, fasted $10-18$ hours, and at complete rest in a thermoneutral environment. BMR includes the expenditure of energy for maintaining membrane potentials, resting cardiorespiratory function and basal rates of turnover of protein. To measure BMR, an air-tight canopy is placed over the head of the subject and connected to sensitive and stable $\mathrm{O}_{2}$ and $\mathrm{CO}_{2}$ sensors to sample the inspired and expired air at fixed time intervals (17).

SMR is approximately $0-5 \%$ lower than BMR among adults (178) and is measured during an overnight stay in a respiration chamber (179). The respiration chamber is an open-circuit indirect calorimeter $\left(14 \mathrm{~m}^{3}\right)$ and maintains a constant air temperature during the night (179).

SMR and BMR are usually compared between subjects by standardizing to an estimate of metabolic body size. Fat-free body mass (FFM) is generally accepted as the best predictor for metabolic body size $(163,180)$. Since the intercept in the relationship between BMR and FFM is different from zero, the preferred way of comparing SMR or BMR is by regression analysis or analysis of covariance. Covariates to be included are FFM, fat mass (FM), age and gender. Throughout childhood and adolescence BMR decreases relative to body weight (125). Although BMR per $\mathrm{kg}$ body weight is fairly constant from $1-4$ years of age (about 55 $\mathrm{kcal} / \mathrm{kg} /$ day), it decreases linearly thereafter until about $16-18$ years of age (about $30 \mathrm{kcal} / \mathrm{kg} /$ day). This is presumably caused by changes in the relative proportions of metabolically active tissues comprising FFM (181). During adulthood BMR further decreases about 2 - $4 \%$ per decade, relative to body weight. The BMR decrease with aging has been attributed primarily to a general decrease in FFM. In addition, several factors (state of disease, caloric restriction, weight loss, caloric excess, and weight gain) contribute to the within- and between-individual differences in BMR.

Nonetheless, in a study including obese as well as non-obese 8- to 12-year-old children, variability between repeated-day tests of BMR was very low (within-individual variation of about $2 \%$ ) (172). 


\section{Diet induced energy expenditure}

Diet induced energy expenditure, originally called 'specific dynamic action of food' by Rubner (161), can be defined as the increase in energy expenditure above basal fasting level, divided by the energy content of the food ingested, and is commonly expressed as a percentage (163). DEE reflects the energy required for digestion and absorption of foods, conversion of foods into nutrients, and storage of energy (172). In adults, 90\% of the DEE was observed within 4 hours after the meal (182, 183), although the postprandial rise in energy expenditure is thought to be completely terminated at approximately 10 hours after the last meal (163). In the condition of energy balance, with normal diets, DEE is normally standardized to 8 $10 \%$ of ADMR (184). Although some studies have shown blunted DEE $(185,186,187$, 188 ) in the obese, others (189) have found a higher DEE for obese children. In fact, DEE can be reduced during periods of under-feeding, or when consuming a highfat diet, or increased during over-feeding, or with a high carbohydrate intake.

\section{Activity induced energy expenditure}

Physical activity is a broad term that describes any bodily movement produced by skeletal muscle that results in energy expenditure. Since mean $24 \mathrm{~h}$ activity induced energy expenditure is the most variable component of ADMR, it plays a key role in the regulation of energy balance.

After the measurement of ADMR became possible with the introduction of the doubly labelled water technique, truly quantitative estimates of AEE in daily life have been made. The WHO has standardized the quantification of AEE by expressing ADMR as a multiple of BMR (124), indicating that the variation in ADMR is mainly caused by metabolic body size and physical activity. Thus, the physical activity level (PAL) is obtained by dividing ADMR by BMR. Several studies $(180,190)$, however, have suggested that using ratios to normalize biological data may lead to spurious comparisons if the relationships between the variables have non-zero intercepts, in analogy with the relationship between BMR and FFM. Analysis of covariance, an approach based on multiple regression, has been suggested as an alternative statistical technique to adjust data with non-zero intercepts (191). The combination with other statistical approaches, to determine if they support a unified conclusion, has been suggested as a valuable strategy (192) to assess physical activity.

The quantity of energy spent on physical activity, expressed as a proportion of total energy expenditure, appears to increase from infancy and early childhood to early adolescence (21). At infancy the measured PAL was 1.35 (193). Between 1 to 4 years of age, the PAL has been estimated as $1.6(130)$, although this level seems an 
overestimation, since at five years the measured PAL was still around 1.4 (126). From 9 to 12 years the influence of gender becomes stronger, resulting in a level of 1.61 for boys and 1.53 for girls (194), whereas the PAL reaches its peak around 12 18 years of age, namely around 1.8 in boys, and 1.7 in girls (195).

Evidence exists that the physical activity associated energy expenditure is inversely related to adiposity $(118,196)$, although this topic is clouded with controversy (197), especially because the energy cost for weight bearing activities is increased for obese individuals (115). A frequently used method to correct AEE for weight bearing activities is to divide AEE by weight. Since not all daily activities are weight dependent, the denominator weight has to be adjusted with an exponent of 0.66 to 0.75 in adults (192). It is impossible, however, to generalize this exponent because of the large variation in physical activity and body sizes, especially in youth.

One of the earliest reports about fat mass and physical activity came from Bruch (198), who studied 140 overweight boys and girls 2 to 14 years of age and reported

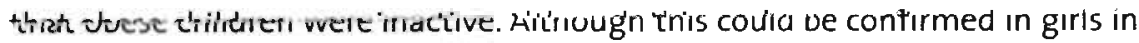
summer camp or boys and girls in home or at school, other studies with children from the same age could not find any difference (199). It must be noted, however, that these studies all used alternative methods to assess physical activity, such as oxygen uptake, heart rate monitoring, and movement counters (199).

On the other hand, several authors have suggested that sedentary activities or the time devoted to physical activity, rather than a decreased physical activity related energy expenditure, seems to be associated with body fatness in young children $(121,200,201)$. In a study by Epstein et al. (202) short term weight loss was greater in a group of children who were instructed to reduce sedentary behaviour than in children who were encouraged to increase exercise. Whether decreased nonbasal energy expenditure increases the risk for the development of childhood or adolescent obesity has not been established (21).

\section{Average daily metabolic rate}

The 'gold standard' for measurement of energy expenditure under daily living conditions, is the doubly labelled water (DLW) technique (203). The method has been applied in humans from the early 1980's onwards (204), and is now validated and standardized (163). Validation studies in four laboratories resulted in an accuracy of $1-3 \%$ and a precision of $2-8 \%(163)$. This technique is based on the principle that the oxygen of expired $\mathrm{CO}_{2}$ is in isotopic equilibrium with the oxygen of body water. When a subject is loaded with ${ }^{2} \mathrm{H}_{2}{ }^{8} \mathrm{O}$, body water is enriched with the stable isotopes ${ }^{2} \mathrm{H}$ and ${ }^{18} \mathrm{O}$. The decrease in ${ }^{18} \mathrm{O}$ in the body water is a measure for $\mathrm{H}_{2} \mathrm{O}$ plus $\mathrm{CO}_{2}$ outputs and the decrease in ${ }^{2} \mathrm{H}$ is a measure for $\mathrm{H}_{2} \mathrm{O}$ 
output alone. When the disappearance rate of both isotopes from the body fluid (e.g. blood, urine, saliva) is measured, the difference between the two disappearance rates is a measure of $\mathrm{CO}_{2}$ production (163).

After the dose, both isotopes equilibrate with the total body water pool (TBW). Both tracers, ${ }^{18} \mathrm{O}$ and $2 \mathrm{H}$, are stable isotopes, which occur naturally in the body water at a level around 2000 and $150 \mathrm{ppm}$, respectively (205). The required excess enrichment of $200-400$ ppm does not have any measurable health consequences. To convert the measurement of $\mathrm{CO}_{2}$ production to energy expenditure, the energy equivalent of $\mathrm{CO}_{2}$ is needed. Often, an assumed RER of 0.85 is used. In children, however, optimum accuracy requires estimations the food quotient (FQ) from the macronutrient composition of the diet from records of dietary intake. Although, these records are notorious for their underestimation of energy intake, the macronutrient composition can be measured with reasonable validity using a weighed dietary record or diet history $(177,206)$. Since in the situation of energy balance, FQ equals RER, the FQ can be used for $\operatorname{ADMR}$ calculation $(163,205,207)$.

\section{Energy cost of growth}

The energy costs of growth consists of the energy content of the newly synthesized tissues and the energy expended in the synthesis of these tissues. Whereas the latter can only be estimated, the first can be measured seemingly simple by determining total body weight (32). Indeed, for adults most excess energy storage is in the form of fat with some increase in fat-free mass. For children, however, the interpretation of energy storage is more difficult because of simultaneous, but not equal, increases in the weights of different tissues (bone, muscle, organs, fat), changes in the water and mineral content of body tissue, and changes in the metabolic rates of various tissues during growth. Therefore, the form in which energy is stored (protein, carbohydrate or fat) may vary, which makes an increase in body weight and energy storage not necessarily constant.

The equivalent energy costs of growth of total energy requirements decreases from $35 \%$ at 1 month to $3 \%$ at 12 months. During infancy the weight gain during the first 6 months averages $4 \mathrm{~g}$ per $\mathrm{kg}$ body weight per day, while in the second half of the first year the mean weight gain decreases to $1.5 \mathrm{~g}$ per kg body weight per day $(124,130)$. In addition, a relatively large amount of energy is lost in the urine and faeces, dependent on the maturation of the gastro-intestinal tract (208). After the first year, the energy costs for growth further decreases to about $2 \%$ of energy intake (209). Nonetheless, also during infancy, BMR is by far the largest component of daily metabolic rate (210). Even the adolescent growth spurt does not increase the energy costs of growth to much above $3 \%$ of energy intake (210). 


\section{Body composition}

As stated above, BMR reflects a composite of metabolic rates from various tissues that comprise body weight. From infancy to adulthood a transition occurs in the extent to which some tissues take part in daily energy expenditure. During infancy the brain will require most of the daily energy, while the liver is the highest metabolically active organ in adulthood. More specifically, in adults, during basal conditions, the major organs (e.g., brain, liver, heart) have the highest metabolic rate (about $60-65 \%$ of BMR), but constitute the lowest percentage of body mass (about $5 \%$ ); muscle tissue has an intermediate metabolic rate ( $20 \%$ of BMR), but constitutes about $35-40 \%$ of body weight; white adipose tissue has the lowest metabolic rate ( $5-10 \%$ of BMR), and constitute roughly $20 \%$ of body mass $(181,211)$. Therefore, differences in body composition will affect BMR. Determination of body composition is also necessary for assessment of the 'nutritional' status (e.g., excess of fat mass) and for monitoring the effect of treatment or interventions (163). The obese child, however, not only has a higher degree of adiposity, but also tends to be taller, heavier, and, tends to have a larger fat-free mass than the nonobese child.

\section{Assessment of body composition}

In obesity research, the most frequently used model for the study of body composition is the molecular model, in which the body's composition is divided into its main molecular components: lipids (included essential and nonessential lipids), water, protein, minerals and glycogen (212). Fat mass (FM) and fat-free mass (FFM) are terms used frequently that refer to the classic two-component $(2 \mathrm{C})$ body composition model in which total body mass is broken down into fat and nonfat tissue masses. A lack of direct quantification methods has led to the development of various models and indirect methods for estimation of FM and FFM, all of which are imperfect and require a number of assumptions, many of which are age-specific (108).

Densitometry is the estimation of body composition based on total body density and requires measurement of body weight and body volume. Total body mass (TBM) is obtained with an electric balance, body volume calculated by underwater weighing. Underwater weighing is usually carried out in a special tank or a large bath. This is the most widely used technique for measuring body volume and uses the Archimedes' principle: the volume of an object submerged in water equals the volume of water displaced by the object. Therefore, the difference between weight in air and weight under water, corrected for the density of the water at the temperature at the time of measurement, is the body volume. 
Simultaneously, the residual lung volume is measured by a helium-dilution spirometer. Generally, the densities of FM and FFM are assumed to be $0.9 \mathrm{~g} / \mathrm{ml}$ and $1.1 \mathrm{~g} / \mathrm{ml}$, however, the density of FFM is known to be influenced by age, gender and ethnicity (212), and little information exists in children (108). Other assumed constants include water content and bone mineral content (BMC) of the FFM.

Further improvement of this $2 \mathrm{C}$-model, therefore, is achieved by dividing the FFM in three more compartments and thus creating a four-component $(4 \mathrm{C})$ reference model:

$T B M=F M+T B W+$ total bone mineral content and remaining fat-free dry mass

In this model, TBM, body volume, total body water (TBW) and BMC are measured separately, thus dividing body weight into fat, water, mineral, and protein, and allowing evaluation of several assumed constant relations that are central to $2 \mathrm{C}$ models. By measuring BMC and TBW with techniques specifically designed for these components, the $4 \mathrm{C}$-model leaves the underwater weighing uninfluenced by the TBW and BMC of FFM, such that it distinguishes not fat and FFM, but fat and protein. The variability in the density of protein is less than that of FFM, making this part of the model more reliable (213).

Bone mineral content is measured by Dual-X-ray Absorptiometry (DXA). DXA is based on measurement of the ratio of tissue attenuation of $X$-rays at two energies $(163,214)$. In practice, the subject is scanned by the DXA. Approximately 10,000 pixel elements are collected during a typical whole-body scan. Of these pixels, $40-45 \%$ are bone and soft tissue, the remaining pixels contain soft tissue alone. The attenuation of $X$-ray by fat and fat-free soft tissues are different, allowing quantitative calculation of the respective masses in each pixel without bone. These data are then extrapolated to cover the whole body (163). The radiation dose is dependent on the scan mode used, 0.01 - 0.06 mrem or $<1 / 100^{\text {th }}$ of the equivalent radiation exposure of a chest $x$-ray (108). The duration of the DXA measurements is approx. 15 - 30 minutes, depending on the size of the individual.

Total body water can be determined with deuterium dilution. This measurement is part of the doubly labelled water method that is described above. The subject receives an orally administered dose of $2 \mathrm{H}_{2} \mathrm{O} \cdot{ }^{2} \mathrm{H}_{2} \mathrm{O}$ enrichment in the body fluid is measured in a body fluid, e.g., urine. Before administration of the dose, a background urine sample is taken. The dose is given in the evening, as part of the ADMR measurement. Urine samples are taken $10 \mathrm{~h}$ after dose administration from the second voiding the next morning (215). TBW is calculated as the ${ }^{2} \mathrm{H}$ dilution space divided by 1.04 correcting for exchange of the ${ }^{2} \mathrm{H}$ label with non-aqueous $\mathrm{H}$ of body solids (216). 
Additionally, bromide dilution can be measured to estimate the extracellular water compartment (ECW). Bromide does not pass the cell membranes, and thus equilibrates with the $\mathrm{ECW}$. In practice, a known amount of $\mathrm{NaBr}$ is mixed with the $2 \mathrm{H}_{2} \mathrm{O}$ solution and, thus, administered simultaneously with the $2 \mathrm{H}_{2} \mathrm{O}$ dose. A venous blood sample is obtained before and $10 \mathrm{~h}$ after ingestion of bromide. Bromide concentration in serum ultrafiltrate is determined and corrected bromide space is calculated according to Miller et al. (217).

The $4 \mathrm{C}$-model is considered one of the most accurate methods of estimating $\% F M(218)$ with relatively high precision (213). Like most of the multicomponent models, however, the $4 \mathrm{C}$-model is based on the measurement of densitometry by underwater weighing. Unfortunately, underwater weighing is not possible in young children or children with mental retardation. A recent study demonstrated that the $2 \mathrm{C}$-model based on the deuterium dilution technique showed negligible mean error $(1.3 \%)$ in measuring FFM relative to the $4 \mathrm{C}$-model and was preferable above other $2 \mathrm{C}$-models for the assessment of body composition in children (213). Furthermore, the published maturation specific values for FFM hydration by Boileau et al. (219) were almost identical to those found in the $4 \mathrm{C}$-model. For these subgroups, therefore, a $2 \mathrm{C}$-model based on the measurement of total body water can be used as an alternative. FFM is assessed with the assumption of FFM containing all body water. Hydration factors of FFM are based on maturation specific values (219). Tanner's puberty ratings can be used to determine the level of maturation of the child (220).

\section{Energy metabolism in Prader-Willi syndrome}

An individual with a predisposition to obesity will stay lean in an environment of food deprivation or high demand of physical activity, whereas an individual not genetically predisposed may still become obese in an environment that includes tasty, energy dense foods and few inducements to physical activity (136).

Paediatric obesity is therefore caused by a combination of susceptibility and environment. Energy metabolism studies in obesity are searching for the phenotypic expression of the genetic susceptibility to obesity.

Some evidence suggests that a reduced energy expenditure may be involved in the aetiology of childhood obesity, genetically $(221,222,223)$ or behaviourally influenced (224). Data indicates that lowered ADMR contributed to latter weight gain in infants who became overweight (163). Other cross-sectional studies do not support the concept that reduced energy expenditure may be related to obesity, nor found differences in FM related to variation in energy expenditure components $(114,225)$. In addition, no significant correlation was found between components 
of energy expenditure in children, and body fat in mothers or fathers (190). It is conceivable, however, that differences in energy expenditure may have different effects on energy balance at different stages of the maturation process (163). When studying the physiological mechanisms of the development of paediatric obesity, a population is needed that is prone to become obese. The Prader(Labhart)-Willi syndrome (PWS) is the most recognized form of genetic obesity in humans. If unmanaged, the child with PWS will almost surely become obese. Currently, the precise aetiology of any specific instance of human obesity, including PWS, remains unknown. Understanding the energy metabolism of this rare dysmorphic syndrome, however, might also give insight into the development of obesity in the population at large, and the paediatric age group in particular.

\section{An introduction to Prader-Willi syndrome}

Prader-Willi syndrome was first described in the medical literature in 1956 by Prader, Labhart and Willi (226), and is characterized by hypotonia in the neonatal period, mental retardation of a variable degree, hypogonadism, failure to thrive, small hands and feet and obesity (227). The incidence of PWS is estimated to be about 1 in 25,000 live births (228). Although the short stature combined with hypogonadism and obesity suggested a central endocrine (i.e. hypothalamic) dysfunction, confirmation of this hypothesis has been sparse $(229,230)$. In 1993, a consensus for the diagnostic criteria was reported, but mis-diagnosis still occurs. Under-diagnosis in younger children and over-diagnosis in obese retarded adole; cents and adults are both common (227). Clinical diagnosis of PWS is still considered difficult because of the subtle nature of the dysmorphic features, and the wide discrepancy between the clinical presentation in infancy and that which is seen in childhood, adolescence, and adulthood (231). Indeed, the symptoms of PWS change dramatically with age. The classic concept of PWS is that of a two stage disorder - a perinatal hypotonic phase, followed by a childhood obese phase. Some include a third, adolescent phase with particular behavioral problems (232). Hypotonia is often already present during pregnancy, resulting in decreased fetal movements and polyhydramnios, and presumably accounting for an increased incidence of breech delivery and a higher incidence of delivery by caesarian section (233).

Ideally, the classic perinatal hypotonic phase will allow an early clinical diagnosis of PWS, which in turn can be confirmed by genetic testing. The basic defect in PWS seems to be an absence of function of genes on the proximal long arm of chromosome 15 that are normally expressed in a monoallelic fashion only from the paternal chromosome (231). This defect is most commonly a result of a de novo interstitial paternal deletion $(60-70 \%)$ or maternal UPD (uniparental dis- 
omy; $30-40 \%$ ) (231). UPD occurs for the whole of chromosome 15 . This can be in the form of heterodisomy, in which both mother's chromosomes 15 are inherited by the child, or as isodisomy, in which the two identical chromatids from one chromosome 15 are inherited. In approximately $1 \%$ of patients imprinting centre mutations have been reported (234). There is no evidence for the common deletion or UPD in these individuals. The majority, but not all, of these patients have inherited small microdeletions in a region of 15911-q13 which has been determined the imprinting centre (235). Contrary to the other two genetic mechanisms these 'imprinting mutation' families may have a high recurrence risk for transmitting this defect to their offspring (234).

\section{Energy metabolism studies in Prader-Willi syndrome}

Prader-Willi syndrome is the most common syndromal cause of obesity in children and obesity is the most prominent health threat in patients with this syndrome (236). Following the hypotonia related feeding problems in the neonatal period, obesity develops in early childhood, when no intervention is undertaken. Hyperphagia in combination with an seemingly unsatiable hunger are obvious reasons for this sudden increase in weight $(236,237)$. However, because of the limitations of current methods in quantifying energy intake, very little is known about the actual intake.

The first observations that suggested a decreased energy expenditure in PWS were done by Pipes and Holm (237). They followed 14 children with PWS (12 males) during growth in periods ranging from 10 months to almost 7 years, and compared them with standard growth data from the literature. Eight children were successful in maintaining their weight loss on $60 \%$ of normal energy intake. It was concluded that children with PWS must be restricted to fewer calories than nonsyndromal obese children of comparable ages in order to maintain their weight in appropriate growth channels. The authors suggested that hypoactivity as a result of hypotonia in this syndrome might be a contributing factor, especially since parents often characterize their children as tiring easily, sleepy, and not having enough strength to keep up with peers. Low muscle tone and poor coordination might result in inactivity and a low energy output. On the other hand, the hypotonia generally improves as the obesity develops.

Nardella et al. (238) measured physical activity levels of 12 individuals with PWS and 13 nonretardated children during a two week summercamp with scheduled daily activities. They ranged in age from 11 to 22 years and were all put on the same 1000 calories per day diet, with 23-23-54 as E\% respectively for protein, fat and carbohydrate. Two instruments for measuring physical activity were used: a pedometer providing a means of converting impulses of movement into distance, 
and an actometer to measure the intensity of physical activity. The study demonstrated a wide range of physical activity levels among PWS persons in a recreational setting. The investigators concluded that it is not valid to stereotype such individuals when describing their physical activity levels.

Because of the difficulties in using actometers in the handicapped population, Davies et al.(239) measured physical activity levels with the DLW method. In 10 PWS subjects ( 5 males, 5 females) (age: 6.01 - 16.00 y) ADMR and BMR were measured and compared with a group of 60 healthy school children (age: $7.00-18.00$ y) recruited from the region of the research centre. After adjustment for age, fatfree mass, and gender by multiple regression, ADMR and BMR were found to be not significantly different between both groups. The physical activity level, however, was significantly reduced in the PWS group.

Another reason for a possible decreased energy expenditure in PWS, which was suggested by Holm (237), was the reduced amount of active metabolic tissue mass in children with PWS. This hypothesis was investigated by Schoeller et al. (240) who measured ADMR and FFM using the DLW method and deuterium dilution technique, respectively. They demonstrated that ADMR for the PWS subjects was on average $46 \%$ lower than for the obese controls. Furthermore, they concluded that PWS patients had small fat-free masses for their age and that standard skinfold measures for assessing fat mass were not reliable in PWS subjects. The reason for this peculiar body composition was not clear but was suggested to be associated with neuroendocrine factors mediated by the hypothalamus such as growth hormone.

Hill et al (241) measured BMR in a large group of PWS subjects and controls at the annual meeting of the PWS association held in Louisville, Kentucky. Their findings demonstrated that BMR in PWS is decreased even when adjusted for the lower FFM in this syndrome. The authors suggested that a low energy expenditure exists initially for persons with PWS but may return to normal as obesity becomes greater.

To summarize, the field of paediatric obesity research has gained interest in PWS since the syndrome is the best known genetic syndrome linked to obesity. The positive energy balance has been related to an increased energy intake as well as a decreased energy expenditure. Although the unsatiable hunger makes an increased appetite plausible, there are only few reports that have documented energy intake. These reports have demonstrated that energy intake after weight loss is decreased compared with obese controls. Although it is possible that PWS children underreport to a greater extend than obese controls, the low energy intake may also be explained on the basis of a decreased total energy expenditure. The DLW method offers a valid approach to objectively assess total energy expenditure. The sparse data on energy expenditure in PWS that exists, however, 
leaves the question of whether this syndrome is associated with a decreased energy expenditure, still in debate. Furthermore, in the case of a decrease in energy expenditure, the next question is, whether this can be explained on the basis of an altered body composition. Finally, the question needs to be addressed whether the peculiar body composition in PWS is purely the result of the suggested hypothalamic lesion or is also related to a sedentary lifestyle, which is associated with this syndrome.

\section{Treatment strategies in paediatric obesity}

The treatment of childhood and adolescent obesity has been almost uniformly unsuccessful (242). As previously discussed, energy metabolism is tightly balanced, which is why there are no easy means through which weight control can be achieved. Dietary intake and energy spent on physical activity represent the only discretionary components of energy intake and expenditure. Behaviour contributes significantly to both (21). Interventions are therefore focussed on influencing the behaviour of the obese individual, mostly family based. In adults, three major types of treatment are used: dietary intervention, a prescribed exercise programme and medication (32). The latter is not recommended for use in children, unless they present with complications of obesity that require certain, rapid weight loss, and they need to be referred to specialized paediatric obesity treatment centers (243). According to the recommendations of an expert committee on this topic (243), the primary goal of obesity therapy should be healthy eating and physical activity (244). Especially in younger children, the family should be ready to make modifications in eating and activity habits (245). Detailed information about treatment strategies can be found in several review articles $(20,32,67$, 245). In terms of energy metabolism, in order to achieve a negative or, in the case of young or less obese children often, less positive energy balance, all interventions are based on a decrease of energy intake or an increase in energy expenditure or a combination of both. With a few exceptions $(246,247)$, the effect of these interventions on energy metabolism, however, is seldom studied.

\section{Outline of the thesis}

Paediatric obesity is a complex phenotype that revolves around the influences of genes, development and environment. Although the exact contributions of each of these factors is unclear, together they result in a prolonged positive energy bal- 
ance. The study of the different components of whole body energy expenditure will give direction to the search for these genetic, developmental and environmental factors, and possibly will give insight into strategies that can cope with the increasing problem of paediatric obesity.

This thesis attempts to address the relative contribution of the major components of daily energy expenditure to the development and maintenance of paediatric obesity. In the first part of this thesis, energy metabolism will be studied in a group of children and adolescents with high genetic susceptibility to obesity, namely young patients with Prader-Willi syndrome. In the second part, energy metabolism will be determined in a group of nonsyndromal obese adolescents, since adolescence is one of the critical periods for persistence of obesity in adulthood. These goals will be pursued through the following specific objectives:

- To determine basal and total energy expenditure in children and adolescents with Prader-Willi syndrome in relation to body composition and metabolic body size

- To assess the relationship of physical activity and growth hormone function with body composition in Prader-Willi syndrome

- To measure the effect of fat mass and gender on basal and total energy expenditure in nonsyndromal obese adolescents

To determine the effect of obesity intervention with sibutramine, an satiety enhancing drug, on basal and total energy expenditure in nonsyndromal obese adolescents during restriction of energy intake

In the first two chapters, following the introduction, the effect of Prader-Willi syndrome (PWS) on energy metabolism is discussed. Children and adolescents with PWS are compared with nonsyndromal obese peers, matched for biological age and gender. Energy expenditure, under basal conditions, and adjusted for body composition, at rest by ventilated hood measurement and during sleep using the respiration chamber, is determined in chapter 2 . To demonstrate the effects of PWS status on basal energy metabolism, the relationship between fat mass and fat-free mass in this syndrome is further explained. In chapter 3, average daily metabolic rate is measured by the doubly labelled water technique, with particular consideration given to activity related energy expenditure. Several methods are discussed that are used to assess the level of physical activity and each is considered on their merits.

The answer to the question of whether the altered body composition in children with PWS is related to decreased levels of physical activity and impaired growth hormone function, is addressed in chapter 4 . This chapter discusses the results of the first 2 chapters, however, from a different perspective, in combination with a measure of growth hormone function.

Prior to the description of the effect of energy restriction on energy metabolism 
of (nonsyndromal) obese adolescents, a compilation of doubly labelled water studies from the literature is presented in chapter 5 . The effect of gender and body composition in this age group is addressed and the biological background discussed.

Chapter 6 presents the results of a randomized and placebo controlled, doubleblind, intervention study on the effect of sibutramine, a serotonin and noradrenalin re-uptake inhibitor, in combination with an energy restricted diet and exercise programme, on energy expenditure and body composition in obese adolescents. In the last chapter, chapter 7 , the results and interpretations of the previous chapters are discussed to come to a general conclusion about the implications of this thesis to the aetiology and treatment of obesity in the paediatric age group.

\section{References}

1. Quetelet LAJ. A treatise on man and the development of his faculties. In: (eds). Comparative Statistics in the 19th century. William and Robert Chambers: Edinburgh, Scotland, 1842.

2. World Health Organisation. Obesity, Preventing and Managing the Global Epidemic. Report of a WHO consultation on Obesity. WHO, Geneva, 1998.

3. World Health Organisation. Expert committee on Physical Status: the Use and Interpretation of Anthropometry. Report of a WHO expert committee. WHO, Geneva, 1995.

4. Seltzer CC. Some re-evaluations of the build and blood pressure study, 1959 as related to ponderal index, somatotype and mortality. New Engl J Med 1966; 274: 254-259.

5. Daniels SR, Khoury PR, Morrison JA. The utility of body mass index as a measure of body fatness in children and adolescents: differences by race and gender. Pediatrics 1997; 99: 804807 .

6. Power C, Lake JK, Cole TJ. Measurement and long-term health risks of child and adolescent fatness. Int J Obes 1997; 21: 507-526.

7. Rolland-Cachera MF, Sempé M, Guilloud-Bataille M, et al. Adiposity indices in children. Am J Clin Nutr 1982; 36: 178-184.

8. Cole TJ. Weight/heightP compared to weight/height ${ }^{2}$ for assessing adiposity in childhood: influence of age and bone age on p during puberty. Ann Hum Biol 1986: 13: 433-451.

9. Poskitt EM. Defining childhood obesity: the relative body mass index (BMI). European Childhood Obesity group. Acta Paediatr 1995; 84: $961-963$.

10. Sorensen TI, Sonne-Holm 5. Mortality in extremely overweight young men. J Chronic Dis 1977: 30: 359-367.

11. Sonne-Holm S, Sorensen TI, Christensen U. Risk of early death in extremely overweight young men. Br Med $s$ 1983; 287: 795-797.

12. Hoffmans MDA, Kromhout $D$, Lezenne Coulander $D C$. The impact of body mass index of 78,612 18-year old Dutch men on 32-year mortality from all causes. J Clin Epidemiol 1988; 41; $7+9-750^{\circ}$. 
13. Must A, Jacques PF, Dallal GE, Bajema C, Dietz WH. Long-term morbidity and mortality of overweight adolescents. N Engl I Med 1992; 327: 1350-1355.

14. Nieto FJ, Szklo M, Comstock GW. Childhood weight and growth rate as predictors of adult mortality. Am J Epidemiol 1992; 136: 201-213.

15. Serdula MK, Ivery D, Coates R, Freedman DS, Williamson DF, Byers T. Do obese children become obese adults? A review of the literature. Prev Med 1993: 22: 167-177.

16. DiPietro L, Mossberg HO, Stunkard AJ. A 40-year history of overweight children in Stockholm: life-time overweight, morbidity, and mortality. Int J Obes 1994; 18: 585-590.

17. Guo S5, Roche AF, Chumlea WC, Gardner JD, Siervogel RM. The predictive value of childhood body mass index values for ovenweight at age 35 y. Am J Clin Nutr 1994; 59: 810-819.

18. Rolland-Cachera MF, Cole TJ, Sempé M, Tichet J, Rossignol C, Charraud A. Body Mass Index variations: centiles from birth to 87 years. Eur J Clin Nutr 1991; 45: 13-21.

19. Clarke WR, Lauer RM. Does childhood obesity track into adulthood? Crit Rev Food Sci Nutr 1993; 33: 423-430.

20. Dietz WH, Robinson TN. Use of body mass index (BMI) as a measure of overweight in children and adolescents. J Pediatr 1998; 132: 191-193.

21. Bray CA, Bouchard C, James WPT. Handbook of Obesity. Marcel Dekker, Inc., New York, 1998.

22. Schonfeld Warden $N$, Warden $C H$. Pediatric obesity. An ovenview of etiology and treatment. Pediatr Clin North Am 1997; 44: 339-361.

23. Himes JH, Dietz WH. Guidelines for overweight in adolescent preventive services: recommendations from an expert committee. The Expert Committee on Clinical Guidelines for Overweight in Adolescent Preventive Services. Am J Clin Nutr 1994; 59: 307-316.

24. Cole TJ, Freeman JV, Preece MA. Body mass index reference curves for the UK, 1990. Arch Diseas Child 1995; 73: 25-29.

25. Gerver WJM, De Bruin R. Paediatric Morphometrics. Wetenschappelijke uitgevery Bunge, The Netherlands, Utrecht, 1996.

26. Troiano RP, Flegal KM. Ovenweight prevalence amoung youth in the United States: Why so many different numbers. Int J Obes 1999; S2: S22-527.

27. Deurenberg P, Weststrate JA, Seidell JC. Body mass index as a measure of body fatness: age. and sex-specific prediction formulas. Br J Nutr 1991; 65: 105-114.

28. Pietrobelli A, Faith MS, Allison DB, Gallagher D, Chiumello G, Heymsfield SB. Body mass index as a measure of adiposity among children and adolescents: a validation study. J Pediatr 1998: 132: 204-210.

29. Troiano RP, Flegal KM, Kuczmarski RJ, Campbell SM, Johnson CL Overweight prevalence and trends for children and adolescents. The National Health and Nutrition Examination Surveys, 1963 to 1991. Arch Pediatr Adolesc Med 1995: 149:1085-1091.

30. Must A, Strauss RS. Risks and consequences of childhood and adolescent obesity. Int J Obes 1999; 23: S2-S11.

31. Kuzmarski RJ, Flegal KM, Campbell SM, Johnson CL Increasing prevalence of overweight among US adults. JAMA 1994; 272: 205-211.

32. Kopelman PG, Stock MJ. Clinical Obesity. Blackwell Sience Ltd, London, 1998. 
33. Reilly JJ, Dorosty AR, Emmett PM. Prevalence of overweight and obesity in British children: cohort study. BMU 1999; 319: 1039.

34. Blokstra A, Kromhout D. Trends in Obesity in Young Adults in The Netherlands from 1974 to 1986. Int J Obes 1991; 15: 513-521.

35. Wekke JS-vd, Meulmeester JF, Radder JJ, Hirasing RA, Verloove-Vanhorick SP. PCO-peiling 1992/ 1993. TNO Preventie en Gezondheid, Leiden, 1994.

36. Fredriks AM, Van Buuren S, Burgmeijer RJF, Verloove-Vanhorick SP, Wit JM. Nederlandse Groeidiagrammen 1997: in historisch perspectief. De vierde landelijk groeistudie (1997) Presentatie nieuwe groeidiagrammen, LUMC, TNO Preventie en Gezondheid, 1998.

37. Seidell JC. Obesity in Europe: scaling an epidemic. Int J Obes 1995; 19: S1-S4.

38. Seidell JC, Verschuren WMM, Kromhout D. Levels and trends of obesity in The Netherlands. Int J Obes 1995; 19: 924-927.

39. Guillaume M, Lapidus L, Beckers F, Drouget B, Lambert AE, Börntorp P. Prevalence of obesity in Belgian Luxembourg. Int J Obes 1993: 17:36.

40. Maffeis C, Schutz Y, Piccoli R, Gonfiantini E, Pinelli L Prevalence of obesity in children in north-east Italy. Int J Obes 1993; 17: 287-294.

41. Moussa MA, Skaik MB, Selwanes SB, Yaghy OY, Bin OS. Factors associated with obesity in school children. Int J Obes 1994; 18: 513-515.

42. Al-Nuaim AR, Bamgboye EA, Al-Herbisch A. The pattern of growth and obesity in Saudi Arabian male school children. Int J Obes 1996; 20: 1000-1005.

43. Esposito-Del-Puente A, Contaldo F, Filipo ED, Scalfi L Maio SD, Franzese A, Valerio G, Rubino A. High Prevalence of Overweight in a Children Population Living in Naples (Italy). Int J Obes 1996: 20: 283-286.

44. Barth N, Ziegler A, Himmelmann GW, Coners $H$, Wabitsch M, Hennighausen K, Mayer $H$, Remschmidt $\mathrm{H}$, Schäfer $\mathrm{H}$, Hebebrand J. Significant weight gains in a clinical sample of obese children and adolescents between 1985 and 1995. Int J Obes 1997; 21: 122-126.

45. Sorensen HT, Sabroe S, Gillman M, Rothman KJ, Madsen KM, Fischer P, Sorensen TIA. Continued increase in prevalence of obesity in Danish young men. Int J Obes 1997; 21: 712-714.

46. Mo-suwan L, Geater AF. Risk Factors for Childhood Obesity in a transitional society in Thailand. Int J Obes 1996; 20: 697-703.

47. Popkin BM, Richards MK, Monteiro CA. Stunting is associated with overweight in children of four nations that are undergoing the nutrition transition. J Nutr 1996; 126: 3009-3016.

48. Ko GTC, Chan JCN, Woo J, Lau E, Yeung VTF, Chow C-C, Wai HPS, Li JKY, So W-F, Cockram CS. Simple anthropometric indexes and cardiovascular risk factors in Chinese. Int J Obes 1997; 21: 995-1001.

49. Chu NF, Rimm EB, Wang DJ, Liou HS, Shieh SM. Clustering of cardiovascular disease risk factors among obese schoolchildren: the Taipei Children Heart Study. Am J Clin Nutr 1998; 67: 1141-1146.

50. Gupta R, Goyle A, Kashyap S, Agarwal M, Consul R, Jain BK. Prevalence of atherosclerosis risk factors in adolescent school children. Indian Heart / 1998; 50: $511-515$.

51. Calle EE, Thun M, Petrelli JM, Rodriguez C. Heath CW. Body mass index and mortality in a prospective cohort of U.S. adults. N Engl J Med 1999; 341: 1097-1105. 
52. Pi-Sunyer FX. Medical hazards of obesity. Ann Intern Med 1993; 119: 665-660.

53. Eckel RH, Krauss RM. American Heart Association Call to Action: Obesity as a major risk factor for coronary heart disease. Circulation 1998; 97: 2099-2100.

54. Ford ES. Body mass index and colon cancer in a national sample of adult US men and women. Am J Epidemiol 1999; 150: 390-398.

55. Rocchini AP, Katch V, Anderson J, Hinderliter J, Becque D, Martin M, Marks C. Blood pressure in obese adolescents: effect of weight loss. Pediatrics 1988; 82: 16-23.

56. Gutin B, Basch C, Shea S, Contento I, DeLozier M, Rips J, Irigoyen M, Zybert P. Blood Pressure, Fitness, and Fatness in 5- and 6-Year-Old Children. JAMA 1990; 264: 1123-1127.

57. Daniels SR. Is there an epidemic of cardiovascular disease on the horizon? J Pediatr 1999; 134: 665-666.

58. Luepker RV, Jacobs DR, Prineas RJ, Sinaiko AR. Secular trends of blood pressure and body size in a multi-ethnic adolescent population: 1986 to 1996. J Pediatr 1999: 134: 668-674.

59. Simsolo RB, Romo MM, Rabinovich L, Bonanno M, Grunfeld B. Family history of essential hypertension versus obesity as risk factor for hypertension in adolescents. Am J Hypertens 1999; 12: 260-263.

60. Friesen CA, Roberts CC. Cholelithiasis: clinical characteristics in children. Clin Pediatr 1989: 7: 294-298.

61. Noguchi $H$, Tazawa $Y$, Nishinomiya F, Takada $G$. The relationship between serum transaninase activities and fatty liver in children with simple obesity. Acta Paediatr Jpn 1995: 37: 621625 .

62. Tazawa $Y$, Noguchi $H$, Nishinomiya F, Takadda G. Serum alanine aminotransferase activity in obese children. Acta Paediatr 1997; 86: 238-241.

63. Mallory GB, Fiser $\mathrm{DH}$, Jackson R. Sleep-associated breathing disorders in morbidly obese children and adolescents. J Pediatr 1989; 115: 892-897.

64. Silvesti JM, Weese-Mayer DE, Bass MT, Kenny AS, Hauptmann SA, PearsalI SM. Polysomnography in obese children with a history of sleep-associated breathing disorders. Pediatr Pulmonol 1993; 16: 124-129.

65. Corbett JJ, Savino PJ, Thompson S, Kansu T, Schatz NJ, Orr LS, Hopson D. Visual loss in pseludotumor cerebri. Arch Neurol 1982; 39: 461-474.

66. Pinhas-Hamiel O, Dolan ML Daniels SR, Standiford D, Khoury PR, Zeitler P. Increased incidence of non-insuline-dependent diabetes mellitus among children and adolescents. $J$ Pediatr 1996; 128: 608-615.

67. Dietz WH, Robinson TN. Assessment and treatment of childhood obesity. Pediatrics in review 1993; 14: 337-344.

68. Caskey SR, Felker DW. Social stereotyping of female body image of elementary school age girls. Res Q 1971; 42: 251-255.

69. Kilpatrich SW, Sanders DM. Body image stereotypes: a developmental comparison. J Gen Psych 1978; 132: 87-95.

70. Richardson SA, Hastorff AH, Goodman N, Dornbusch SM. Cultural uniformity in reaction to physical disabilities. Am Sociol Rev 1961; 26: 241-247. 
71. Maddox GL, Back K, Liederman V. Overweight as social deviance and disability. J Heafth Soc Behav 1968; $9: 287-298$.

72. Klesges RC, Haddock CK, Stein RJ, Klesges LM, Eck LH, Hanson CL. Relationship between psychosocial functioning and body fat in preschool children: a longitudinal investigation. J Consul Clin Psych 1992; 60: 793-796.

73. Stunkard A, Burt V. Obesity and the body image: II Age at onset of disturbance in the body image. Am J Psychiatr 1967; 123: 1443-1447.

74. Canning H, Mayer J. Obesity: its possible effect on college acceptance. N Engl J Med 1966; 275: $1172-1174$.

75. Canning H, Mayer J. Obesity: an influence on high school performance. Am J Clin Nutr 1967; 20: $352-354$.

76. Gortmaker SL Must A, Perrin JM, Sobol AM, Dietz WH. Social and economic consequences of overweight in adolescece and young adulthood. N Eng J Med 1993; 329: 1008-1012.

77. Gerald LB, Anderson A, Johnson GD, Hoff C, Trimm RF. Social class, social support and obesity risk in children. Child Care Health Dev 1994; 20: 145-163.

78. Lauer RM, Lee J, Clarke WR. Factors affecting the relationship between childhood and adult cholesterol levels: the Muscatine Study. Pediatrics 1988; 82: 309-318.

79. Lauer RM, Clarke WR, Witt J. Childhood risk factors for high adult blood pressure: the Muscatine study. Pediatrics 1989; 84: 633-641.

8o. Sangri H, Mueller WH. Which measure of body fat distribution is best for epidemiologic research among adolescents. Am J Epidemiol 1991; 133: 870-883.

81. Dwyer T, Blizzard CL Defining Obesity in Children by Biological Endpoint rather than population distribution. Int J Obes 1996; 20:472-480.

82. Zwiauer K, Widhalm K, Kerb| B. Relationships between body fat distribution and blood lipids in obese adolescents. Int J Obes 1990; 14:271-277.

83. Asayama K, Hayashibe H, Dobashi K, Uchida N, Kawada Y, Nakazawa S. Relationships between biochemical abnormalities and anthropometric indices of overweight, adiposity and body fat distribution in Japanese elementary school children. Int J Obes 1995; 19: 253259 .

84. Gidding SS, Bao W, Srinivasan SR, Berenson GS. Effects of secular trends in obesity on coronary risk factors in children: the Bogalusa Heart Study. J Pediatr 1995; 127: 868-874.

85. Hager RL, Tucker LA, Seljaas GT. Aerobic fitness, blood lipids, and body fat in children. Am J Public Health 1995; 85: $1702-1706$.

86. Gutin B. Owens S, Treiber F, Islam S, Karp W, Slavens G. Weight-independent cardiovascular fitness and coronary risk factors. Arch Pediatr Adolesc Med 1997; 151: 462-465.

87. Freedman DS, Dietz WH, Srinivasan SR, Berenson GS. The relation of overweight to cardiovascular risk factors among children and adolescents: The Bogalusa Heart Study. Pediatrics 1999: 103: 1175-1182.

88. Smoak CG, Burke GL, Webber LS, Harsha DW, Srinivasan SR, Berenson GS. Relation of obesity to clustering of cardiovascular disease risk factors in children and young adults. Am J Epidemiol $1987 ; 125: 364-372$. 
89. Hoffmann RP, Armstrong PT. Glucose effectiveness, peripheral and hepatic insulin sensitivity, in obese and lean prepubertal children. Int J Obes 1996; 20: 521-525.

90. MCGill HCJ, MCMahan CA, Malcom GT, Oalman MC, Strong JP, Group PR. Relation of glycohemoglobin and adiposity to atherosclerosis in youth. Arterioscler Thromb Vasc Biol 1995; 15: 431-440.

91. Mossberg H. 40-year follow-up of overweight children. The Lancet 1989; 2: 491-493.

92. Dietz WH. Childhood weight affects adult morbidity and mortality. J Nutr 1998; 128: 4115. 4145.

93. Gunnell DJ, Frankel SJ, Nanchahal K, Peters TJ, Davey Smith G. Childhood obesity and adult cardiovascular mortality: a 57-y follow-up study based on the Boyd Orr cohort. Am J Clin Nutr 1998; 67: 1111-1118.

94. Rolland-Cachera MF, Bellisle F, Sempe $M$. The prediction in boys and girls of the weight/height2 index and various skinfold measurements in adults: a two-decade follow-up study. Int J Obes 1989; 13: 305-311.

95. Rolland-Cachera MF, Deheeger M, Guilloud-Bataille M, Avons P, Sempe M. Tracking the development of adiposity from one month of age to adulthood. Ann Hum Biol 1987; 14: 219-229.

96. Kotani K, Nishida M, Yamashita S, Funahashi T, Fujioka S, Tokunaga K, Ishikawa K, Tarui S, Matsuzawa Y. Two decades of annual medical examinations in Japanese obese children: Do obese children grow into obese adults? Int J Obes 1997; 21: 912-921.

97. Whitaker RC, Wright JA, Pepe MS, Seidell KD, Dietz WH. Predicting obesity in young adulthood from childhood and parental obesity. N Engl J Med 1997: 337: 869-873.

98. Rolland-Cachera MF. Onset of obesity assessed from the weight/stature ${ }^{2}$ curve in children: the need for a clear definition [letter; comment]. Int J Obes 1993: 17: 245-246.

99. Prentice AM, Jebb SA. Obesity in Britain: gluttony or sloth? BM 1995: 311: 437-439.

100. Payne JA, Belton NR. Nutrient intake and growth in pre-school children. Comparison of energy intake and sources of energy with growth. J Hum Nutr Diet 1992; 5: 287-298.

101. Davies PS, Gregory J, White A. Energy expenditure in children aged 1.5 to 4.5 years: a comparison with current recommendations for energy intake. Eur J Clin Nutr 1995; 49: 360-364.

102. Drewnowski A, Popkin BM. The nutrition transition: new trends in the global diet. Nutr Rev 1997; 55: 31-43.

103. Schrauwen P. Determinants of energy and substrate metabolism. [Thesis] Dept. Human Biology. Maastricht, the Netherlands, Maastricht University, 1998

104. Kumanyika SK. Obesity in minority populations: an epidemiological assessment. Obes Res 1994: 2: 166-182.

105. McKenzie J. Social changes and the food industry. Nutr. Rev 1982;40:13-17.

106. Crawley HF. The energy, nutrient and food intakes of teenagers aged 16-17 years in Britain. $B r$ J Nutr 1993: 70: 15-26.

107. Baranowski T, Sprague D, Baranowski JH, Harrison JA. Accuracy of maternal dietary recall for preschool children. J Am Diet Assoc 1991; 91: 669-674.

108. Goran MI. Measurement issues related to studies of childhood obesity: assessment of body composition, body fat distribution, physical activity, and food intake. Pediatrics 1998; 101: 505518. 
109. Luepker RV. How physically active are American children and what can we do about it? Int $f$ Obes 1999; 23: S12-S17.

110. Dietz WH, Gortmaker SL Do we fatten our children at the television set? Obesity and television viewing in children and adolescents. Pediotrics 1985; 75: 807-812.

11. Robinson TN, Hammer LD, Killen JD, Kraemer HC, Wilson DM, Hayward C, Barr Taylor C. Does television viewing increase obesity and reduce physical activity. Pediatrics 1993: 91: 273-280.

112. Gortmaker SL, Must A, Sobol AM, Peterson K, Colditz GA, Dietz WH. Television Viewing as a Cause of increased Obesity among Children in the United States, 1986-1990. Arch Ped Adol Med 1996; 150: 356-362.

113. Saris WHM. Changes in physical activity of children aged 6-12 years. In: I Rutenfranz (eds). Children and Exercise. Human Kinetics Publ: 1986.

114. Treuth MS. Figueroa-Colon R, Hunter GR, Wensier RL, Burtte NF, Goran MI. Energy expenditure and physical fitness in overweight vs non-overweight prepubertal girls. Int J Obes 1998; 22: 440-447.

115. Maffeis C, Schutz Y, Schena F, Zaffanello M, Pinelli L. Energy expenditure during walking and running in obese and nonobese prepubertal children. J Pediatr 1993; 123: 193-199.

116. Maffeis C, Schena F, Zaffanello M, Zoccante L, Schutz Y, Pinelli L. Maximal aerobic power during running and cycling in obese and non-obese children. Acta Paediatr 1994; 83: 113-116.

117. Stunkard A, Pestka J. The physical activity of obese girls. Am J Dis Child 1962; 103: 116-121.

118. Davies PS, Gregory J, White A. Physical activity and body fatness in pre-school children. Int J Obes 1995; 19: 6-10.

119. Li R, O'Connor L, Buckley D, Specker B. Relation of activity levels to body fat in infants of 6 to 12 months of age. J Pediatr 1995; 126: 353-357.

120. Moore LL, Nguyen U-SDT, Rothman KJ, Cupples LA, Ellison RC. Preschool physical activity level and change in body fatness in young children. Am J Epidemiol 1995; 142: 982-988.

121. Maffeis $C$, Zaffanello $M$, Schultz Y. Relationship between physical activity and adiposity in prepubertal boys. I Pediatr 1997; 131: 288-292.

122. Chirico AM, Stunkard AJ. Physical inactivity and human obesity. N Engl J Med 1960; 263: 935940.

123. Buchowski $M$, Sun $M$. Energy expenditure, television viewing, and obesity. Int J Obes 1996; 20: $236-244$.

124. Energy and protein requirements: report of a joint FAO/WHO/UNU Expert Consultation. World Health Organization, Geneva, 1985.

125. Schofield WN, Schofield C, James WPT. Basal metabolic rate - review and prediction together with an annoted bibliography of source material. Hum Nutr Clin Nutr 1985; 39 C: 51-96.

126. Fontvieille AM, Harper IT, Ferraro RT, Spraul M, Ravussin E. Daily energy expenditure by fiveyear-old children, measured by doubly labeled water. J Pediatr 1993; 123: 200-207.

127. Goran $\mathrm{Ml}_{1}$ Carpenter $\mathrm{WH}$, Poehlman ET. Total energy expenditure in 4- to 6-yr-old children. Am J Physiol 1993; 264: E706-E7r.

128. Maffeis $C$, Schutz $Y$, Micciolo $R$, Zoccante $L$, Pinelli $L$ Resting metabolic rate in six- to ten-yearold obese and nonobese children. J Pediatr 1993; 122: 556-562. 
129. Molnar $D$, Jeges $S$, Erhardt $E$, Schulz $Y$. Measured and predicted resting metabolic rate in obese and nonobese adolescents. I Pediat 1995: 127:571-57.

130. Saris WHM, De Bekker GIPM. Breedveld BC, Den Hartog C. Jonxis JHP, Luyken R. Schaafsma C. Schrijuer 1. Voedingsraad - Nederlandse voedingsnormen 1989 . Voorlichtingsbureau voor de voeding, Den Haag, 1989 .

731. Pate RR, Baranowski T, Dowda M, Trost 5G. Tracking of physical activity in young children. Med Sci Sports Exerc 1996; 28:92-96.

132. Malina RM. Tracking of physical activity and physical fitness across life span. Res Quart Exerc Sports 1996; 67: S48-557.

333. Raitakari OT, Porkka KVK, Taimela S, Telama R, Rasanen L, Viikara JSA. Effect of persistent physical activity and inactivity on coronary risk factors in children and young adults. The cardiovascular Risk in Young Finns Study. Am J Epidemiol 1994; 140: 195-205.

134. Neel J. Diabetes mellitus: a "thrifty" genotype rendered detrimental by "progress". Am I Hum Genet 1962: 14:353-362.

135. Hales CN, Barker DJP. Type 2 (non-insulin-dependent) diabetes mellitus: the thrifty phenotype hypothesis. Diabetologia 1992; 35: 595-601.

136. Rosenbaum $M$, Leibel $R$. The physiology of body weight regulation: Relevance to the etiology of obesity in children. Pediatrics 1998; 101: 525-539.

137. Rosenbaum M, Leibel R. Pathophysiology of childhood obesity. Adv Pediatr 1988; 35: 73-137.

138. Bouchard C. Genetics of obesity. CRC Press, Boca Raton, FI, 1994.

139. Cheek DB, Mellits D, Elliott D. Body Water, Height, and Weight During Growth in Normal Children. Am J Dis Child 1966; 112: 312-317.

140. Knittle JL, Timmers K, Ginsberg-Fellner F, Brown RE, Katz DP. The growth of adipose tissue in children and adolescents. Cross-sectional and longitudinal studies of adipose tissue cell number and size. J Clin Invest 1979; 63: 239-246.

141. Poissonet CM, LaVelle M, Burdi AR. Growth and development of adipose tissue.J Pediatr 1988; $113: 1-9$.

142. Dauncey M, Gairdner DG. Size of adipose cells in infancy. Arch Dis Child 1975; 50: 286-290.

143. Hager A, Sjorstrom L Arvidsson B, Bjorntorp P, Smith U. Body fat and adipose tissue cellularity in infancy: a longitudinal study. Metabolism 1977; 26: 607-614.

144. Cornelius P, MacDougald OA, Lane MD. regulation of adipocyte development. Annu Rev Nutr 1994; 14: 99-129.

145. Durnin JVGA, Womersley J. Body fat assessment from total body density and its estimation from skinfold thickness: measurements on 481 men and women aged from 16 to 72 years. $B r$ I Nutr 1974; 32: $77-97$.

146. Cheek. Human Growth. Lea \& Febiger, Philadelphia, 1968.

147. Kemper HCG. Crowth health and fitness of teenagers. Karger, Basel, 1985.

148. Saris WHM (1987). Referentiewaarden voor maximaal en submaximaal prestatievermogen. Nijmegen, Catholic university of Nijmegen.

149. Knittle JL Ginsberg-Felner F. Effect of weight reduction on in vitro adipose tissue lipolysis and cellularity in obese adolescents an adults. Diabetes 1972; 21: 754-761. 
150. Dietz WH. Critical periods in childhood for the development of obesity. Am J Clin Nutr 1994; 59: 955-959.

151. Vohr BR, Lipsitt LP, Oh W. Somatic growth of children of diabetec mothers with reference to birth size. J Pediatr 1980; 97: 196-199.

152. Pettit DJ, Baird HR, Aleck KA, Benett PA, Knowler WC. Excessive obesity in offspring of Pima Indian women with diabetes during pregnancy. N Engl I Med 1983; 308: 242-245.

153. Rolland-Cachera M-F, Deheeger $M$, Bellisle F, Sempe $M$, Guilloud-Bataille $M$, Patois $E$. Adiposity rebound in childre: a simple indicator for predicting obesity. Am J Clin Nutr 1984; 39: 129-135.

154. Barker DJP, Hales CN, Fall CHD, Osmond C, Phipps K, Clark PMS. Type 2 (non-insuline-dependent) diabetes mellitus, hypertension and hyperlipidemia (Syndrome $\mathrm{X}$ ): relation to reduced fetal growth. Diabetologia 1993; 36: 9.

155. Allison DB, Paultre F, Heymsfield SB, Pi-Sunyer FX. Is the intra-uterine period really a critical period for the development of adiposity. Int J Obes 1995: 19: 397-402.

156. Ravelli G, Stein Z, Susser M. Obesity in young men after famine exposure in utero and early pregnancy. N Engl J Med 1976; 295: 349-353.

757. Barker DJP. Mothers, Babies, and Disease in Later Life. British Medical Journal Books, London, 1994.

758. Siervogel RM, Roche AF, Guo S, Mukherjee D, Chumlea WC. Patterns of change in weight/stature ${ }^{2}$ from 2 to 18 years: findings form long-term serial data for children in the Fels Longitudinal Growth Study. Int J Obes 1991; 15: 479-485.

159. Goran MI, Gower BA, Nagy TR, Johnson RK. Developmental changes in energy expenditure and physical activity in children: evidence for a decline in physical activity in girls before puberty. Pediatrics 1998; 101: 887-891.

160. Braddon FEM, Rodgers B, Wadsworth MEJ, Davies JMC. Onset of obesity in a 36 year birth cohort. Br Med J 1986; 293: 299-303.

161. Rubner M. Die Quelle der Thierischen Wärme. Biologie 1894; 30.

162. Simonson DC, Defronzo RA. Indirect calorimetry: methodological and interpretative problems. Am J Physiol 1990; 258: E399-E412.

163. Westerterp-Plantenga MS, Steffens AB. Tremblay A. Regulation of food intake and energy expenditure. Edra, Milano, 1999.

164. Ferrannini E. The theoretical basis of indirect calorimetry: a review. Metabolism 1988; 37:287301.

165. Klesges RC, Hanson LC. Determining the environmental causes and correlates of childhood obesity: Methodologica issues and future directions. Telford, Caldwell, NJ, 1988.

166. Fontvieille AM, Dwyer J, Ravussin E. Resting metabolic rate and body composition of Pima indian and caucasian children. Int J Obes 1992; 16: 535-542.

167. Bandini LG, Vu D, Must A, Cyr H, Goldberg A, Dietz WH. Comparison of high-calorie, lownutrient-dense-food consumption among obese and non-obese adolescents. Obes Res 1999; $7: 438-443$. 
168. Livingstone MBE, Prentice AM, Strain JJ. Accuracy of weighed dietary records in studies of diet and health. Br Med J 1990; 300: 708-712.

169. Maffeis $C$, Schutz Y, Zaffanello M, Piccoli R, Pinelli L Elevated energy expenditure and reduced energy intake in obese prepubertal children: paradox of poor dietary reliability in obesity? J Pediatr 1994; 124: 348-354.

170. Birch LL, Fisher JA. Appetite and eating behavior in children. Pedr Clin North Am 1995; 42: 931953.

177. Griffiths $M$, Payne PR. Energy intake in children at high and low risk of obesity. Hum Nutr Clin Nutr 1987; 41C: 425-430.

172. Puhl JL. Energy expenditure among children: Implications for childhood obesity 1: resting and dietary energy expenditure. Ped Exer Sci 1989; 1: 212-229.

173. Lissau I, Breum L Sorenson TIA. Maternal attitude to sweet eating habits and risk of overweight in offspring: a ten-year prospective population study. Int J Obes 1993; 17: 125-129.

174. Johnson SL, Birch LL. Parents' and children's adiposity and eating style. Pediatrics 1994; 94 : 653-661.

175. Weir JBdV. New methods for calculating metabolic rate with special reference to protein metabolism. J Physiol 1949; 612: 511-521.

176. Ravussin E, Lillioja S, Anderson TE, Christin L, Bogardus C. Determinants of 24-hour Energy Expenditure in Man. J Clin Invest 1986; 78: 1568-1578.

177. Wells JCK. Energy metabolism in infants and children. Nutrition 1998; 14: 817-820.

178. Goldberg GR, al. e. Overnight and basal metabolic rate in men and women. Eur J Clin Nutr 1988; 42: 137-144

179. Schoffelen PFM, Westerterp KR, Saris WHM, Hoor FT. A dual-respiration chamber system with automated calibration. J Appl Physiol 1997; 83: 2064-2072.

180. Ravussin E, Bogardus C. Relationship of genetics, age, and physical fitness to daily energy expenditure and fuel utilization. Am J Clin Nutr 1989; 49: 968-975.

81. Weinsier $R L$, Schutz $Y, B$ racco $D$. Reexamination of the relationship of resting metabolic rate to fat-free mass and to the metabolically active components of fat-free mass in humans. Am J Clin Nutr 1992; 22: 790-794.

182. Weststrate JA, Weys PJM, Poortvliet EJ, Deurenberg P, Hautvast JGAJ. Diurnal variation in postabsorptive resting metabolic rate and diet-induced thermogenesis. Am J Clin Nutr 1989; 50: $908-915$.

183. Blaak EE, Saris WHM. Postprandial Thermogenesis and Substrate Utilization After Ingestion of Different Dietary Carbohydrates. Metabolism 1996; 45: 1235-1242.

184. Schutz $Y$, Bessard T, Jequier E. Thermogenesis measured over a whole day in obese and nonobese women. Am J Clin Nutr 1984; 40: 542-552.

185. Bessard T, Schutz $Y$, Jequier E. Energy expenditur and postprandial thermogenesis in obese women before and after weight loss. Am J Clin Nutr 1983; 36: 680-693.

186. Epstein LH, Wagner S, Nudelman S, Marks BL The stability of resting metabolic rate and diet induced thermogenesis in children. J Psychopath Behav Assess 1987: 9: 423-428. 
187. Salas Salvado J, Barenys Manent $M$, Recasens Gracia MA, Marti Henneberg $C$. Influence of adiposity on the thermic effect of food and exercise in lean and obese adolescents. Int J Obes 1993: 17: 717-722.

188. Tounian P, Girardet JP, Carlier L, Frelut ML Veinberg F, Fontaine JL Resting energy expenditure and food-induced thermogenesis in obese children. J Pediatr Gastroenterol Nutr 1993; 16:451457.

189. Molnár D, Varga P, Rubecz I, Hamar A, Mestyán J. Food-induced thermogenesis in obese children. Eur J Pediatr 1985; 144: 27-31.

190. Goran MI, Carpenter WH, MCGloin A, Johnson R, Hardin MM, Weinsier RL Energy expenditure in children of lean and obese parents. Am J Physiol 1995; 0054:

191. Goran MI. Variation of total energy expenditure in humans. Obes Res 1995; 3: 59-66.

192. Prentice AM, Goldberg GR, Murgatroyd PR, Cole TJ. Physical activity and obesity: problems in correcting expenditure for body size. Int J Obes 1996; 20: 688-691.

193. Davies PS, Wells JC, Fieldhouse CA, Day JM, Lucas A. Parental body composition and infant energy expenditure. Am J Clin Nutr 1995; 61: 1026-1029.

194. Livingstone MB, Coward WA, Prentice AM, Davies PS, Strain JJ, McKenna PG, Mahoney CA, White JA, Stewart CM, Kerr M. Daily energy expenditure in free-living children: comparison of heart-rate monitoring with the doubly labeled water method. Am J Clin Nutr 1992; 56: 343-352.

195. Bandini LG, Schoeller DA, Dietz WH. Energy Expenditure in Obese and Nonobese adolescents. Pediatr Res 1990; 27: 198-203.

196. Lenthe FJv, Mechelen Wv, Kemper HCG, Post GB. Behavioral variables and development of a central pattern of body fat from adolescence into adulthood in normal-weight whites: the Amsterdam Growth and Health Study. Am J Clin Nutr 1998; 67: 846-852.

197. Goran MI, Shewchuk R, Gower BA, Nagy TR, Carpenter WH, Johnson RK. Longitudinal changes in fatness in white children: no effect of childhood energy expenditure. Am J Clin Nutr 1998; 67: 309-316.

198. Bruch H. Obesity in childhood IV: energy expenditure of obese children. Am J Dis Child 1940; 60: $1082-1109$.

199. Saris WHM. Habitual physical activity in children: methodology and findings in health and disease. Med Sci Sports Exerc 1986; 18: 253-263.

200. Craig SB, Bandini LC, Lichtenstein AH, Schaefer E, Dietz WH. The impact of physical activity on lipids, lipoproteins and blood pressure in preadolescent girls. Pediatrics 1996; 98: 389-395

201. Goran MI, Hunter $\mathrm{G}$, Johnson R. Physical activity related energy expenditure and fat mass in young children. Int J Obes 1997; 21: 171-178.

202. Epstein LH, Valoski AM, Vara LS, MCCurley J, Wisniewski L, Kalarchian MA, Klein KR, Shrager LR. Effects of decreasing sedentary behavior and increasing activity on weight change in obese children. Health Psychol 1995; 14: 109-115.

203. Lifson N, Gordon GB, MCClintoch R. Measurement of total carbon dioxide production by means of D2-180. J Appl Physiol 1955; 7: 704-710.

204. Schoeller DA, Santen EV. Measurement of Energy Expenditure in Humans by Doubly Labeled Water. / Appl Physiol 1982: 53: 955-959. 
205. Westerterp KR, Wouters L, Marken-Lichtenbelt WDv. The Maastricht Protocol for the Measurement of Body Composition and Energy Expenditure with Labeled Water. Obes Res 1995: 3: 49-57.

206. Livingstone MBE, Prentice AM, Coward WA, Strain J, Black AE, Davies PSW, Stewart CM, MCKenna PG, Whitehead RG. Validation of estimates of energy intake by weighed dietary record and diet history in children and adolescents. Am J Clin Nutr 1992; 56: 29-35.

207. Black AE, Prentice AM, Coward WA. Use of food quotients to predict respiratory quotients for the doubly-labelled water method of measuring energy expenditure. Human Nutrition: Clinical Nutrition 1986; 40C: 381-391.

208. Durnin JVGA. Energy balance in childhood and adolescents. Proc Nutr Soc 1984; 43: 271-279.

209. Butte NF. Energy requirements of infants. Eur J Clin Nutr 1996; 50 Suppl 1: S24-36.

210. Davies PS. Energy requirements and energy expenditure in infancy. Eur J Clin Nutr 1992; 46: S29-S35.

211. Holliday MA. Metabolic rate and organ size during growth from infancy to maturity and during late gestation and early infancy. Pediatrics 1971; 47: 169-179.

212. Roche AF, Heymsfield SB, Lohman TG. Human Body Composition. Human Kinetics, Champaign, IL, USA, 1996.

213. Wells JCK, Fuller NJ, Dewit O, Fewtrell MS, Elia M, Cole TJ, Four-component model of body composition in children: density and hydration of fat-free mass and comparison with simpler models. Am J Clin Nutr 1999; 69: 904-912.

214. Roubenoff R, Khayias JJ, Dawson-Hughes B. Heymsfield SB. Use of dual-energy $x$-ray absorptiometry in body composition studies: not yet a 'gold standard'. Am J Clin Nutr 1993; 58: 589591.

215. Van Marken Lichtenbelt W, Kester A, Baarends EM, Westerterp KR. Bromide dilution in adults: optimal equilibration time after oral administration. J App/ Physiol 1996; 81: 653-656.

216. Schoeller DA. Energy expenditure from doubly labeled water: some fundamental considerations in humans. Am J Clin Nutr 1983; 38: 999-1005.

217. Miller ME, Cosgriff JM, Forbes GB. Bromide space determination using anion-exchange chromatography for measurement of bromide. Am J Clin Nutr 1989; 50: 168-171.

218. Van Marken Lichtenbelt W, Fogelholm M. Body composition. In: MS Westerterp-Plantenga, $A B$ Steffens and A Tremblay (eds). Regulation of food intake and energy expenditure. EDRA: Milano, 1999.

219. Boileau RA, Lohman TG, Slaughter MH, Ball TE, Going SB, Hendrix MK. Hydration of the fatfree body in children during maturation. Hum Biol 1984; 56: 651-666.

220. Tanner JM. Growth at adolescence. Blackwell Scientific Publications Ltd., London, 1962.

221. Griffiths $M$, Payne PR. Energy expenditure in small children of obese and non-obese parents. Nature 1976; 260: 698-700.

222. Ravussin E, Lillioja S, Knowler WC, Christin PHL, Freymont D, Abott WGH, Boyce V, Howard BV, Bogardus $C$. Reduced rate of energy expenditure as a risk factor for body-weight gain. NEngl J Med 1988; 318: 467-472.

223. Roberts SB, Savage J, Coward WA, Chew B, Lucas A. Energy expenditure and intake in infants born to lean and overweight mothers. N Engl / Med 1988; 318: 461-466. 
224. Dietz WH, Bandini LG, Morelli JA, Peers KF, Ching PL. Effect of sedentary activities on resting metabolic rate. Am J Clin Nutr 1994; 59: 556-559.

225. DeLany JP, Harsha DW, Kime J, Kumler J, Melancon L, Bray GA. Energy expenditure in lean and obese pre-pubertal children. Obes Res 1995; S67-S72.

226. Prader A, Labhart A, Willi H. Ein Syndrom von Adipositas, Kleinwuchs, Kryptorchismus und Oligophrenie nach myotonieartigem Zustand in Neugeborenenalter. Schweizerische Medizinische Wochenschrift 1956; 86:1260-1261.

227. Holm VA, Cassidy SZ, Butler MG, Hanchett JM, Greenswag LR, Whitman BY, Greenberg FG. Prader-Willi Syndrome: Consensus Diagnostic Criteria. Pediatrics 1993; 91: 398-402.

228. Butler MC. Prader-Willi Syndrome: Current Understanding of Cause and Diagnosis. American Journal of Medical Cenetics 1990; 35: 319-332.

229. Swaab DF, Purba JS, Hofman MA. Alterations in the Hypothalamic Paraventricular Nucleus and Its Oxytocin Neurons (Putative Satiety Cells) in Prader-Willi Syndrome: A Study of Five Cases. J Clin Endocrinol Metabol 1995; 80: 573-579.

230. Akefeldt A, Ekman R, Gillberg C, Mansson JE. Cerebrospinal fluid monoamines in Prader-Willi syndrome. Biol Psych 1998; 44: 1321-1328.

231. Mascari MJ, Gottlieb W, Rogan PK, Butler MG, Waller DA, Armour JA, Jeffreys AJ, Ladda RL, Nicholls RD. The frequency of uniparental disomy in Prader-Willi syndrome. Implications for molecular diagnosis. N Engl J Med 1992; 326: 1599-1607.

232. Donaldson MD, Chu CE, Cooke A, Wilson Az Greene SA, Stephenson JB. The Prader-Willi Syndrome. Arch Dis Child 1994; 70: 58-63.

233. Cassidy SB. Prader-Willi Syndrome and Other Chromosome $15 q$ Deletion Disorders. In: (eds). NATO ASI Series. Springer-Verlag: Noordwijkerhout, the Netherlands, 1991.

234. Nicholls RD, Knoll JH, Butler MG, Karam S, Lalande M. Genetic Imprinting suggested by Maternal Heterodisomy in Nondeletion Prader-Willi Syndrome. Nature 1989; 342: 281-285.

235. Glenn CC, Driscoll DJ, Yang TP, Nicholls RD. Genomic imprinting: potential function and mechanisms revealed by the Prader-Willi and Angelman syndromes. Mol Hum Reprod 1997; 3: 321-332.

236. Bray GA, Dahms WT, Swerdloff RS, al RHFe. The Prader-Willi Syndrome: a study of 40 patients and a review of the literature. Medicine 1983; 62: $59-80$.

237. Holm VA, Pipes PL Food and children with Prader-Willi syndrome. Am J Dis Child 1976; 130: 1063-1067.

238. Nardella MT, Sulzbacher SI, Worthington-Roberts BS. Activity Levels of Persons with PraderWilli Syndrome. Am J Ment Defic 1983: 87: 498-505.

239. Davies PSW, Joughin C. Using Stable Isotopes to Assess Reduced Physical Activity of Individuals With Prader-Willi Syndrome. Am J Ment Retard 1993: 98: 349-353.

240. Schoeller DA, Levitsky LL, Bandini LG, Dietz WW, Walczak A. Energy Expenditure and Body Composition in Prader-Willi Syndrome. Metabolism 1988; 37: 115-120.

241. Hill JO, Kaler M. Spetainick $B$, Reed G, Butler MC. Resting metabolic rate in Prader-Willi syndrome. Dysmorphol Clin Genet 1990; 4: 27-32.

242. Williams CL, Kimm SYS. Prevention and Treatment of Childhood Obesity. The New York Academy of Sciences, New York, 1993. 
243. Barlow SE, Dietz WH. Obesity evaluation and treatment: expert committee recommendations. Pediatrics 1998; 102: E29 (available at http://www.pediatrics.org).

244. Epstein LH. Exercise in the treatment of childhood obesity. Int J Obes 1995; 19 Suppl 4: S117121.

245. Epstein LH. Family-based behavioural intervention for obese children. Int J Obes 1996; 20: S14 - S21.

246. Maffeis C, Schutz Y, Pinelli L. Effect of weight loss on resting energy expenditure in obese prepubertal children. Int J Obes 1992; 16: 41-47.

247. Tounian P, Frelut M-L, Parlier G, Abounaufal C, Aymard N, Veinberg F, Fontaine J-F, Girardet J.P. Weight loss and changes in energy metabolism in massively obese adolescents. Int $J$ Obes 1999; 23: 830-837. 


\section{Chapter 2}

\section{Energy expenditure at rest and during sleep in children with Prader-Willi syndrome is explained by body composition}

Edgar G.A.H. van Mil, Klaas R. Westerterp, Willem J.M. Gerver, Leopold M.G. Curfs, Constance T.R.M. Schrander-Stumpel, Arnold D.M. Kester, Wim H.M. Saris

From the Department of Human Biology, Nutrition Environment and Toxicology Research Institute Maastricht, the Department of Clinical Genetics, the Department of Methodology and Statistics, Maastricht University; and the Department of Paediatrics, University Hospital Maastricht, The Netherlands

Published in: The American Journal of Clinical Nutrition. 2000; 71: 752-756 


\section{Abstract}

Background: Obesity in Prader-Willi syndrome (PWS) seems related to a decreased basal metabolic rate (BMR). In addition, abnormal sleep patterns reported in PWS, might affect sleeping metabolic rate (SMR).

Objective: To assess BMR and SMR, adjusted for FFM, in young PWS patients.

Design: Subjects were seventeen PWS subjects (10 females, 7 males, age 7.5-19.8 y) and 17 obese controls, matched for gender and bone age. SMR was measured in a respiration chamber, BMR with a ventilated hood system and body composition by deuterium dilution.

Results: BMR, SMR were significantly lower in the PWS group compared with the control group $(5.36 \pm 1.18,4.62 \pm 1.08 \mathrm{MJ} /$ day, compared with $6.38 \pm 1.55,5.60 \pm$ $1.52 \mathrm{MJ} /$ day, respectively) $(\mathrm{p}<0.05)$. When FFM was included in the analysis, multiple regression showed no differences in BMR and SMR between both groups. When weight was included in the analysis, instead of FFM, the SMR was decreased in the PWS group. FFM was lower in the PWS group, both in absolute value as well as adjusted for height.

Conclusion: BMR and SMR are decreased in young patients with PWS, because of a lower FFM. 


\section{Introduction}

Prader-Willi syndrome (1) (PWS) is a clinically diagnosed genetic disorder and results from the absence of normally active paternally inherited genes at chromosome $15(q 11-q 13)(2)$. About $70-75 \%$ of the patients has an interstitial deletion in this region. The majority of the remaining PWS patients have a maternal uniparental disomy for chromosome 15 . The major clinical criteria (3) for the diagnosis of PWS include neonatal and infantile central hypotonia with feeding problems in infancy, hypogonadism and global developmental delay resulting in mild to moderate mental retardation (4). Supported by other symptoms such as short stature, altered temperature sensitivity, high pain threshold and characteristic behaviour problems (e.g. - temper tantrums or obsessive/compulsive behaviour), this syndrome is strongly suggested to be based on dysfunction of various hypothalamic centre's $(5,6,7)$. PWS is also known as the most common human genetic disorder linked to obesity (8). The high prevalence of obesity in PWS is likely caused by a combination of low energy expenditure and an almost unsatiable hunger that starts in early childhood $(9,10)$.

Schoeller et al.(11) were the first to report that common formula's using age, gender, height and weight to predict basal metabolic rate (BMR), would overestimate BMR in adult PWS patients. They found that the Cunningham formula (12), that uses fat-free mass (FFM) in the equation, did not overestimate BMR significantly. Later studies, however, could either not confirm the decreased BMR in young PWS patients (13), or contradictory found a reduced BMR, even when adjusted for FFM (14). The question therefore, whether BMR, adjusted for FFM, is decreased in young PWS patients, is still unanswered.

BMR is composed of two components, sleeping metabolic rate (SMR) and arousal. The respiration chamber measures SMR overnight and offers an alternative measurement of metabolic rate in the inactive and fasted state. In addition, parents and carers often report excessive sleepiness, daytime hypersomnolence and sleep disturbance at night in PWS patients. Studies have shown abnormal sleep with abnormal REM sleep cycles and multiple brief REM periods suggesting a specific disruption to the timing of REM/NREM cycles $(15,16,17)$, possibly causing an alteration in SMR in patients with PWS.

As a result of contradictory reports of basal metabolic rate and of abnormal sleep patterns in patients with Prader-Willi syndrome, the aim of our study was to measure basal and sleeping metabolic rate, adjusted for fat-free mass, in children and adolescents with Prader-Willi syndrome, compared with obese controls. 


\section{Subjects and methods}

\section{Subjects}

Seventeen PWS subjects (age $7.5-19.8$ y) were recruited with the assistance of the Dutch Prader-Willi Association. The subjects were assessed according to the Holm criteria (3). The Holm system provides a quantitative measure of PWS symptoms. PWS was preferably confirmed by either a deletion on chromosome 15 or uniparental disomy. When only clinical data were available critical evaluation took place by the same clinical geneticist. The PWS subjects were gender- and boneage-matched with nonsyndromal obese controls (age 6.3 - 15.3 y) recruited from the regional public health department. Bone-age was determined by assessing epiphysal maturation by the same paediatric endocrinologist using an X-ray of the mid portion of the left hand and standard growth data (18). None of the PWS subjects was receiving hormone therapy or treatment with human growth hormone before or during the study.

Controls with endocrine causes or other secondary causes of obesity were excluded. Subject characteristics are shown in Table 2.1.

Before the start of the study the parents gave written informed consent confirmed by an oral approval of the child. The study was approved by the medical ethical committee of Maastricht University.

Table 2.1

Body composition, energy expenditure and other characteristics of subjects with Prader-Willi syndrome (PWS) and obese control subjects'

\begin{tabular}{|c|c|c|c|c|c|c|}
\hline & \multicolumn{3}{|c|}{ PWS } & \multicolumn{3}{|c|}{ Controls } \\
\hline$n(F / M)$ & \multicolumn{3}{|c|}{$17(10 / 7)$} & \multicolumn{3}{|c|}{$17(10 / 7)$} \\
\hline Bone age $(y)$ & 12.7 & \pm & 2.9 & 12.7 & \pm & 3.2 \\
\hline Age $(y)$ & 11.9 & \pm & 3.4 & 11.3 & \pm & 2.6 \\
\hline Height (m) & 1.43 & \pm & 0.16 & 1.49 & \pm & 0.20 \\
\hline Weight (kg) & 50.0 & \pm & 19.7 & 61.5 & \pm & 25.6 \\
\hline FFM $(\mathrm{kg})$ & 27.5 & \pm & $9.9^{* *}$ & 35.9 & \pm & 13.4 \\
\hline $\mathrm{FM}(\mathrm{kg})$ & 22.4 & \pm & 11.7 & 25.6 & \pm & 12.7 \\
\hline BMI $\left(\mathrm{kg} / \mathrm{m}^{2}\right)$ & 23.5 & \pm & 6.0 & 26.0 & \pm & 6.5 \\
\hline FFMI $\left(\mathrm{kg} / \mathrm{m}^{2}\right)$ & 12.9 & \pm & $2.3^{* * *}$ & 15.4 & \pm & 2.7 \\
\hline $\mathrm{FMI}\left(\mathrm{kg} / \mathrm{m}^{2}\right)$ & 10.6 & \pm & 4.5 & 10.6 & \pm & 4.0 \\
\hline SMR (M/day) & 4.62 & \pm & $1.08^{* *}$ & 5.60 & \pm & 1.52 \\
\hline BMR (MJ/day) & 5.36 & \pm & $1.18^{* *}$ & 6.38 & \pm & 1.55 \\
\hline
\end{tabular}

1 mean \pm sd; FFM, fat-free mass; FM, fat mass; FFMI, fat-free mass index; FMI, fat mass index; SMR, sleeping metabolic rate; BMR, basal metabolic rate

..... Significantly different from control group (Independent-samples t-test): ${ }^{-} p<0.05, \cdots p<0.01$ 


\section{Methods}

SMR was measured overnight in a respiration chamber. Following this, BMR and body composition were determined by ventilated hood and deuterium dilution, respectively.

The subject and parent were invited to come to the laboratory at 19.00 hours after a normal dinner. At 22.00 hours the subject entered the respiratory chamber. The hours in between were used to familiarize the subject with the study equipment, do a practice session with the ventilated hood, and produce a background urine sample for body composition analysis.

Body composition was measured with the dilution technique according to the Maastricht protocol (19). In summary, the subject received an orally administered dose of $\mathrm{D}_{2} \mathrm{O}$ of $0.1 \mathrm{~g} / \mathrm{l}$ Total Body Water (TBW), diluted in $75 \mathrm{ml}$ tap water, as the last drink before bedtime. TBW was estimated from age- and sex-specific formulas (20). After the dosing the subject went into the respiratory chamber and was asked to go to sleep before $22.30 \mathrm{~h}$. A urine sample was taken toh after dose administration from the second voiding the next morning. Isotope abundance in urine was determined with an isotope-ratio mass spectrometer (Aqua Sira, VG Isogas Ltd. (Micromass, Manchester) UK). TBW was calculated as the ${ }^{2} \mathrm{H}$ dilution space divided by 1.04 correcting for exchange of the ${ }^{2} \mathrm{H}$ label with non-aqueous $\mathrm{H}$ of body solids (21). FFM was assessed with the assumption of FFM containing all body water. Hydration factors of FFM were based on maturation specific values (22). Maturation was assessed according to Tanner's puberty ratings (23). Fat Mass (FM) was calculated by subtracting FFM of the subject's total body weight. To allow for comparisons between subjects, FM and FFM were expressed as an index: FFMI $\left(\mathrm{kg} / \mathrm{m}^{2}\right)$ and FMI $\left(\mathrm{kg} / \mathrm{m}^{2}\right)$, respectively. Patients with PWS experience specific periods of growth stunting, leading to changes in age related body composition. In this way we have corrected for the large variation in height, in analogy with the $\mathrm{BMI}, \mathrm{BMI}=\mathrm{FFMI}+\mathrm{FMI}$.

SMR was measured during a $12 \mathrm{hr}$ overnight stay in the respiration chamber which was described in detail previously (24). The respiration chamber, an opencircuit indirect calorimeter $(14 \mathrm{~m} 3$ ) was maintained at a constant air temperature of $18^{\circ} \mathrm{C}$ during the night. The chamber was ventilated with fresh air at about 40 $\mathrm{I} / \mathrm{min}$. Activity of the subject was measured by an analog ultrasound radar system. SMR was calculated automatically according to Weir (25), between $23.00 \mathrm{~h}$ and $6.30 \mathrm{~h}$ over the 3 -hour interval with the lowest radar count. The next morning the subject came out of the respiratory chamber at $6.30 \mathrm{~h}$ to do their first morning voiding and immediately returned to bed for BMR measurement in an adjacent room. Because the subject was not active that morning the BMR measurement was started after lying supine for 10 minutes.

Oxygen consumption and carbon dioxide production were measured by means of 
computerized, open circuit, ventilated hood system between $7.00 \mathrm{~h}$ and $8.00 \mathrm{~h}$ AM, for 40-50 minutes, when the subject was lying supine, watching television. Gas analyses were performed using a paramagnetic oxygen analyzer (Servomex, Crowborough, UK) and an infrared carbon dioxide analyzer (Uras $3 G$, Hartmann \& Braun, Frankfurt, Germany). BMR was calculated according to the Weir's formula over the 14-min. interval with the lowest standard deviation.

Before the subjects consumed any food or drink, after voiding and whilst wearing under-clothing, body weight was measured on an electronic scale (E1200, Mettler Instrumente $A G$, Greifensee, Switzerland). Height of subjects was measured using a stadiometer.

\section{Statistical analysis}

Differences between the independent variables of the PWS group and control group were analyzed by the two-sample $t$-test. The grouping variable PWS status was defined as: PWS $=1$; controls $=0$. A multiple-linear-regression model with BMR as the dependent variable and bone age, FFM, FM, gender and PWS status as independent variables was used to analyze the differences between both groups adjusted for these independent variables. Firstly, the difference in regression slope, of the influence of FFM on BMR, was tested using an interaction variable of PWS status and FFM (PWS FFM) after correction for the variables in the equation. Secondly, the difference between groups, again corrected for these independent variables, was estimated and tested for significance using linear regression assuming equal slopes. This analysis was also done for SMR as the dependent variable, but now with weight, bone age, gender and PWS status as the independent variables, using an interaction variable of PWS status and weight (PWS*weight). The significance level was chosen at $5 \%$. Data were expressed as means \pm sd. SPSS release 6.1 for Macintosh (SPSS Inc. Chicago, Illinois, USA) was used as the statistical package.

\section{Results}

Clinical characteristics of PWS patients and controls are shown in Table 2.1. There were no statistically significant differences in age, height, weight and BMI between both groups. Additionally, Table 2.1 shows the body composition and energy expenditure results. The FFM and FFMI were significantly lower in the PWS group ( $p<0.05$ and $p<0.01$, respectively), whereas the FM and FMI were similar in both groups. The SMR and BMR were also significantly lower in the PWS group $(p<0.05)$. FFM was plotted against BMR in Figure 2.1. When BMR was expressed 
as a function of FFM in separate linear regression lines for the PWS group and the control group, the $R^{2}$ was 0.91 and 0.83 , respectively. Both lines were not significantly different as was evident from multiple regression when BMR was predicted by bone age, FFM, FM and gender with PWS status as the grouping variable. The coefficients of bone age and FM were also not significant (Table 2.2). When SMR was plotted as a function of FFM, the regression lines of the PWS group $\left(R^{2}=\right.$ 0.94) and the controls $\left(R^{2}=0.91\right.$ ) were remarkably similar (Figure 2.2$)$. In Table 3 the observed variability in SMR was explained by the variables bone age, gender, weight and PWS status, resulting in a significant difference in SMR between both groups. FFMI was plotted as a function of FMI (Figure 2.3). In this plot the difference between both regression lines was statistically significant $(p<0.001)$. Since the interaction variables PWS*FFM and PWS "weight were not significant in the regression analyses, these variables were not included in the related tables.

Fig. 2.1

Basal metabolic rate (BMR, in M/day) as a function of fat-free mass (FFM, in $\mathrm{kg}$ ) plotted for the Prader-Willi group (PWS, filled circles) and obese control group (controls, open squares). The regression equation for PWS: $B M R=0.11 F F M+2.21\left(R^{2}=0.91\right)$; for controls: $B M R=0.11$ $F F M+2.60\left(R^{2}=0.83\right)$.

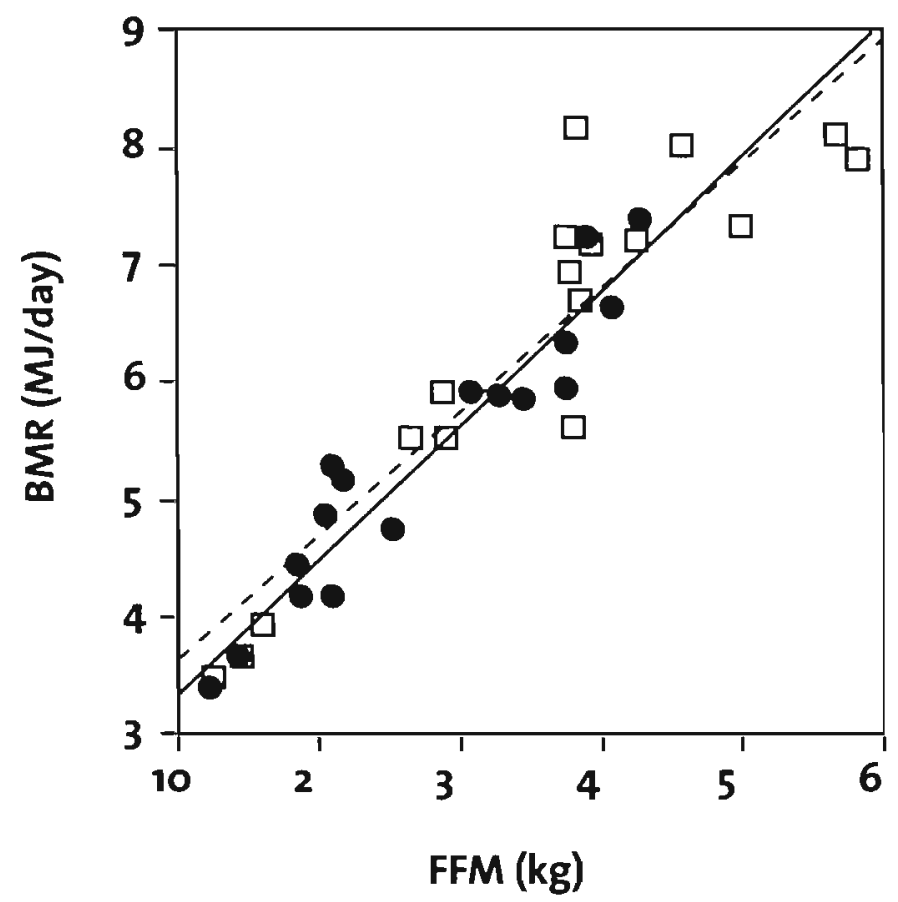


Table 2.2

Results of multiple-linear-regression analysis of the influence of bone age, fat-free mass (FFM), fat mass (FM), gender and Prader-Willi syndrome (PWS) on basal metabolic rate (BMR).

\begin{tabular}{lccrc} 
Variable & $\beta$ Coefficient' $^{\prime}$ & SE & \multicolumn{1}{c}{$95 \% \mathrm{Cl}^{2}$} & $\mathrm{P}$ \\
\hline Bone age $(\mathrm{y})$ & 0.017 & 0.055 & $-0.095-0.129$ & 0.756 \\
FFM $(\mathrm{kg})$ & 0.096 & 0.017 & $0.061-0.131$ & 0.000 \\
FM (kg) & 0.014 & 0.013 & $-0.012-0.039$ & 0.285 \\
Gender3 & -0.548 & 0.179 & $-0.916--0.181$ & 0.005 \\
PWS4 & -0.175 & 0.204 & $-0.593-0.244$ & 0.399 \\
\hline
\end{tabular}

1 The partial regression coefficient which is the change in BMR for a change in a specific variable adjusted for the other independent variables in the equation

2 The range of values that includes the population value of the coefficient

3 Gender was defined as: Female $=1$, Male $=0$

4 Grouping variable PWS status was defined as: $P W S=1$, Obese controls $=0$. The interaction variable PWS"FFM was not significant

Fig. 2.2

Sleeping metabolic rate (SMR, in M/day) as a function of fat-free mass (FFM, in $\mathrm{kg}$ ) for the Prader-Willi group (PWS, filled circles) and obese control group (controls, open squares). The regression equation for PWS: $S M R=0.11 F F M+1.70\left(R^{2}=0.94\right)$; for controls: $S M R=0.11 F F M+$ $1.73\left(R^{2}=0.91\right)$.

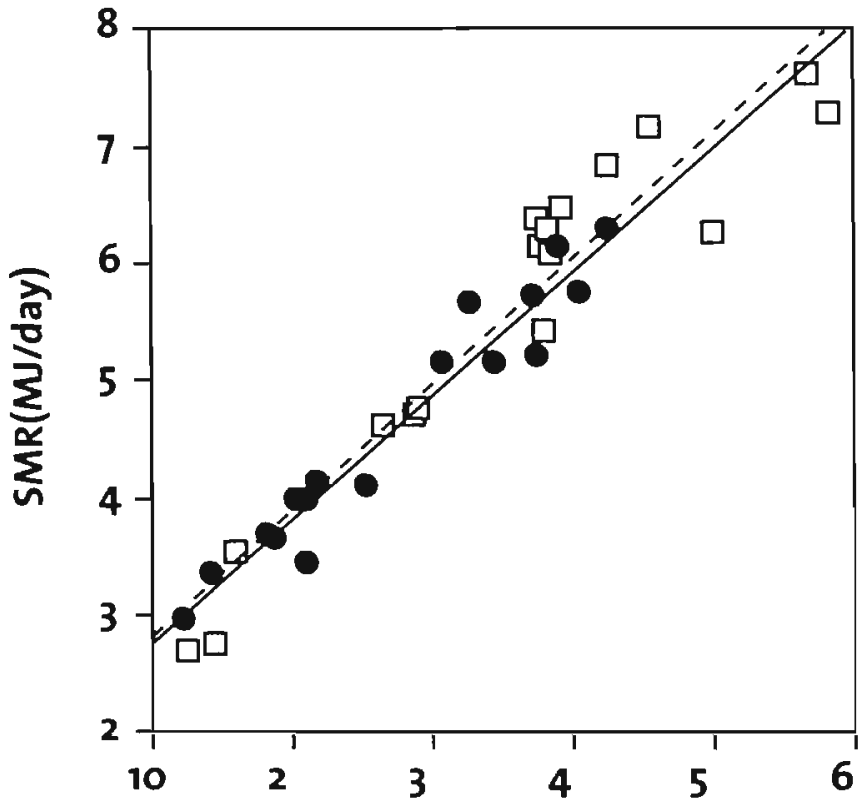

FFM (kg) 
Table 2.3

Results of multiple-linear-regression analysis of the influence of bone age, gender, weight, and Prader-Willi syndrome (PWS) on sleeping metabolic rate (SMR).

\begin{tabular}{|c|c|c|c|c|c|}
\hline Variable & $\beta$ Coefficient $^{1}$ & SE & $95 \%$ & $\mathrm{Cl} \beta^{2}$ & $p$ \\
\hline Bone age $(y)$ & 0.039 & 0.043 & -0.050 & 0.128 & 0.380 \\
\hline Gender 3 & -0.505 & 0.149 & -0.810 & - $\quad 0.200$ & 0.002 \\
\hline Weight & 0.052 & 0.006 & 0.040 & - $\quad 0.064$ & 0.000 \\
\hline PWS4 & -0.380 & 0.157 & -0.701 & - $\quad 0.059$ & 0.022 \\
\hline
\end{tabular}

1 The partial regression coefficient which is the change in SMR for a change in a specific variable adjusted for the other independent variables in the equation

2 The range of values that includes the population value of the coefficient

3 Gender was defined as: Female $=1$. Male $=0$

4 Grouping variable PWS status was defined as: $P W S=1$, Obese controls $=0$. The interaction variable PWS" weight was not significant

Fig. 2.3

Fat-free mass index (FFMl, in $\mathrm{kg} / \mathrm{m}^{2}$ ) as a function of fat mass index (FMl, in $\left.\mathrm{kg} / \mathrm{m}^{2}\right)$ plotted for the Prader-Willi group (PWS, filled circles) and obese control group (controls, open squares). The PWS regression line is significantly different from the regression line of the controls (Multiple-linear-regression analysis: $p<0.001$ ).

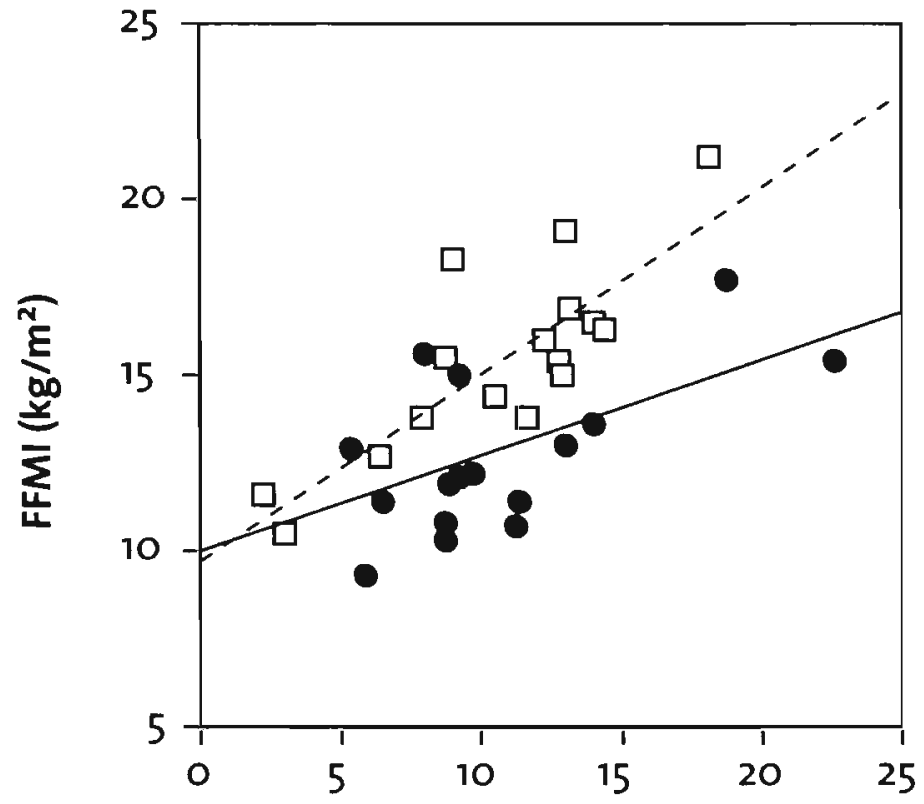

FMI $\left(\mathrm{kg} / \mathrm{m}^{2}\right)$ 


\section{Discussion}

The present study demonstrates that children and adolescents with PWS have a decreased energy expenditure both during rest and during sleep compared with gender and bone-age matched controls. Previous reports $(21,26)$, indicating a decreased BMR in this syndrome, were based on studies with small groups of adult PWS patients, without a control group. In a more recent study (13) that measured BMR in children and adolescents, 10 subjects with PWS were compared with a cohort of 60 healthy school children. Although the difference in BMR between both groups was not significant, the difference further decreased after adjusting for age, gender and FFM. Therefore, in order to study the relationship between FFM and energy expenditure in PWS, a control group is needed that is matched for age and gender. However, possibly because of the suggested hypothalamic insufficiencies, most children with PWS have a delay in biological maturation. Calendar age often overestimates the physical development of a PWS child (8). Bone age measurement, as a means of assessing the rate of maturational change throughout the growing period, provides an estimate of physiological maturation (27). Thus, in the present study, the control group was matched for gender and bone-age.

To adjust BMR for FFM, BMR was plotted as a function of FFM. Since FFM explained more than $87 \%$ of the observed variability of $B M R$, the reduction of $B M R$ must mainly be the result of a low FFM. Indeed, the similarity of the regression lines of both groups demonstrates that the relationship between FFM and BMR in PWS is comparable with the relationship in nonsyndromal obese children. There is a small, not significant difference in intercepts, as well as equal slopes for both lines. This finding differs from a report by Hill et al. (14), who found a decreased BMR, even when adjusted for FFM, compared with two groups of lean and obese controls. The authors suggested that low energy expenditure initially exists for persons with PWS but returns to normal, as these patients grow older and obesity becomes greater. In the present study using multiple regression, bone age nor FM could significantly explain the observed variability in BMR with FFM in the analysis. Moreover, having PWS or not was not important to predict BMR, whilst adjusted for FFM. A possible explanation for this conflicting result might be that the study by Hill et al. used bioelectrical impedance analysis to measure FFM instead of a dilution technique. Especially the high correlation between the skinfold measurements and the bioelectrical impedance outcome suggests that the latter may overestimate the actual FFM, since skinfolds are known to underestimate the amount of FM in PWS due to the altered distribution of body fat (11). Another reason might be that the differences within and between studies are caused by the residual variability of the BMR measurement. Previous studies have reported that it was difficult for PWS children to lay quiet for a BMR measure- 
ment, often leading to no satisfactory measurement at all $(13,14)$. By measuring SMR overnight in the respiration chamber, the influence of agitation is much lower. Thus, FFM could explain 93\% of the observed variability (Figure 2.2). Other variables as FM, gender and bone age could therefore only play a minor role in the prediction of SMR. However, when body weight is used to predict SMR, instead of FFM, the grouping variable PWS status is significant, even when adjusted for bone age and gender, indicating that indeed young PWS patients have a decreased SMR.

Thus, the decreased BMR and SMR must be the result of a decreased FFM. In the present study the FFM is significantly lower in the PWS group, both in absolute value as well as adjusted for height (FFMI). FFMI is an objective measure for comparing healthy subjects with patients with growth deficiency. Indeed, when corrected for height the difference in FFM is even more significant $(p<0.01)$.

Furthermore, it is also necessary to adjust FFM for the effect of FM, since an increase in FM will induce an increase in FFM. When FFMI is plotted as a function of FMI, however, the slope of the PWS group is significantly lower compared with the control group, indicating that for each unit increase in fat mass the increase of fat-free tissues will be reduced in the PWS group.

The precise etiology of the reduction in growth of FFM in PWS is still unclear. The profound hypotonia in PWS might prevent the child from becoming physically active, resulting in low stimulation of muscle and bone tissue and consequently leading to a growth deficit of FFM.

A more general explanation relates the deficit in FFM to a dysfunction of the hypothalamic systems. Abnormalities of the somatotrophic axis would explain why most patients have a blunted growth hormone $(\mathrm{GH})$ response to various provocative stimuli, or show decreased 24 -hour $\mathrm{GH}$ secretion $(28,29,30,31)$. In addition, decreased levels of gonadotrophins, consistent with hypogonadotrophic hypogonadism, suggest a dysfunction of the hypothalamic-pituitary-gonadal axis (7). Although a structural hypothalamic lesion has not been found, a recent study demonstrated a complete absence of the posterior pituitary bright spot on magnetic resonance imaging, indicating a disturbed function of the hypothalamichypophyseal system (6). It is known from several studies that the use of growth hormone in subjects with PWS has a positive effect on increasing height as well as on decreasing percentage body fat $(31,32,33)$. Currently, prolonged trials of growth hormone treatment are undertaken to explore different dosage regimens and possible long term adverse effects of these interventions.

In conclusion, this is the first report that demonstrates the energy expenditure to be decreased in rest as well as during sleep in children and adolescents with 
Prader-Willi syndrome compared with obese subjects matched for bone-age and gender. The decreased energy expenditure is the result of a reduction of fat-free mass, in absolute value as well as adjusted for height. There was no difference between the groups, when basal metabolic rate or sleeping metabolic rate was adjusted for fat-free mass.

\section{References}

1. Prader A, Labhart A, Willi H. Ein Syndrom von Adipositas, Kleinwuchs, Kryptorchismus und Oligophrenie nach myotonieartigem Zustand in Neugeborenenalter. Schweizerische Medizinische Wochenschrift 1956; 86: 1260-1261.

2. Nicholls RD, Knoll JH, Butler MG, Karam S, Lalande M. Genetic Imprinting suggested by Maternal Heterodisomy in Nondeletion Prader-Willi Syndrome. Nature 1989; 342: 281-285.

3. Holm VA, Cassidy SZ, Butler MG, Hanchett JM, Greenswag LR, Whitman BY, Greenberg FG. Prader-Willi Syndrome: Consensus Diagnostic Criteria. Pediatrics 1993; 91: 398-402.

4. Curfs LMG, Fryns J-P. Prader-Willi syndrome: a review with special attention to the cognitive and behavioral profile. In: G Evers-Kiebooms, J-P Fryns, JJ Cassiman and HVd Berghe (eds). Psychosocial aspects of genetic counseling. Wiley-Liss: New York, 1992.

5. Swaab DF. Development of the Human Hypothalamus. Neurochem Res 1995; 20: 509-519.

b. Miller L, Angulo M, Price D, Taneja S. MR of the pituitary in patients with Prader-Willi syndrome: size determination and imaging findings. Pediat Radiol 1996; 26:43-47.

7. Swaab DF. Prader-Willi syndrome and the hypothalamus. Acta Paediatr Supp/ 1997; 423: 5054.

8. Cassidy SB. Prader-Willi Syndrome and Other Chromosome $15 q$ Deletion Disorders. In: (eds). NATO ASI Series. Springer-Verlag: Noordwijkerhout, the Netherlands, 1991.

9. Coplin SS, Hine J, Gormican A. Out-Patient Dietary Management in the Prader-Willi Syndrome. I Am Diet Assoc 1976; 68: 330-334.

10. Holm VA, Pipes PL Food and children with Prader-Willi syndrome. Am J Dis Child 1976; 130: 1063-1067.

11. Schoeller DA, Levitsky LL, Bandini LG, Dietz WW, Walczak A. Energy Expenditure and Body Composition in Prader-Willi Syndrome. Metabolism 1988; 37: 115-120.

12. Cunningham J. An individualization of dietary requirements for energy in adults. J Am Diet Assoc 1982; 80: 335-338.

13. Davies PSW, Joughin C. Using Stable Isotopes to Assess Reduced Physical Activity of Individuals With Prader-Willi Syndrome. Am J Ment Retard 1993: 98: 349-353.

14. Hill JO, Kaler M, Spetalnick B, Reed $G$, Butler MC. Resting metabolic rate in Prader-Willi syndrome. Dysmorphol Clin Genet 1990; 4:27-32.

15. Bueno AV, Kales A. Soldatos CR. Sleep in the Prader-Willi syndrome: clinical and polygraphic findings. Arch Neurol 1984; 41: 294-296.

16. Hertz $G$, Cataletto $M$, Feinsilver $S H$, Angulo $M$. Sleep and Breathing Patterns in Patients with Prader-Willi Syndrome (PWS): effects of age and gender. Sleep 1993; 16:366-37. 
17. Clift S, Dahlitz M, Parker JD. Sleep apnoea in the Prader-Willi syndrome. J Sleep Res 1994: 3: 121-126.

18. Tanner JM, Whitehouse RH, Marshall WA, Healy MJR, Goldstein H. Assessment of skeletal maturity and prediction of adult height (TW2 Method). Academic Press, London, 1983.

19. Westerterp KR, Wouters L Marken-Lichtenbelt WDv. The Maastricht Protocol for the Measurement of Body Composition and Energy Expenditure with Labeled Water. Obes Res 1995: 3: 49-57.

20. Cheek DB, Mellits D, Elliott D. Body Water, Height, and Weight During Growth in Normal Children. Am J Dis Child 1966; 112: 312-317.

21. Schoeller DA, Santen Ev, Petterson DW, Dietz W, Jaspan J, Klein PD. Total Body Water Measurement in Humans with $18 \mathrm{O}$ and $2 \mathrm{H}$ labeled Water. Am J Clin Nutr 1980; 33: 2686 2693.

22. Boileau RA, Lohman TG, Slaughter MH, Ball TE, Going SB, Hendrix MK. Hydration of the fatfree body in children during maturation. Hum Biol 1984; 56: 651-666.

23. Tanner JM. Growth ot adolescence. Blackwell Scientific Publications L.td., London, 1962.

24. Schoffelen PFM, Westerterp KR, Saris WHM, Hoor FT. A dual-respiration chamber system with automated calibration. J App/ Physiol 1997; 83: 2064-2072.

25. Weir JBdV. New methods for calculating metabolic rate with special reference to protein metabolism. J Physiol 1949; 612: 511-521.

26. Bakke BL, Draheim CC, Mendoza W, Serfass RC. Metabolic rate during rest and exercise in adults with Prader-Willi syndrome. Tenth annual scientific conference of the Prader-Willi syndrome Association (USA), Seattle, Washington, Am J Med Genet, 1995.

27. Cox LA. The biology of bone maturation and ageing. Acta Paediatr Supp/ 1997; 423: 107-108.

28. Costeff H, Holm VA, Ruvalcaba R, Shaver J. Growth Hormone Secretion in Prader-Willi Syndrome. Acta Paediatr Scand 1990; 79: 1059-1062.

29. Angelo $M$, Castro-Magna M, Uv J, Rosenberg W. Growth hormone evaluation and treatment in Prader-Willi syndrome. Pediatr Res 1991; 29: 126A.

30. Cappa M, Grossi A, Borrelli P, Ghigo E, Bellone J, Benedetti S, Carta D, Loche S. Growth Hormone $(\mathrm{GH})$ Response to Combined Pyridostigmine and GH-Releasing Hormone Administration in Patients with Prader-Labhart-Willi Syndrome. Horm Res 1993; 39: 51-55.

31. Lee PD, Hwu K, Henson H, Brown BT, Bricker JT, LeBlanc AD, Fiorotto ML, Greenberg F, Klish WJ. Body Composition Studies in Prader-Willi Syndrome: Effects of Growth Hormone Therapy. In: (eds). Human Body Composition. Plenum Press, NY and London: Houston, Texas, 1993.

32. Lee PDK, Wilson DM, Rountree L Hintz RL, Rosenfeld RG. Linear Growth Response to Exogenous Growth Hormone in Prader-Willi Syndrome. Am J Med Genet 1987; 28: 865-871.

33. Lindgren AC, Hagenas L, Muller J, Blichfeldt S, Rosenborg M, Brismar T, Ritzen EM. Growth hormone treatment of children with Prader-Willi syndrome affects linear growth and body composition favourably. Acta Paediatr 1998; 87: 28-31. 
$62 \mid$ 


\section{Chapter 3}

\section{Activity related energy expenditure in children and adolescents with Prader-Willi syndrome}

Edgar C.A.H. van Mil, Klaas R. Westerterp, Arnold D.M. Kester, Leopold M.G. Curfs, Willem J.M. Gerver, Constance T.R.M. Schrander-Stumpel, Wim H.M. Saris

From the Department of Human Biology, Nutrition Environment and Toxicology Research Institute Maastricht, the Department of Methodology and Statistics, the Department of Clinical Genetics, Maastricht University; and the Department of Paediatrics, University Hospital Maastricht, The Netherlands

Published in: International Journal of Obesity. 2000; 24:429-434 


\section{Abstract}

Objective: To measure activity related energy expenditure in Prader-Willi syndrome (PWS) corrected for body size.

Subjects: 17 PWS subjects (10 females, 7 males, age 7.5 - $19.8 \mathrm{y}$ ) and 17 obese controls, matched for gender and bone age.

Methods: Basal metabolic rate (BMR) was measured by ventilated hood and average daily metabolic rate (ADMR) was measured with doubly labelled water. Activity induced energy expenditure (AEE) was calculated as 0.9ADMR - BMR. Activity related energy expenditure was corrected for body size using the following measures: AEE per kg body weight (AEE/ $\mathrm{kg}$ ), ADMR/BMR (PAL), and the residual of the regression of ADMR on BMR ( $\mathrm{TADMR}$ ). Group differences were analyzed by analysis of covariance adjusting for bone age, fat mass (FM) and gender.

Results: ADMR, AEE and PAL were lower $(p<0.01)$ in the PWS group compared with the control group $(7.14 \pm 1.72 \mathrm{MJ} /$ day, $1.07 \pm 0.69 \mathrm{M} /$ day and $1.33 \pm 0.15$ $\mathrm{MJ} /$ day compared with $9.94 \pm+2.64 \mathrm{M} /$ day, $2.56 \pm 1.03 \mathrm{MJ} /$ day and $1.55 \pm 0.12$ $\mathrm{MJ} /$ day, respectively). The variance of $A E E / \mathrm{kg}$ and $\mathrm{PAL}$ was significantly explained by gender and PWS status, while AEE was additionally explained by FM. The variance of rADMR was explained by PWS status and not by FM or gender.

Conclusion: Activity related energy expenditure is decreased in PWS compared with controls adjusted for bone age, FM and gender. 


\section{Introduction}

Prader-Willi syndrome (PWS) is known as the most common human genetic disorder linked to obesity (1). This complex, multisystem disorder is characterized by perinatal and neonatal hypotonia, followed by a childhood obese phase $(2,3)$. The obesity is likely to be caused by a combination of low energy expenditure and high energy intake $(4,5)$. Eating problems, characterized by hyperphagia often combined with food stealing are well-reported problems in PWS $(4,6)$, however, the actual energy intake is difficult to measure with current methods. The doubly labelled water technique offers a valid method to measure the individual's daily metabolic rate (ADMR) (7), which consists of basal metabolic rate (BMR), activity induced energy expenditure (AEE) and diet induced thermogenesis $(8,9)$. In a previous report we have demonstrated that the low energy expenditure in rest as well as during sleep could be explained by a relative low fat-free mass (FFM) as one of the major compounds of the pathophysiological background of PWS (10). Schoeller et al (5) demonstrated that the average daily metabolic rate (ADMR) in PWS patients as well as the level of physical activity were significantly lower compared with obese controls. Other investigators (11) were unable to confirm the decreased ADMR in patients with this syndrome. One of the problems of comparing physical activity between subjects with large differences in body weight is the correction for body size. The relatively low fat-free mass, resulting in a high adiposity level in PWS is an extra complication to this matter. Measuring physical activity directly by an actometer or pedometer could provide an alternative approach to this problem and has indeed been used measuring physical activity in PWS children (12). However, because of the large variation in physical activity, the investigators could not find a difference between PWS children and obese controls. Another possibility is to measure activity using the doubly labelled water method in combination with BMR, and correct the results for body size differences to test if they support a unified conclusion (13).

As a result of contradictory reports of total energy expenditure and physical activity levels in PWS, the specific objective was to examine whether the activity related energy expenditure, corrected for body size, is different in PWS subjects compared with matched obese controls.

\section{Methods}

\section{Subjects}

Seventeen PWS subjects (10 females, 7 males) were recruited with the assistance of the Dutch Prader-Willi Association. The subjects were assessed according to the 
Holm criteria (14). The Holm system provides a quantitative measure of PWS symptoms. PWS was preferably confirmed by either a deletion on chromosome 15 or uniparental disomy. When only clinical data were available critical evaluation took place by the same clinical geneticist. The PWS subjects were gender- and bone-age-matched with nonsyndromal obese controls recruited from the regional public health department. Bone-age was determined by assessing epiphysal maturation by the same paediatric endocrinologist using an $X$-ray of the mid portion of the left hand and standard growth data (15). It is preferable to use bone age instead of calendar age in studying energy metabolism in PWS, because it provides a correction for the potential delay in biological maturation of PWS subjects (16). None of the PWS subjects were receiving hormone therapy or treatment with human growth hormone $(\mathrm{GH})$ before or during the study. Controls with endocrine causes or other secondary causes of obesity were excluded. All subjects were measured within three months during the summer. Subject characteristics are shown in Table 3.1. Before the start of the study the parents gave written informed consent confirmed by an oral approval of the child. The study was approved by the medical ethical committee of Maastricht University.

Table 3.1

Body composition and other characteristics of subjects with Prader-Willi syndrome (PWS) and obese control subjects'.

\begin{tabular}{|c|c|c|c|c|c|}
\hline & \multicolumn{2}{|c|}{ PWS } & \multicolumn{3}{|c|}{ Controls } \\
\hline$n(F / M)$ & \multicolumn{2}{|c|}{$17(10 / 7)$} & \multicolumn{3}{|c|}{$17(10 / 7)$} \\
\hline Bone age $(y)$ & 12.7 & $\pm \quad 2.9$ & 12.7 & \pm & 3.2 \\
\hline Age $(y)$ & 11.9 & 3.4 & 11.3 & \pm & 2.6 \\
\hline Height $(m)$ & 1.43 & 0.16 & 1.49 & \pm & 0.20 \\
\hline Weight (kg) & 50.0 & $\pm \quad 19.7$ & 61.5 & \pm & 25.6 \\
\hline $\mathrm{BMI}\left(\mathrm{kg} / \mathrm{m}^{2}\right)$ & 23.5 & $\pm \quad 6.0$ & 26.0 & \pm & 6.5 \\
\hline$\%$ RBW (\%) & 142 & $\pm \quad 30$ & 148 & \pm & 29 \\
\hline FFM $(\mathrm{kg})$ & 27.5 & $\pm \quad 9.9^{*}$ & 35.9 & \pm & 13.4 \\
\hline$F M(k g)$ & 22.4 & $\pm \quad 11.7$ & 25.6 & \pm & 12.7 \\
\hline$\% F M(\%)$ & 43.7 & $\pm \quad 7.9$ & 39.1 & \pm & 8.8 \\
\hline
\end{tabular}

1 mean \pm 5.d.; \%RBW, percentage relative body weight: FFM, fat-free mass: FM, fat mass; \% FM, percentage fat mass

- Significantly different from control group (Independent-5amples $t$-test): $p<0.05$ 


\section{General outline of protocol}

\section{Procedures for energy expenditure and body composition measurements}

ADMR and total body water (TBW) were measured by doubly labelled water according to the Maastricht Protocol (7). BMR was measured by ventilated hood. The subject and parent were invited to the laboratory at 19.00 hours after a normal dinner. At 22.00 hours the subject produced a urine sample to determine the background isotope level. As a last consumption before the night the subject received an orally administered mixture of ${ }^{2} \mathrm{H}_{2} \mathrm{O}$ and $\mathrm{H}_{2}{ }^{18} \mathrm{O}$. After the dosing the subject went to sleep in a respiration chamber of which the results were previously reported (10). The following morning the subject came out of the respiratory chamber at $6.30 \mathrm{~h}$ to do the first morning voiding and immediately returned to bed for BMR measurement in an adjacent room. Because the subject was not active that morning, the BMR measurement was started after lying supine for 10 minutes. Oxygen consumption and carbon dioxide production were measured by means of computerized, open circuit ventilated hood system, for 40-50 minutes, when the subject was watching television. Gas analyses were performed using a paramagnetic oxygen analyzer (Servomex, Crowborough, UK) and an infrared carbon dioxide analyzer (Uras $3 \mathrm{G}$, Hartmann \& Braun, Frankfurt, Germany). BMR was calculated according to Weir (17) over the 14-min. interval with the lowest standard deviation. The same morning a urine sample was taken from the second voiding $10 \mathrm{~h}$ after dose administration. Isotope abundance in the urine was determined with an isotope-ratio mass spectrometer (Aqua Sira, VG Isogas Ltd. (Micromass, Manchester) UK). TBW was calculated as the ${ }^{2} \mathrm{H}$ dilution space divided by 1.04 , correcting for exchange of the ${ }^{2} \mathrm{H}$ label with non-aqueous $\mathrm{H}$ of body solids (18). Fat-free mass (FFM) was assessed with the assumption of FFM containing all body water. Hydration factors of FFM were based on gender and maturation specific values (19). Maturation was assessed according to Tanner's puberty ratings (20). Fat Mass (FM) was calculated by subtracting FFM of the subject's total body weight. Before the subjects consumed any food or drink, after voiding and whilst wearing under-clothing, body weight was measured on an electronic scale (E1200, Mettler Instrumente AG, Greifensee, Switzerland). Height of subjects without shoes was measured using a stadiometer.

Isotope disappearance rate in the urine from the samples of day 1,8 and 14 from the following 14 days was used to calculate carbon dioxide production. Carbon dioxide production was converted to ADMR with a respiratory exchange ratio (RER) equal to the food quotient (FO) that was derived from a one-week food diary. This weighed dietary record, was handed to the parent(s) and subject, after instruction on how to measure portion size. They were asked to record brand names, methods of preparation, and ingredients of mixed dishes. The same dieti- 
cian reviewed the record with the parent(s) and subject and calculated the energy intake and macronutrients.

\section{Measures of activity related energy expenditure}

Four different measures of activity were assessed from ADMR and BMR measurements. Firstly, AEE was calculated using the formula 0.9 ADMR - BMR, correcting for $10 \%$ diet induced energy expenditure. Secondly, in order to correct for weightbearing activities, AEE was divided by total body weight, leading to AEE/ $/ \mathrm{kg}$. Thirdly the physical activity level (PAL) was determined by dividing ADMR by BMR. Finally, the residual of $A D M R$ ( $R A D M R$ ) was calculated from the regression of ADMR on BMR (Figure 3.1).

Fig.3.1

Average Daily Metabolic Rate (ADMR, in M/day) as a function of Basal Metabolic Rate (BMR, in M/day) plotted for the Prader-Willi group (PWS, in filled circles) and obese control group (controls, in open squares). The regression equation for PWS: $A D M R=1.32 B M R+0.06\left(R^{2}=\right.$ $0.83)$; for controls: $A D M R=1.61 B M R-0.34\left(R^{2}=0.90\right)$.

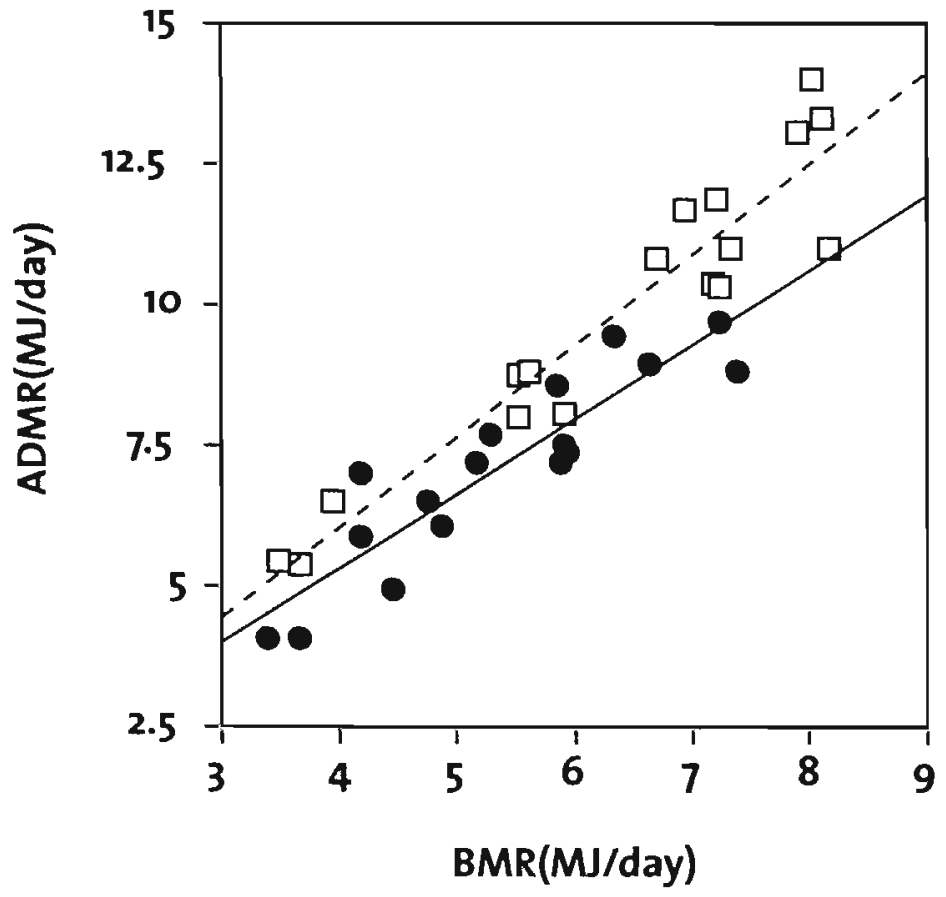




\section{Statistical analysis}

Differences between the independent variables of the PWS group and the obese control group were analyzed by the two-sample $t$-test. Analysis of covariance was used to calculate the difference in ADMR between both groups, defined by the binary variable PWS status, adjusted for bone age, BMR, FM and gender as the other independent variables in the model. Firstly, the difference in regression slope, of the influence of BMR on ADMR, was tested using an interaction variable of PWS status and BMR (PWS*BMR) adjusted for the variables in the model. Secondly, the difference between groups, again adjusted for these independent variables, was estimated and tested for significance using linear regression assuming equal slopes. An analysis of covariance was also done for each of the measures of activity as the dependent variable, consequently using bone age, gender, FM and PWS status as independent variables. The significance level was chosen at $5 \%$. Data were expressed as means \pm sd. SPSS release 6.1 for Macintosh (SPSS Inc. Chicago, Illinois, USA) was used as the statistical package.

\section{Results}

\section{Energy expenditure and body composition}

Clinical characteristics of PWS patients and obese controls are shown in Table 3.1. There were no statistically significant differences in age, height, weight, BMI, \%RBW ([(body weight/ weight predicted by height and gender)"100]) between both groups. FFM was smaller in the PWS group, while FM and \%FM were similar. FQ was also similar in both groups (PWS and controls: $0.87 \pm 0.02$ ). $B M R, A D M R$ as well as the measures of activity related energy expenditure were significantly lower in the PWS group compared with the controls (Table 3.2). BMR adjusted for weight $\left(B M R_{\text {weight }}\right)$ was lower in the PWS group, while BMR adjusted

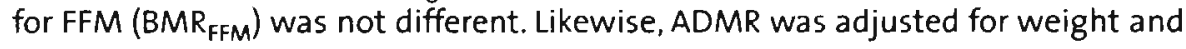
also for FFM, however, both calculations were lower in the PWS group compared with the controls $(p<0.001)$. ADMR was plotted against BMR in Figure 3.1. When $A D M R$ was expressed as a function of $B M R$ in separate linear regressions for the $P W S$ group and the control group, the $R^{2}$ was 0.83 and 0.90 respectively. From a further linear regression model, it was evident that, corrected for $B M R$, bone age, $F M$ and gender, the difference in ADMR between PWS and controls was significant. The coefficients of BMR, gender and PWS status significantly explained the variance of ADMR. Because the interaction variable PWS*BMR was not significant in the regression analysis, this variable was not included in the table (Table 3.3). 
Table 3.2

Energy expenditure measures and calculations of subjects with Prader-Willi syndrome (PWS) and obese control subjects'.

\begin{tabular}{|c|c|c|c|c|c|c|}
\hline & \multicolumn{3}{|c|}{ PWS } & \multicolumn{3}{|c|}{ Controls } \\
\hline$n(F / M)$ & \multicolumn{3}{|c|}{$17(10 / 7)$} & \multicolumn{3}{|c|}{$17(10 / 7)$} \\
\hline BMR (MJ/day) & 5.36 & \pm & $1.18^{*}$ & 6.38 & \pm & 1.55 \\
\hline$B M R_{\text {Weight }}$ (MJ/day) & 5.17 & \pm & $1.57^{*}$ & 6.57 & \pm & 1.92 \\
\hline $\mathrm{BMR}_{\mathrm{FFM}}(\mathrm{M} /$ day) & 5.31 & \pm & 1.38 & 6.43 & \pm & 1.86 \\
\hline ADMR (MJ/day) & 7.14 & \pm & $1.72^{* *}$ & 9.94 & \pm & 2.64 \\
\hline $\mathrm{ADMR}_{\text {weight }}(\mathrm{MJ} /$ day) & 6.28 & \pm & $2.60^{* * *}$ & 10.80 & \pm & 3.12 \\
\hline $\operatorname{ADMR}_{\text {FFM }}(\mathrm{MJ} /$ day $)$ & 6.55 & \pm & $2.02^{* * *}$ & 10.54 & \pm & 3.04 \\
\hline AEE (MJ/day) & 1.07 & \pm & $0.69^{* * *}$ & 2.56 & \pm & 1.03 \\
\hline AEE $/ \mathrm{kg}\left(\mathrm{KJ} / \mathrm{day}^{*} \mathrm{~kg}^{-1}\right)$ & 23.11 & \pm & $17.05^{* * *}$ & 46.09 & \pm & 17.79 \\
\hline PAL & 1.33 & \pm & $0.15^{2 \times *}$ & 1.55 & \pm & 0.12 \\
\hline
\end{tabular}

1 mean $\star$ s.d.; $B M R$, basal metabolic rate; $B M R_{\text {weight }} B M R$ adjusted for weight; $B M R_{F F M}, B M R$ adjusted for fat-free mass; $A D M R$, average daily metabolic rate; $A D M R_{\text {weight }} A D M R$ adjusted for weight; $A D M R_{F F M}$, $A D M R$ adjusted for fat-free mass; AEE, activity induced energy expenditure; AEE $/ \mathrm{kg}$. AEE per kg body weight; PAL, physical activity level (ADMR/BMR)

$\because \cdots$. Significantly different from control group (Independent-samples $t$-test):

" $p<0.05, \cdots p<0.01, \cdots p<0.001$

Table 3.3

Results of multiple-linear-regression analysis of the influence of basal metabolic rate (BMR), bone age, fat mass (FM), gender and Prader-Willi syndrome (PWS) on average daily metabolic rate (ADMR, in M/day).

\begin{tabular}{lccccc} 
Variable & $\beta$ Coefficient $^{1}$ & SE & $95 \% \mathrm{Cl} \beta^{2}$ & P \\
\hline BMR (MJiday) & 1.285 & 0.211 & $0.853-$ & 1.716 & 0.000 \\
Bone age $(y)$ & 0.011 & 0.082 & $-0.157-$ & -0.179 & 0.892 \\
FM (kg) & 0.027 & 0.020 & $-0.015-0.069$ & 0.193 \\
Gender & -0.743 & 0.327 & $-1.414--0.073$ & 0.031 \\
PWS4 & -1.394 & 0.327 & $-2.064-0.725$ & 0.000
\end{tabular}

1 The partial regression coefficient which is the change in ADMR for a change in a specific variable adjusted for the other independent variables in the equation

2 The range of values that includes the population value of the coefficient, with $95 \%$ probability

3 Gender was defined as: $\mathrm{Female}=1$, $\mathrm{Male}=0$

4 Grouping variable PWS status was defined: $P W S=1$, Obese controls $=0$. The interaction variable PWS"BMR was not significant 


\section{Measures of activity related energy expenditure}

Table 3.4 presents the results of the difference between the PWS and obese control group for $A E E, A E E / k g$, PAL and rADMR adjusted for bone age, FM, gender. The variance of $A E E$ was significantly explained by $F M$, gender and PWS status. When $\mathrm{AEE} / \mathrm{kg}$ or PAL was used as dependent variable, the coefficient of FM was not statistically significant. Only the coefficient of PWS status significantly contributed to the variance of rADMR.

Table 3.4

Results of multiple-linear-regression analyses of the influence of bone age, fat mass (FM), gender and Prader-Willi syndrome (PWS) on measures of activity related energy expenditure.

\begin{tabular}{|c|c|c|c|c|}
\hline Activity parameter ${ }^{1}$ & Variable & $\beta$ Coefficient $^{2}$ & SE & P \\
\hline \multirow[t]{4}{*}{ AEE (M/day) } & Bone age $(y)$ & 0.046 & 0.060 & 0.451 \\
\hline & $\mathrm{FM}(\mathrm{kg})$ & 0.033 & 0.015 & 0.042 \\
\hline & Gender3 & -0.785 & 0.259 & 0.005 \\
\hline & PWS4 & -1.386 & 0.247 & 0.000 \\
\hline \multirow[t]{4}{*}{ AEE/kg (KJ/day ${ }^{*} \mathrm{~kg}^{-1}$ ) } & Bone age $(y)$ & -1.515 & 1.167 & 0.204 \\
\hline & $F M(k g)$ & -0.287 & 0.302 & 0.350 \\
\hline & Gender 3 & -13.88 & 5.069 & 0.010 \\
\hline & PWS4 & -24.00 & 4.826 & 0.000 \\
\hline \multirow[t]{4}{*}{ PAL } & Bone age $(y)$ & -0.001 & 0.011 & 0.933 \\
\hline & $F M(k g)$ & 0.002 & 0.003 & 0.510 \\
\hline & Gender 3 & -0.121 & 0.046 & 0.015 \\
\hline & PWS4 & -0.218 & 0.044 & 0.000 \\
\hline \multirow[t]{4}{*}{ rADMR (M/day) } & Bone age $(y)$ & -0.074 & 0.069 & 0.293 \\
\hline & $\mathrm{FM}(\mathrm{kg})$ & 0.008 & 0.018 & 0.675 \\
\hline & Gender 3 & -0.469 & 0.300 & 0.128 \\
\hline & PWS4 & -1.080 & 0.285 & 0.001 \\
\hline
\end{tabular}

1 AEE: activity induced energy expenditure, 0.9ADMR - BMR ; AEE/kg: AEE per kg body weight; PAL: physical activity level, $A D M R / B M R$ : rADMR: residual of ADMR on BMR.

2 The partial regression coefficient which is the change in the parameter for a change in a specific variable adjusted for the other independent variables in the equation

3 Gender was defined as: Female $=1$. Male $=0$

4 Grouping variable PWS status was defined: $P W S=1$, Obese controis $=0$. 


\section{Discussion}

The present study demonstrates a low activity related energy expenditure in children and adolescents with Prader-Willi syndrome as reflected in the following parameters: AEE, AEE $/ \mathrm{kg}$, PAL, and $\mathrm{rADMR}$. To control for the possible effects of body composition, biological maturation and gender on the measures of activity, each of the parameters was adjusted for fat mass (FM), bone age and gender. Daily physical activity can be divided into weight-dependent and non-weightdependent activities. Although at present the doubly labelled water method functions as the golden standard to calculate the energy expended for activity in a free-living situation, the optimal adjustment for body weight as a correction for weight-bearing activities is still under debate $(13,21,22)$. The most direct method of measuring absolute activity related energy expenditure is by subtracting ADMR with BMR, correcting for $10 \%$ of diet-induced energy expenditure:

$A E E=0.9 A D M R-B M R$. The present results show that the variation in AEE between subjects is not only caused by PWS but also by the differences in FM. Because at least part of the routine daily activities are weight dependent, a higher FM will result in a higher energy cost performing the same, weight dependent, tasks. In a study with prepubertal children (23), FM did not correlate with AEE. This is possibly related to the energy efficiency of physical activity that improves with maturation, which may lead to a higher sensitivity towards the effect of FM on activity when age increases. Moreover, in an earlier report by the same group, AEE was found to correlate significantly with FM (24).

AEE divided by total body weight $(25,26)$ is an alternative approach assuming that all activity induced energy expenditure is related to weight-bearing activities. Previous studies, in children $(27,28)$, as well as adults $(29,30)$ used this approach to demonstrate that obesity was associated with decreased levels physical activity. Others $(22,31,32,33)$ could not find an effect of obesity. In the present study however, AEE/ $\mathrm{kg}$ was not influenced by FM. Moreover, FM could not take away the influence of PWS status on AEE/kg, indicating that adiposity cannot explain the decreased activity related energy expenditure in PWS, not even for weight bearing activities. Since the majority of daily activities involve only limb movements and are not weight dependent, it has been suggested for sedentary adults to divide AEE by weighto.5 (13). However, such an exponent is likely to be population specific. The amount and intensity of whole-body movements during the day is probably related to age, gender and especially to disease or disability. Even if such group specific exponents for weight correction would be determined, one of the general problems of using AEE as a measure of activity remains the positive correlation with ADMR. As AEE will generally increase for higher values of ADMR, AEE as a measure of activity cannot be validly compared between groups with large differences in ADMR. 
Correcting for metabolic body size by dividing ADMR by BMR is a way of losing the positive correlation between ADMR and $B M R$, leading to the measurement of physical activity index or level (PAL). The results show that the subjects with the highest PAL are the boys in the obese control group. Other studies $(27,34,35)$, measuring PAL in adolescents, did not show a gender difference in PAL during childhood through adolescence. Probably, the gender difference is caused by an average higher BMR in boys from the control group, as was previously demonstrated in obese adolescents (27). An important assumption when comparing the PAL between groups is a constant relationship between ADMR and BMR. The positive intercept of the PWS group and the negative intercept of the control group (Fig. 3.1) show that the assumption is incorrect. Although the gender difference in BMR within the control group was not significant, the combination with the negative intercept of the control group will result in a higher PAL for boys by mathematical definition $(8,21)$. Therefore, the PAL is not the most appropriate way to compare groups with significant intercepts in the regression of $A D M R$ on $B M R$, in spite of the similar ranges of BMR and ADMR in both study groups.

$A$ valid technique suggested as an alternative approach to adjust data with nonzero intercepts is the analysis of covariance by multiple regression (22). In this technique, the residuals from the regression of ADMR on BMR ( $\mathrm{rADMR}$ ) are itself a (relative) measure of the activity related energy expenditure corrected for BMR, assuming independence, a normal distribution of the data and a significant correlation between the dependent and independent variable. In the present study, BMR was the best single determinant of ADMR in the PWS as well as the control group, explaining respectively $90 \%$ and $83 \%$ of its variance, which was even higher than in other studies $(22,27)$. Interestingly, when rADMR is used as measure of activity, gender is no longer statistically significant, which indeed indicates that the gender difference in the previous measures of activity was in fact a BMR effect. Again, this approach points out a decrease in activity related energy expenditure in PWS patients.

One of the modulators for activity related energy expenditure is seasonality. Goran et al. (36) showed that the AEE, and as a result also ADMR, in prepubertal children was significantly higher in the Spring compared with Autumn, even when adjusted for body composition. In the present study the PWS and control subjects were all measured during the Summer avoiding this potential confounding factor. It is unclear whether seasonality has influenced the results of the other studies on energy metabolism in PWS, because the season of measurement was not mentioned in any of the reports. In the study by Schoeller et al. (5) the average ADMR of the PWS group was $53 \%$ of that of obese controls, which is lower than the $72 \%$ that was found in the present study. In Schoeller's study a standard RER of 0.85 was used to calculate ADMR, while in this report RER was equal to FQ, that 
was derived from a food record. Since FQ was similar in the PWS and control group it is unlikely that this discrepancy in methods could help understand the group difference in ADMR. It is more likely that this is influenced by our younger study population. On the other hand, the average activity related energy expenditure was $60 \%$ lower for the PWS group in the present study, where Schoeller et al. observed only a $40 \%$ reduction. The difference might be explained by the use of an equation derived by Ravussin et al (25) to calculate the ADMR, containing FFM, $\%$ activity and weight as explanatory variables. This equation was developed from respiration chamber measurements, when in the present study ADMR was measured by doubly labelled water. It is likely that inter-individual differences in activity cannot be detected in a laboratory setting as easily as in a free-living situation, which presumably resulted in a small coefficient for activity in Ravussin's formula. Davies et al (11) measured PAL in a group of ro children with PWS and compared them with a cohort of schoolchildren from an existing database. Although the authors were not able to detect a statistically significant difference in ADMR, and, given the small difference in age, the absolute outcome of ADMR, AEE and PAL results of the PWS subjects are remarkably similar. Therefore, as the authors suggested, the small study sample was probably the cause of the insignificant difference in ADMR between groups.

The cause of PWS children spending less energy on activity cannot be answered by the present study. The dysfunction of various hypothalamic systems, as one of the possible reasons for the low FFM in patients with this syndrome, might well be the underlying cause. The hypotonia in early childhood and underdevelopment of muscle strength and coordination with delayed motor milestones may lead to a lack of capability and interest to be physically active. Additionally, the possible functional growth hormone deficiency and decreased levels of gonadotrophins (37) might take away the natural urge of children to be lively and playful.

In conclusion, the present study demonstrates that AEE is lower in children and adolescents with PWS than in obese controls, matched for bone age and gender. In addition, all measures of activity related energy expenditure corrected for body size and adjusted for bone age, gender and FM, support the conclusion that PWS patients are less active during childhood and adolescence.

\section{References}

1. Glenn CC, Driscoll DJ, Yang TP, Nicholls RD. Genomic imprinting: potential function and mechanisms revealed by the Prader-Willi and Angelman syndromes. Mol Hum Reprod 1997; 3: 321-332. 
2. Prader A, Labhart A, Willi H. Ein Syndrom von Adipositas, Kleinwuchs. Kryptorchismus und Oligophrenie nach myotonieartigem Zustand in Neugeborenenalter. Schweizerische Medizinische Wochenschrift 1956; 86: 1260-1261.

3. Cassidy SB. Prader-Willi Syndrome and Other Chromosome $15 q$ Deletion Disorders. In: (eds). NATO ASI Series. Springer-Verlag: Noordwijkerhout, the Netherlands, 1991.

4. Holm VA, Pipes PL Food and children with Prader-Willi syndrome. Am J Dis Child 1976; 130: 1063-1067.

5. Schoeller DA, Levitsky LL, Bandini LG, Dietz WW, Walczak A. Energy Expenditure and Body Composition in Prader-Willi Syndrome. Metabolism 1988; 37: 115-120.

6. Coplin SS, Hine J, Gormican A. Out-Patient Dietary Management in the Prader-Willi Syndrome. J Am Diet Assoc 1976; 68: 330-334.

7. Westerterp KR, Wouters L, Marken-Lichtenbelt WDv. The Maastricht Protocol for the Measurement of Body Composition and Energy Expenditure with Labeled Water. Obes Res 1995: 3: 49-57.

8. Ravussin E, Bogardus C. Relationship of genetics, age, and physical fitness to daily energy expenditure and fuel utilization. Am J Clin Nutr 1989; 49: 968-975.

9. Westerterp-Plantenga MS, Fredrix EWHM, Steffens AB. Food intake and energy expenditure. CRC Press, Boca Raton, Florida, 1994.

10. Van Mil EGAH, Westerterp KR, Gerver WJ, Curfs LM, Schrander-Stumpel CT, Kester AD, Saris WH. Energy expenditure at rest and during sleep in children with Prader-Willi syndrome is explained by body composition. Am J Clin Nutr 2000;71: 752-756.

11. Davies PSW, Joughin C, Cole TJ, Livingstone MBE, Barnes ND. Total energy expenditure in the Prader-Willi syndrome. Am J Clin Cenet 1992; 44: 75-78.

12. Nardella MT, Sulzbacher SI, Worthington-Roberts BS. Activity Levels of Persons with PraderWilli Syndrome. Am J Ment Defic 1983; 87: 498-505.

13. Prentice $A M$, Goldberg GR, Murgatroyd PR, Cole TJ. Physical activity and obesity: problems in correcting expenditure for body size. Int J Obes 1996; 20: 688-691.

14. Holm VA, Cassidy SZ, Butler MG, Hanchett IM, Greenswag LR, Whitman BY, Greenberg FG. Prader-Willi Syndrome: Consensus Diagnostic Criteria. Pediatrics 1993; 91: 398-402.

15. Tanner JM, Whitehouse RH, Marshall WA, Healy MJR, Goldstein H. Assessment of skeletal maturity and prediction of adult height (TW2 Method). Academic Press, London, 1983.

16. Cox LA. The biology of bone maturation and ageing. Acta Paediatr Suppl 1997; 423: 107-108.

17. Weir JBdV. New methods for calculating metabolic rate with special reference to protein metabolism. J Physiol 1949; 612: 511-521.

18. Schoeller DA, Santen Ev, Petterson DW, Dietz W, Jaspan J, Klein PD. Total Body Water Measurement in Humans with 180 and $2 \mathrm{H}$ labeled Water. Am J Clin Nutr 1980; 33: 2686 2693.

19. Boileau RA, Lohman TG, Slaughter MH, Ball TE, Going SB, Hendrix MK. Hydration of the fatfree body in children during maturation. Hum Biol 1984; 56: 651-666.

20. Tanner JM. Growth at adolescence. Blackwell Scientific Publications Ltd., London, 1962.

21. Goran MI. Variation of total energy expenditure in humans. Obes Res 1995; 3:59-66. 
22. Goran MI, Carpenter WH, McGloin A, Johnson R, Hardin JM, Weinsier RL Energy expenditure in children of lean and obese parents. Am J Physiol 1995; 268:e917-eg24.

23. Goran $\mathrm{MI}$, Hunter $\mathrm{C}$, Johnson R. Physical activity related energy expenditure and fat mass in young children. Int J Obes 1997; 21: 177-178.

24. Goran MI, Carpenter WH, Poehlman ET. Total energy expenditure in 4- to 6-yr-old children. Am J Physiol 1993; 264: E706-E711.

25. Ravussin E, Lillioja S, Anderson TE, Christin L, Bogardus C. Determinants of 24-hour Energy Expenditure in Man. J Clin Invest 1986: 78: 1568-1578.

26. Maffeis C, Schutz Y, Schena F, Zaffanello $M$, Pinelli L. Energy expenditure during walking and running in obese and nonobese prepubertal children. J Pediatr 1993; 123: $193-199$.

27. Bandini LG, Schoeller DA, Dietz WH. Energy Expenditure in Obese and Nonobese adolescents. Pediatr Res 1990; 27: 198-203.

28. Davies PS. Gregory J, White A. Physical activity and body fatness in pre-school children. Int J Obes 1995; 19: 6-10.

29. Schoeller DA, Fjeld CR. Human energy metabolism: what have we learned from the doubly labeled water method? Annu Rev Nutr 1991; 11: 355-373.

30. Schultz LO, Schoeller DA. A compilation of total daily energy expenditure and body weights in healthy adults. Am J Clin Nutr 1994; 60: 676-681.

31. Welle S, Forbes GB, Statt M, Barnard RR, Amatruda JM. Energy expenditure under free-living conditions in normal-weight and overweight women. Am J Clin Nutr 1992; 55: 14-21.

32. Arciero PJ, Goran MI, Poehiman ET. Resting metabolic rate is lower in women than in men.J Appl Physiol 1993; 75: 2514-2520.

33. Westerterp KR. Obesity and physical activity. Int J Obes 1999; 23: 59-64.

34. Davies PSW, Livingstone MBE, Prentice AM, Coward WA, Jagger SE, Steward C, Strain JJ, Whitehead RG. Total energy expenditure during childhood and adolescents. Proc Nutrition Soc 1991; 50: 14A.

35. Bratteby LE, Sandhagen B, Fan $H$, Enghardt $H$, Samuelson $G$. Total energy expenditure and physical activity as assessed by the doubly labeled water method in Swedish adolescents in whom energy intake was underestimated by 7-d diet records. Am J Clin Nutr 1998; 67: 905911.

36. Coran MI, Nagy TR, Gower BA, Mazariegos M, Solomons $N$, Hood V, Johnson R. Influence of sex, seasonality, ethnicity, and geographic location on the components of total energy expenditure in young children: implications for energy requirements. Am J Clin Nutr 1998; 68: 675-682.

37. Swaab DF. Prader-Willi syndrome and the hypothalamus. Acta Paediatr Suppl 1997; 423: 50-54. 


\section{Chapter 4}

Body composition in Prader-Willi syndrome compared with nonsyndromal obesity:

Relationship to physical activity and growth hormone function

Edgar G.A.H. van Mil, Klaas R. Westerterp, Willem J.M. Gerver, Wouter D. van Marken Lichtenbelt, Arnold D.M. Kester, Leopold M.G. Curfs, Constance T.R.M. Schrander-Stumpel, Guido A.K Heidendal, Wim H.M. Saris

From the Department of Human Biology, Nutrition Environment and Toxicology Research Institute Maastricht, the Department of Methodology and Statistics, the Department of Clinical Genetics, Maastricht University; the Department of Paediatrics and the Department of Nuclear Medicine, University Hospital Maastricht, The Netherlands

Accepted for: The Journal of Pediatrics 


\section{Abstract}

Objective: To study the relationship of fat mass (FM), extracellular-to-intracellularwater ratio (ECW/ICW) and bone mineral density (BMD) with growth hormone (CH) function and physical activity (PA) in Prader-Willi syndrome (PWS).

Study design: Subjects were 17 PWS patients (10 females, 7 males, age 7.5-19.8 y) and 17 obese controls, matched for gender and bone age. FM and ECW/ICW were measured by bromide-deuterium dilution, $\mathrm{BMD}$ by dual-energy $\mathrm{X}$-ray absorptiometry, GH function by fasted serum ICF-I concentration and PA by doubly labelled water in combination with basal metabolic rate by ventilated hood.

Results: The PWS group had a similar FM, but a lower fat-free mass (FFM), whereas the ECW/ICW was higher compared with controls ( $0.87 \pm 0.07$ and $0.80 \pm 0.06$, respectively $(p<0.01))$. FM was inversely related with PA in the PWS group, whereas IGF-I was positively correlated with FFM, ICW and BMD of the limbs. BMD tended to be lower in PWS patients.

Conclusions: In children and adolescents with PWS, adiposity is mainly caused by a reduced $F F M$, and $E C W / I C W$ is increased. Both findings are related to $\mathrm{GH}$ function and PA. BMD, especially in the limbs, tends to be reduced in PWS and is related to $\mathrm{GH}$ function. 


\section{Introduction}

Prader-Willi syndrome (PWS) was first described by Prader, Labhart and Willi as a syndrome of hypotonia, hypogonadism, mental retardation and obesity (1). At present, PWS is known as a complex genetic disorder, resulting from the absence of normally active paternally inherited genes at chromosome 15(911-13). In the majority of the cases this genetic defect is caused by an interstitial deletion in this region, or a maternal uniparental disomy for chromosome 15 , whereas a minority is the result of an imprinting mutation (2).

Although, nowadays, early recognition of the syndrome and dietary intervention seem to prevent the PWS child from becoming massively obese, obesity is still one of the major causes of morbidity and mortality in PWS. PWS is also the most common genetic disorder linked to obesity (3). The main characteristics of PWS, supported by other clinical features such as short stature, delayed or incomplete puberty and osteoporosis (4), suggest abnormalities of the somatotrophic and hypothalamic-pituitary-gonadal axis, however, a structural lesion has not yet been discovered $(5,6,7,8)$. Moreover, the pattern of adiposity in PWS and the reduced lean and bone mass, especially in the limbs (9), have a close resemblance to the body composition present in children with growth hormone deficiency (GHD). Although GHD cannot be confirmed in all patients, the effect of growth hormone $(\mathrm{GH})$ intervention does support a functional GHD (10). Consequently, a functional GHD might result in an increased extracellular-to-intracellular water ratio (ECW/ICW) as was shown in GHD adults (11). In PWS, however, body water com. partments have not been studied before.

Another possible factor that may influence these alterations in body composition is inactivity. PWS children are known to be less active than nonsyndromal controls (12). Although the inverse relationship between obesity and activity has been established in nonsyndromal or primary obesity $(13,14)$ and discouragement of sedentary activities is now an important element in the prevention of childhood obesity (15), it is unclear whether this relationship also exists in secondary obesity, like Prader-Willi syndrome. A positive effect of activity on body composition might lead the way to alternative intervention strategies, which combine physical activity with hormonal therapy to prevent the development of obesity in PWS. The aim of the present study was to measure fat mass, body water compartments and bone mineralization in patients with PWS, compared with controls with nonsyndromal obesity matched for gender and bone age, and to associate these body composition parameters with growth hormone function and physical activity in PWS. 


\section{Methods}

\section{Subjects}

Seventeen PWS subjects (age $7.5-19.8$ y) were recruited with the assistance of the Dutch Prader-Willi Association. The subjects were assessed according to the Holm criteria (4). The Holm system provides a quantitative measure of PWS symptoms. PWS was preferably confirmed by either a deletion on chromosome 15 or uniparental disomy. When only clinical data were available, critical evaluation took place by the same clinical geneticist. The PWS subjects were gender- and boneage-matched with nonsyndromal obese controls (age 6.3 - 15.3y) recruited from the regional public health department. Bone age measurement, as a means of assessing the rate of maturational change throughout the growing period, provides an estimate of biological maturation, and is therefore a better matching criterion than calendar age (16). Bone-age was determined by assessing epiphysal maturation by the same paediatric endocrinologist using an X-ray of the mid portion of the left hand and standard growth data (17). None of the PWS subjects was receiving hormone therapy or treatment with human $\mathrm{GH}$ before or during the study. Controls with endocrine causes or other secondary causes of obesity were excluded. Subject characteristics are shown in Table 4.1. All subjects were measured in the summer months avoiding the potential confounding factor of seasonal variation in activity (18).

Before the start of the study the parents gave written informed consent confirmed by an oral approval of the child. The study was approved by the medical ethical committee of Maastricht University.

Table 4.1

Characteristics of subjects with Prader-Willi syndrome (PWS) and obese control subjects'.

\begin{tabular}{|c|c|c|c|c|c|}
\hline & \multicolumn{2}{|c|}{ PWS } & \multicolumn{3}{|c|}{ Controls } \\
\hline$n(F / M)$ & \multicolumn{2}{|c|}{$17(10 / 7)$} & \multicolumn{3}{|c|}{$17(10 / 7)$} \\
\hline Bone age $(y)$ & 12.7 & $\pm \quad 2.9$ & 12.7 & \pm & 3.2 \\
\hline$A g \in(y)$ & 11.9 & 3.4 & 11.3 & \pm & 2.6 \\
\hline Tanner $(1-5)$ & 2.6 & 1.6 & 2.6 & \pm & 1.7 \\
\hline Height (m) & 1.43 & 0.16 & 1.49 & \pm & 0.20 \\
\hline Weight (kg) & 50.0 & $\pm \quad 19.7$ & 61.5 & \pm & 25.6 \\
\hline BMI $\left(\mathrm{kg} / \mathrm{m}^{2}\right)$ & 23.5 & \pm 6.0 & 26.0 & \pm & 6.5 \\
\hline
\end{tabular}

1 mean \pm s.d. Tanner, sexual development stage according to Tanner (25) 


\section{General outline of protocol}

Total energy expenditure or average daily metabolic rate (ADMR) and total body water (TBW) were measured according to the Maastricht Protocol for the measurement of body composition and energy expenditure with labelled water (19). Each subject was invited with a parent to the laboratory at 19.00 hours after a normal dinner. Around 22.00 hours the subject produced a urine sample to determine the background isotope level. As a last consumption before the night the subject received an orally administered stable isotope mixture of ${ }^{2} \mathrm{H}_{2} \mathrm{O}$ and $\mathrm{H}_{2}{ }^{18} \mathrm{O}$. A known amount of sodium bromide (<60 mg bromide / I. estimated TBW; Ph. Eur., Genfarma, Maarssen, The Netherlands) was offered directly after the doubly labelled water drink and thus administered simultaneously with the ${ }^{2} \mathrm{H}_{2}{ }^{18} \mathrm{O}$ dose. After the dosing the subject went to sleep in a bedroom at the laboratory. The following morning the subject was waken up at $6.30 \mathrm{~h}$ to do the first morning voiding. After voiding the subject immediately returned to bed for measurement of basal metabolic rate (BMR) in an adjacent room. After the BMR measurement, a blood sample and urine sample, taken from the second voiding, was collected roh after dose administration. Isotope abundance in the urine from samples of day 1 , 8 and 14 from the following 2 weeks, was determined with an isotope-ratio mass spectrometer (Aqua Sira, VG Isogas Ltd (Micromass, Manchester) UK). The bromide concentration in serum ultrafiltrate was determined with high performance liquid chromatography.

In the same morning, before the subjects consumed any food or drink, after voiding and whilst wearing under-clothing, total body weight was measured on an electronic scale (E1200, Mettler Instumente AG, Greifensee, Switserland). Height of subjects without shoes was measured using a stadiometer.

Furthermore, a total body scan was made with a dual energy $X$-ray absorptiometer (DXA) (DPX-L, Lunar Corp., Madison, WI, USA)

\section{Basal metabolic rate}

The BMR measurement was started after lying supine for 10 minutes. Oxygen consumption and carbon dioxide production were measured by means of a computerized, open circuit ventilated hood system, for 40-50 minutes, while the subject was watching television. Gas analyses were performed using a paramagnetic oxygen analyzer (Servomex, Crowborough, UK) and an infrared carbon dioxide analyzer (Uras 3G, Hartmann \& Braun, Frankfurt, Germany). BMR was calculated according to Weir (20) over the 14-min. interval with the lowest standard deviation. 
ADMR and physical activity by doubly labelled water

The isotope disappearance rate in the urine from the samples of day 1,8 and 14 was used to calculate carbon dioxide production. Carbon dioxide production was converted to ADMR with a respiratory exchange ratio (RER) equal to the food quotient that was derived from a one-week food diary calculated by a dietician. The total observed variance in ADMR, plotted as a function of BMR, is subdivided into two components - that which is attributable to the regression with $B M R$ and that which is not attributable to this regression, the residual of the regression. The residual of each subject represents the variance in physical activity related energy expenditure, and can be used as a relative measure of physical activity. Activity related energy expenditure was therefore defined as the residual from the regression of ADMR as a function of BMR (rADMR) (Figure 4.1). This measure was chosen instead of the physical activity index (ADMR/BMR), because of the non-zero intercept in the regression of AMDR with BMR. The use of ADMR/BMR

Fig. 4.1

Activity related energy expenditure) Average daily metabolic rate ( $A D M R$, in $M /$ day) as a function of basal metabolic rate (BMR, in MI/day) plotted for the Prader-Willi group (PWS, filled circles) and obese control group (open squares). The dotted lines represent examples of the residual of the regression for a specific subject, which is a relative measure of activity related energy expenditure.

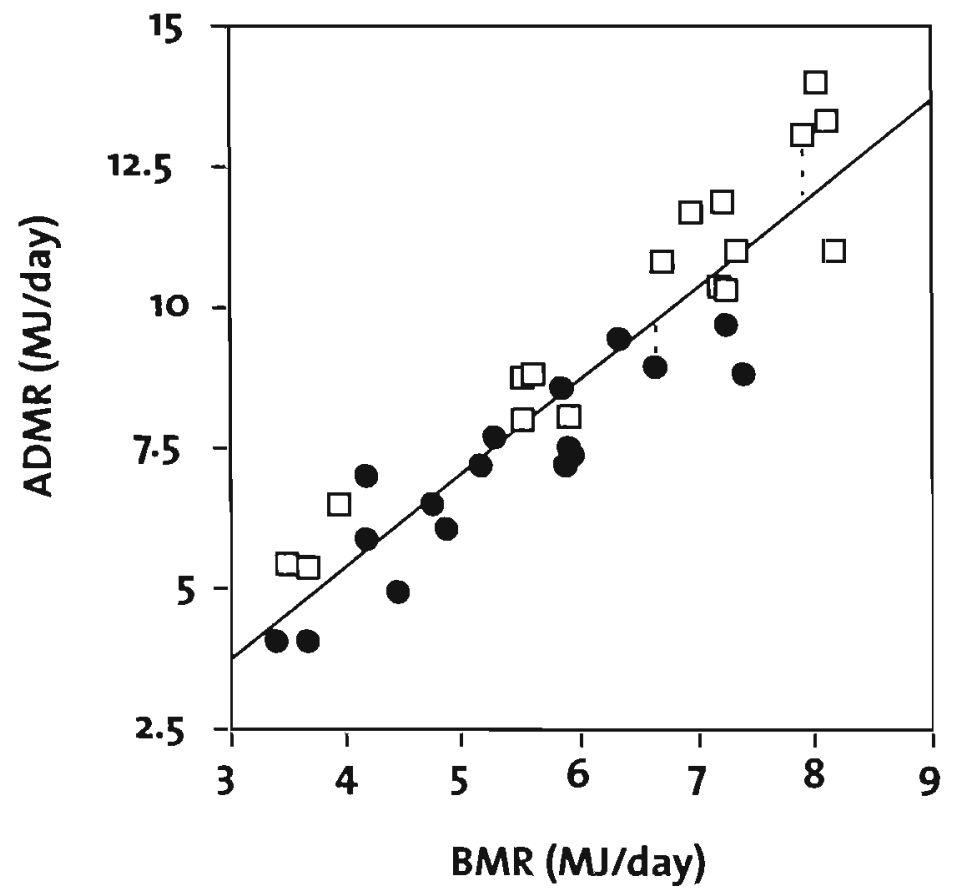


may lead to a misinterpretation of the physical activity level in the younger subjects with lower values of $\operatorname{BMR}(21,22)$.

\section{Body composition by deuterium dilution}

Fat-free mass (FFM) was assessed with the assumption of FFM containing all body water (TBW). TBW was calculated from isotope abundance in the urine, as the ${ }^{2} \mathrm{H}$ dilution space divided by 1.04 correcting for exchange of the ${ }^{2} \mathrm{H}$ label with nonaqueous $\mathrm{H}$ of body solids (23). Hydration factors of FFM were based on gender and maturation specific values (24). Maturation was assessed according to Tanner's puberty ratings (25). Using a two-compartment model, fat mass (FM) was calculated by subtracting FFM of the subject's total body weight, and also expressed as percentage of total body weight (\%FM). To allow for comparisons between subjects, FM and FFM were expressed as an index: FFMI $\left(\mathrm{kg} / \mathrm{m}^{2}\right)$ and $F M I\left(\mathrm{~kg} / \mathrm{m}^{2}\right)$, respectively. Patients with PWS experience specific periods of growth stunting. In this way we have corrected for the large variation in height, analogous with BMI, where $B M I=F F M I+F M I(26)$.

\section{Extracellular water}

Total body water can be divided into intracellular water (ICW) and extracellular water (ECW). The ECW compartment was determined by bromide dilution. The bromide concentration in serum ultrafiltrate was determined from a blood sample, collected 10 hours after ingestion of bromide. Corrected bromide space was calculated according to the method of Miller et al. (27). ICW is calculated by subtracting ECW from TBW.

\section{Bone mineral content, bone mineral density and percentage fat mass by DXA}

On the same day, total bone mineral content and total bone mineral density were measured by DXA, using a paediatric scan mode. Bone mineral content (BMC) was measured as total mass, as well as calculated as a percentage of FFM, as determined by DXA. Bone mineral density (BMD) as well as BMC were separately calculated for the limbs $\left(B M D_{\text {limbs }}, B M C_{\text {limbs }}\right)$. All DXA measurements were calculated by Lunar software (version $1.5 \mathrm{~g}$ ). Furthermore, the percentage fat mass (\%FM $\mathrm{dxa}_{\mathrm{a}}$ ) was calculated as an alternative measurement to be compared with \%FM, provided by the deuterium dilution method. 


\section{Measurement of serum IGF-I}

The serum IGF-I concentration was measured using a commercially available assay (RIA: Nichols Institute Diagnostics, San Juan Capistrano, CA, USA). IGF-I was only determined in the PWS group. The measurement was performed in serum taken from the same fasted venous blood sample as for the bromide dilution protocol.

\section{Statistical analysis}

Differences between the independent variables of the PWS group and the obese control group were analyzed by the two-sample $t$-test.

A multiple-linear-regression model with ECW/ICW as the dependent variable, and bone age, FMI, gender, PWS status and TADMR as independent variables, was used to analyze the difference in ECW/ICW between both groups, adjusted for the independent variables.

Specifically for the PWS group, the partial correlation coefficients of IGF-I and ECW/ICW, and of IGF-I and ICW, adjusted for bone age and FMI were calculated. Additionally, the correlation coefficients of IGF-I and FM, and of IGF-I and FFM, adjusted for bone age were assessed. Finally, the partial correlation coefficients of IGF-I and measures of bone mineralization, adjusted for bone age and body weight were calculated.

The significance level was chosen at $5 \%$. Data were expressed as mean \pm s.d. SPSS release 6.1 for Macintosh (SPSS Inc. Chicago, Illinois, USA) was used as the statistical package.

\section{Results}

Age, height, weight and BMI of the subjects of the PWS and obese control group were not statistical significantly different, as shown in Table 4.1. Sexual maturation in both groups, ranged from pre- to post-pubescent.

FFM as well as FFMI were lower in the PWS group. On the contrary, FM, \% FM and FMI values were not significantly different. TBW, measured by deuterium dilution technique, was significantly lower in the PWS group. ECW and ICW were lower, however, ECW/ICW was higher in the PWS group. Because of difficulties obtaining blood samples. ECW values were not obtained in one subject of the PWS group and one subject of the control group (Table 4.2). \%FM dxa was comparable with $\% F M$, measured by deuterium dilution. BMC, expressed as a percentage of FFM, was higher in the PWS group, however, the other measurements of bone mineral- 
ization, although not significant, tended to be lower in the PWS group, especially for the limbs (Table 4.3).

Table 4.2

Body composition results by bromide- and deuterium dilution of subjects with Prader-Willi syndrome (PWS) and obese control subjects'.

PWS

\begin{tabular}{|c|c|c|c|c|c|}
\hline$n(F / M)$ & \multicolumn{2}{|c|}{$17(10 / 7)$} & \multicolumn{3}{|c|}{$17(10 / 7)$} \\
\hline FFM (kg) & 27.5 & $9.9^{\circ}$ & 35.9 & \pm & 13.4 \\
\hline$F M(k g)$ & 22.4 & $\pm \quad 11.7$ & 25.6 & \pm & 12.7 \\
\hline$\% F M(\%)$ & 43.7 & 7.9 & 39.1 & \pm & 8.8 \\
\hline FFMI $\left(\mathrm{kg} / \mathrm{m}^{2}\right)$ & 12.9 & $2.3^{* *}$ & 15.4 & \pm & 2.7 \\
\hline $\mathrm{FMI}\left(\mathrm{kg} / \mathrm{m}^{2}\right)$ & 10.6 & 4.5 & 10.6 & \pm & 4.0 \\
\hline TBW $(\mathrm{L})$ & 20.5 & $7.1^{*}$ & 26.7 & \pm & 9.8 \\
\hline$E C W(L) \#$ & 9.6 & $3.3^{*}$ & 12.3 & \pm & 4.1 \\
\hline $\mid C W(L) *$ & 11.2 & $4.0^{\circ}$ & 15.5 & \pm & 4.9 \\
\hline ECW/ICW & 0.87 & $0.07^{* *}$ & 0.80 & \pm & 0.06 \\
\hline
\end{tabular}

1 mean \pm s.d; FFM, fat-free mass; FM, fat mass; \% FM, percentage fat mass. FFMI, fat-free mass index; FMI, fat mass index; TBW, total body water; ECW, extracellular body water; ICW, intracellular water

\# $2 \times n=16$

$\because$ Significantly different from control group (Independent-samples t-test): $p<0.05, \cdots p<0.01$

Table 4.3

Body composition results by dual $x$-ray absorptiometry of subjects with Prader-Willi syndrome (PWS) and obese control subjects'.

Controls

$n(F / M)$

TBMC (g)

$\mathrm{BMC}_{\text {limbs }}(\mathrm{g})$

TBMC \%FF $(\%)$

$B^{B M C F M-1}(\%)$

$\operatorname{TBMD}\left(\mathrm{g} / \mathrm{cm}^{2}\right)$

$\mathrm{BMD}_{\text {limbs }}\left(\mathrm{g} / \mathrm{cm}^{2}\right)$

$\% F M_{d x a}(\%)$

\begin{tabular}{cll}
\multicolumn{3}{c}{$17(10 / 7)$} \\
1564 & \pm 590 \\
315 & \pm 143 \\
6.0 & \pm & $0.7^{*}$ \\
5.3 & \pm & 0.9 \\
1.005 & \pm & 0.126 \\
0.832 & \pm & 0.157 \\
44.9 & \pm & 8.9
\end{tabular}

$\begin{array}{ccc}c 17(10 / 7) \\ 1897 & \pm 803 \\ 439 & \pm & 216 \\ 5.2 & \pm & 1.1 \\ 5.2 & \pm & 1.2 \\ 1.036 & \pm & 0.152 \\ 0.888 & \pm & 0.181 \\ 40.2 & \pm & 12.1\end{array}$

1 mean \pm s.d.; TBMC, total bone mineral content; $B M C_{\text {limbs }}$, bone mineral content of the limbs; TBMC\%FFM. total bone mineral content as a percentage of fat-free mass; $B M C_{\% F F}$, bone mineral content of the limbs as a percentage of fat-free mass of the limbs; TBMD, total bone mineral density: $B M D$ limbs bone mineral density of the limbs; \%FM $\mathrm{dxa}_{\mathrm{a}}$. percentage fat mass by dual energy absorptiometry Significantly different from control group (Independent-samples t-test): $p<0.05$ 
The mean IGF-I level for the PWS group was $151.8( \pm 94.7) \mathrm{Ng} / \mathrm{ml}$, which is within the low-normal range. IGF-I, adjusted for bone age, showed a positive correlation with FFM $(p<0.05)$, however, the correlation with FM was not significant. There was no significant correlation between IGF-I and ECW/ICW, when corrected for bone age and FMI, whereas for ICW, the partial correlation coefficient of IGF-I was significant $(p<0.01)$. IGF-I, adjusted for bone age and body weight, was positively correlated with $\mathrm{BMD}_{\text {limbs }}$ (Table 4.4).

There was no effect of physical activity on $\mathrm{BMD}_{\text {limbs }}$ (Figure 4.2). FMI plotted as a function of rADMR resulted in a negative relation, but only for the PWS patients $(p<0.05)$, not for the controls (Figure 4.3).

The increased ECW/ICW in the PWS group was confirmed by multiple regression, correcting for bone age, FMl, gender and activity. Using this model, other significant determinants in explaining the variance in ECW/ICW, besides PWS status, were bone age and FMI (Table 4.5).

\section{Table 4.4}

Partial correlation coefficients of IGF-I ( $r$ ) and body composition parameters in patients with Prader-Willi syndrome

$\begin{array}{llll}\text { Variable }^{1} & r^{5} & \text { Variable } & r \\ \text { FM } & -0.31 & \text { FFM } & 0.6^{*}\end{array}$

\begin{tabular}{lccc} 
Variable & ${ }^{4}$ & Variable & $r^{9}$ \\
\hline ECW/ICW & 0.06 & ICW & $0.7^{* *}$
\end{tabular}

\begin{tabular}{llll} 
Variable & $r \Delta$ & Variable & $r^{\Delta}$ \\
\hline TBMC $_{\text {\%FF }}$ & -0.28 & $T B M D$ & 0.37 \\
BMC $_{\text {XFM-1 }}$ & -0.25 & $B M D_{\text {limbs }}$ & $0.63^{*}$
\end{tabular}

1 FM, fat mass; FFM, fat-free mass; ECW/CW, ratio of extracellular-to-intracellular body water; ICW, intracel-

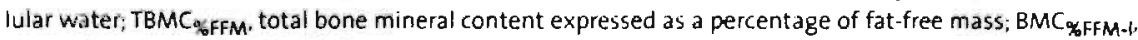
bone mineral content of the limbs expressed as a percentage of fat-free mass of the limbs: TBMD, total bone mineral density $\left(\mathrm{g} / \mathrm{cm}^{2}\right) ; B M D_{\text {limbs }}$. bone mineral density of the limbs $\left(\mathrm{g} / \mathrm{cm}^{2}\right)$

- Partial correlation coefficient of ICF-I, adjusted for bone age

1 Partial correlation coefficient of ICF-I, adjusted for bone age and fat mass index

$\Delta \quad$ Partial correlation coefficient of ICF-I, adjusted for bone age and body weight

- $p<0.05,{ }^{*} p<0.01$ 
Fig.4.2

Bone mineral density of the limbs $\left(B M D_{\text {limbs }}\right.$ in $\left.\mathrm{g} / \mathrm{cm}^{2}\right)$ as a function of activity related energy expenditure ( $r A D M R$, in $M /$ /day) plotted for the Prader-Willi group (PWS, filled circles) and obese control group (controls, open squares). The regression lines were not significant. The straight and dotted line represent the mean $B M D_{\text {limbs }}$ of PWS and controls, respectively.

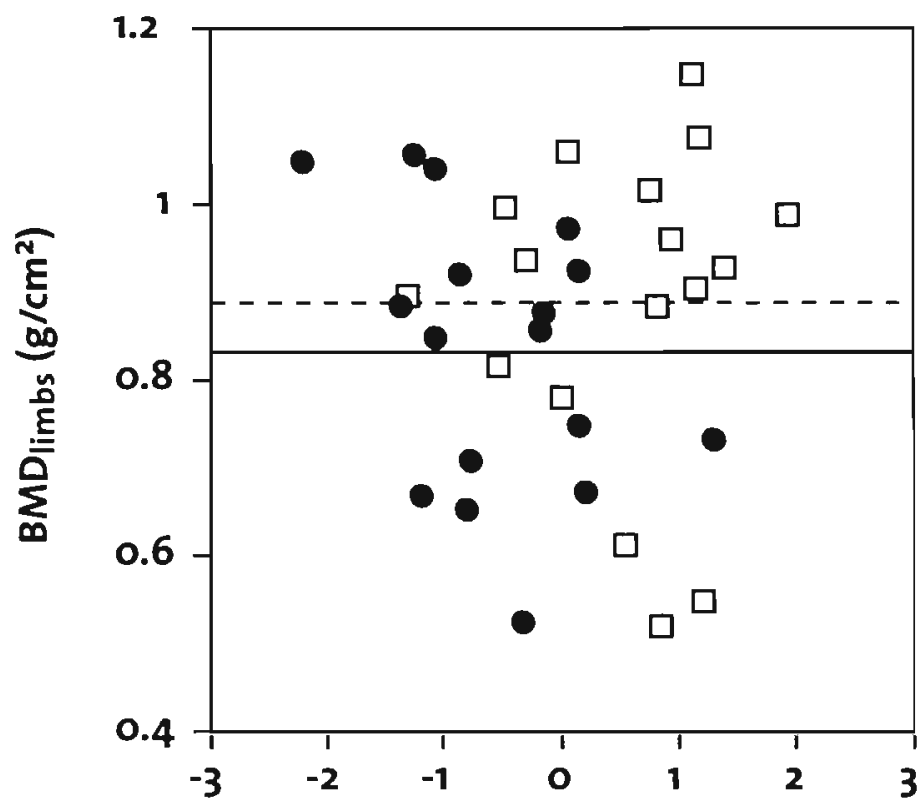

\section{rADMR (MJ/day)}

Table 4.5

Results of multiple-linear-regression analysis of the influence of bone age, fat mass index (FMI), gender, activity ( $\mathrm{ADMMR}$ ), and Prader-Willi syndrome (PWS), on the ratio of extracellularto-intracellular water (ECW/ICW).

\begin{tabular}{lccrcc} 
Variable & $B$ Coefficient $^{1}$ & SE & $95 \% \mathrm{Cl} \mathrm{B}$ & $\mathrm{P}$ \\
\hline Bone age $(\mathrm{y})$ & -0.010 & 0.004 & $-0.018--0.001$ & 0.026 \\
FMI $\left(\mathrm{kg} / \mathrm{m}^{2}\right)$ & 0.006 & 0.003 & $0.001-0.012$ & 0.046 \\
Gender & 0.015 & 0.023 & $-0.032-0.062$ & 0.520 \\
rADMR & -0.013 & 0.013 & $-0.039-0.013$ & 0.318 \\
PWS4 & 0.054 & 0.024 & $0.004-0.104$ & 0.034
\end{tabular}

1 The partial regression coefficient which is the change in ECW/ICW for a change in a specific variable adjusted for the other independent variables in the equation

2 The range of values that includes the population value of the coefficient

3 Gender was defined as: Female $=1$, Male $=0$

4 Grouping variable PWS was defined as: PWS $=1$, Obese controls $=0$ 
Fig.4.3

Fat mass index (FMI, in $\mathrm{kg} / \mathrm{m}^{2}$ ) as a function of activity related energy expenditure ( $\mathrm{FADMR}$, in $\mathrm{M} /$ /day) plotted for the Prader-Willi group (PWS, filled circles) and obese control group (open squares). The regression line of the controls was not significant. The dotted line represents the mean FMI of the control group. The regression equation for PWS: $F M I=-3.30$ rADMR + 8.75 $\left(R^{2}=0.36 ; p<0.05\right)$.

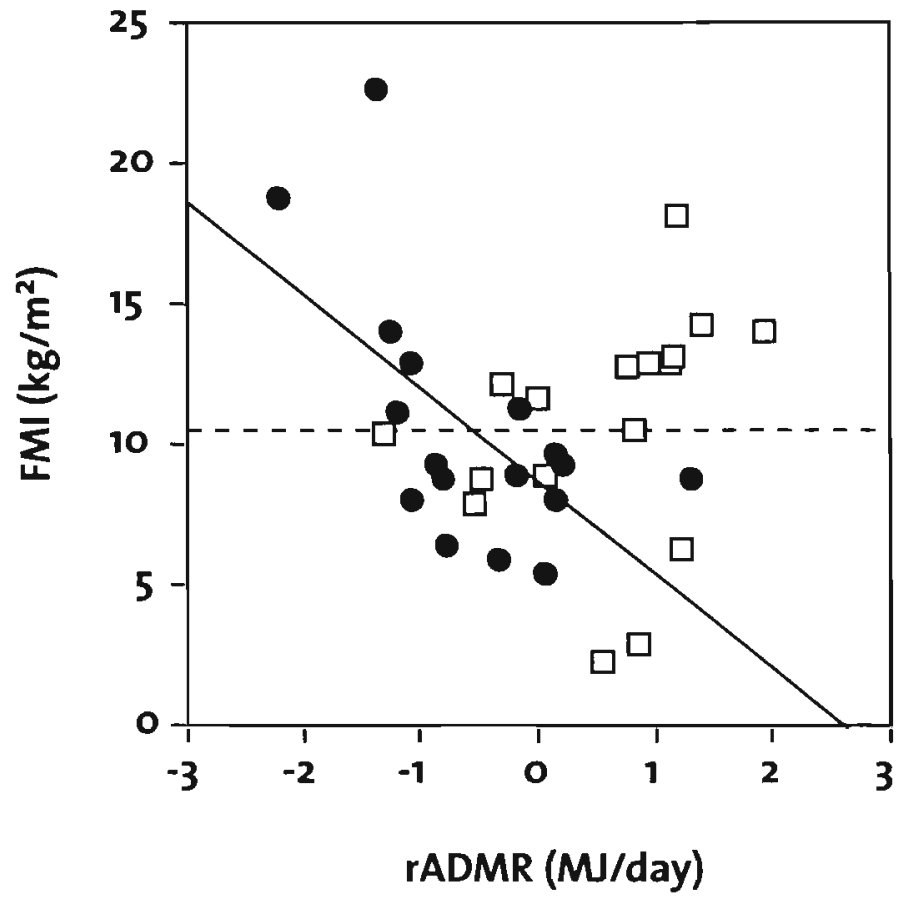

\section{Discussion}

In the present study, fat mass, body water compartments and bone mineralization in patients with PWS were compared with nonsyndromal obese controls, and related to $\mathrm{GH}$ function and PA. Previous reports showed a combination of increased FM and reduced FFM in patients with PWS $(28,29)$. The present results demonstrate that the adiposity in PWS is more characterized by an underdevelopment of FFM, than of excessive growth of FM. Although weight and BMI tended to be lower in the PWS group, the differences were not significant. The FFM, however, was significantly lower in the PWS group, both in absolute value as well as corrected for height (FFMI), whereas the absolute and relative measures of fat mass (FM, FMI and \%FM) were similar. The use of indices for FFM and FM, which correct for height, offer a comparison in body composition based mainly on body 
weight, analogous with BMI. The lower BMI in the PWS group is therefore explained by a reduction in FFMI, resulting in a similar level of adiposity in both groups. BMI underestimates the adiposity in PWS and is not the appropriate measure for comparison with nonsyndromal individuals.

The underdevelopment of FFM as the basis for adiposity in PWS is probably caused by a functional GHD, as supported by the positive relationship between IGF-I and FFM, adjusted for bone age, in combination with an absent correlation between IGF-I and FM.

Although the effect of physical activity on FFM is well-established, the relationship between activity and FM in healthy children and adults is still in debate (22, $30,31)$. Some studies have shown a positive relationship between activity related energy expenditure and adiposity, mainly because of the increasing energy costs for weight bearing activities (32). Others reported no effect of adiposity on activity, when corrected for body weight or BMR (33). In the present study, the control group showed no effect of activity related energy expenditure, corrected for BMR, on adiposity, whereas in PWS patients adiposity was inversely related with activity. Since the data in the present study were obtained in a cross-sectional manner, it remains unclear whether in PWS patients a reduced activity causes an increase in body fat, or whether the higher level of body fatness restricts them from being physically active.

It has been speculated that besides GHD and physical inactivity, puberty delay could also be responsible for the reduction in FFM (9). In the present study the subjects were matched for bone age and gender, resulting in a closely resembling puberty development, ranging from pre- to post-pubescent, as was confirmed by the sexual maturation stages of Tanner (25). In spite of the similarity in puberty development and sexual maturation, the reduction of FFM is still present, which does not support puberty delay as a explanatory factor for this reduction. The reduced lean body mass in PWS resembles that of individuals with growth hormone deficiency (GHD) $(34,35)$. It has been shown in adults that GHD was associated with shrinking of the ICW compartment, possibly as a result of protein catabolism $(11,36)$. The higher ECW/ICW in the PWS group seems to support the hypothesis of functional GHD. In the obese state, however, the ECW compartment (plasma water, interstitial water including lymph and connective tissue water, including bone and cartilage) increases with the level of adiposity $(37,38)$. In fact, the strong relation of ECW with FM, is thought to be one of the reasons why a high ECW/ICW is associated with cardiovascular diseases, such as hypertension (39). Multiple linear regression is therefore needed to correct for the effect of adiposity on ECW/ICW. Furthermore, it is known that ECW/ICW shows a gender specific decrease during maturation (40). The present results show, that, even when corrected for adiposity, as well as for gender differences and physiological maturation, ECW/ICW was higher in the PWS group compared with nonsyndromal obese 
controls. There was no significant relationship between $\mathrm{ECW} / \mathrm{ICW}$ and $\mathrm{GH}$ function when corrected for maturation and adiposity, however, ICW showed a positive correlation with ICF-I, using the same correction. It is therefore likely that the higher ECW/ICW is caused by two separate effects: firstly, an increase in ECW as a result of adiposity, and secondly, a decrease in ICW as a results of diminished $\mathrm{GH}$ function.

Although the fasting level of IGF-I cannot be used as the 'gold standard' for $\mathrm{GH}$ function, IGF-I is known to be principally regulated by $\mathrm{GH}$ (41) and proposed to be used as marker for $\mathrm{GH}$ status in disturbed $\mathrm{GH}$ secretion $(42,43)$. In healthy children, IGF-I changes with age, puberty development and outdoor temperature, when short-term variations are mainly influenced by weight changes and illness (44). All of these factors were controlled for in the present study. Arguably, although IGF-I levels in PWS patients have been reported to range from normal to subnormal in PWS $(35,45,46)$, as was confirmed in the present study, it may still be possible that the growth hormone function is diminished because of a loss of sensitivity for growth hormone metabolites.

It has been reported that patients with PWS, often already at adolescence, fracture easily following minor trauma (47). A functional GHD in PWS could be responsible for the specific reduction of bone mass in the limbs. The positive association between IGF-I and $\mathrm{BMD}_{\text {limbs, }}$ adjusted for bone age and body weight, supports this relationship. Moreover, the present data show an increased BMC in relation to FFM in the PWS group, in combination with a tendency towards lower absolute measure of BMC, especially in the limbs $(p=0.051)$. This would suggest that, on the level of the total body there is a relatively larger deficit of muscle mass, whereas in the limbs a relatively stronger reduction of bone mass is present. Brambilla et al. (9), who measured bone mineralization in children as well as in adults with PWS, found a significant difference in BMC of the total body as well as in the limbs, but only in the older PWS group, whereas the BMC in relation to FFM was normal. Presumably, the abnormalities of the somatotrophic and hypothalamic-pituitary-gonadal axis in PWS will have a stronger effect on bone metabolism after growth, leading to an increased risk for osteoporosis starting from adolescence.

Assuming that the specific reduction of bone mass in the limbs of patients with PWS is mainly the result of altered hormonal function, activity is not likely to have a strong effect on bone mineralization, as confirmed by Figure 2 . Bone mass is known to be positively affected by physical activity (48) and, acquired during adolescence, it is an important determinant for the risk of osteoporosis later in life (49). The effect of growth on bone mineralization in this group of young subjects, however, most likely outweighs the effect of physical activity.

From a clinical point of view, assuming causal relationships, increased levels of IGF-I as well as PA would have beneficial effects on adiposity and ECW/ICW, each 
via a different mode of action, and would therefore provide an interesting combination for therapeutic purposes. IGF-l would lead to an increase in FFM, whereas PA decreases FM, in both cases decreasing the level of adiposity. Consequently, the decrease in FM would lead to a decrease in ECW/ICW. This reduction in ECW/ICW would also be achieved when ICW is increased as a result of increased levels of IGF-I. Furthermore, IGF-I may have an additional positive effect on $B M D_{\text {limbs. }}$.

In conclusion, adiposity in children and adolescents with Prader-Willi syndrome (PWS) is mainly the result of a reduced fat-free mass, which is related to growth hormone function. Furthermore, adiposity is negatively related to physical activity in these patients. Children and adolescents with PWS have an increased extracellular-to-intracellular water ratio, even when adjusted for adiposity, gender and biological maturation. Finally, growth hormone function is positively related to bone mineral density in the limbs, which already tends to be reduced in these young patients.

\section{Acknowledgements}

We thank the Dutch Prader-Willi Association, the public health department of the Maastricht region and especially the children and their parents for participating and making the study possible.

\section{References}

1. Prader A, Labhart A, Willi H. Ein Syndrom von Adipositas, Kleinwuchs, Kryptorchismus und Oligophrenie nach myotonieartigem Zustand in Neugeborenenalter. Schweizerische Medizinische Wochenschrift 1956; 86: 1260-1261.

2. Glenn CC, Driscoll DJ, Yang TP, Nicholls RD. Genomic imprinting: potential function and mechanisms revealed by the Prader-Willi and Angelman syndromes. Mol Hum Reprod 1997; 3: 321-332.

3. Cassidy SB. Prader-Willi syndrome. J Med Genet 1997: 34: 917-923.

4. Holm VA, Cassidy SZ, Butler MC, Hanchett JM, Greenswag LR, Whitman BY, Greenberg FG. Prader-Willi Syndrome: Consensus Diagnostic Criteria. Pediatrics 1993; 91: 398-402.

5. Costeff H, Holm VA, Ruvalcaba R, Shaver J. Growth Hormone Secretion in Prader-Willi Syndrome. Acta Paediatr Scand 1990; 79: 1059-1062.

6. Angelo M, Castro-Magna M, Uv J, Rosenberg W. Growth hormone evaluation and treatment in Prader-Willi syndrome. Pediatr Res 1991; 29: 126A.

7. Kamel A, Margery V, Norstedt B, Thoren M, Lindgren A-N, Bronnegard M, Marcus C. Growth Hormone (GH) Treatment Up-Regulates GH receptor mRNA levels in Adipocytes from Patients with GH Deficiency and Prader-Willi Syndrome. Pediatr Res 1995; 38: 418-421. 
8. Swaab DF. Prader-Willi syndrome and the hypothalamus. Acta Paediatr Supp/ 1997; 423: 5054.

9. Brambilla P, Bosio L, Manzoni P, Pietrobelli A, Beccaria L, Chiumello G. Peculiar body composition in patients with Prader-Labhart-Willi syndrome. Am J Clin Nutr 1997; 65: 1369-1374.

10. Lindgren AC, Hagenäs L, Müller J, Blichfeldt $S$, Rosenborg $M$, Brismar T, Ritzén EM. Effect of growth hormone treatment on growth and body composition in Prader-Willi syndrome: a preliminary report. Acta Paediatr Suppl 1997; 423: 60-62.

11. Marken-Lichtenbelt WDV, Snel YEM, Brummer RIM, Koppeschaar HPF. Deuterium and bromide dilution, and bioimpedance spectrometry indepently show that growth hormone-deficient adults have an enlarged extracellular water compartment related to intracellular water. J Clin Endocrinol Metab 1997: 82: 907-911.

12. Davies PSW, Joughin C. Using Stable Isotopes to Assess Reduced Physical Activity of Individuals With Prader-Willi Syndrome. Am J Ment Retard 1993; 98: 349-353.

13. Stunkard A, Pestka J. The physical activity of obese girls. Am J Dis Child 1962; 103: 116-121.

14. Gortmaker SL, Must A, Sobol AM, Peterson K, Colditz GA, Dietz WH. Television Viewing as a Cause of Increased Obesity among Children in the United States, 1986-1990. Arch Ped Adol Med 1996; 150: 356-362.

15. Hill OJ, Trowbridge FL Childhood Obesity: Future Directions and Research Priorities. Pediatrics 1998; 101: 570-574.

16. Cox LA. The biology of bone maturation and ageing. Acta Paediatr Suppl 1997; 423: 107-108.

17. Tanner JM, Whitehouse RH, Marshall WA, Healy MR, Goldstein H. Assessment of skeletal maturity and prediction of adult height (TW2 Method). Academic Press, London, 1983.

18. Goran MI, Nagy TR, Gower BA, Mazariegos M, Solomons N, Hood V, Johnson R. Influence of sex, seasonality, ethnicity, and geographic location on the components of total energy expenditure in young children: implications for energy requirements. Am J Clin Nutr 1998; 68: $675-682$.

19. Westerterp KR, Wouters L, Marken-Lichtenbelt WDV. The Maastricht Protocol for the Measurement of Body Composition and Energy Expenditure with Labeled Water. Obes Res 1995: 3: 49-57.

20. Weir JBdV. New methods for calculating metabolic rate with special reference to protein metabolism. J Physiol 1949; 612: 511-521.

21. Goran MI. Variation of total energy expenditure in humans. Obes Res 1995; 3: 59-66.

22. Goran MI, Carpenter WH, MCGloin A, Johnson R, Hardin JM, Weinsier RL. Energy expenditure in children of lean and obese parents. Am J Physiol 1995; 0054:

23. Schoeller DA, Santen Ev, Petterson DW, Dietz W, Jaspan J, Klein PD. Total Body Water Measurement in Humans with 180 and $2 \mathrm{H}$ labeled Water. Am J Clin Nutr 1980; 33: 2686-2693.

24. Boileau RA, Lohman TG, Slaughter MH, Ball TE, Going SB, Hendrix MK. Hydration of the fatfree body in children during maturation. Hum Biol 1984; 56: 651-666.

25. Tanner JM. Growth at adolescence. Blackwell Scientific Publications Ltd., London, 1962. 
26. Westerterp KR, Meijer GAL, Kester ADM, Wouters L, Ten Hoor F. Fat-free mass as a function of fat mass and habitual activity level. Int J Sport Med 1992; 13: 163-166.

27. Miller ME, Cosgriff JM, Forbes GB. Bromide space determination using anion-exchange chromatography for measurement of bromide. Am J Clin Nutr 1989; 50: 168-171.

28. Schoeller DA, Levitsky LL, Bandini LG, Dietz WW, Walczak A. Energy Expenditure and Body Composition in Prader-Willi Syndrome. Metabolism 1988; 37: 115-120.

29. Lee PD, Hwu K, Henson H, Brown BT, Bricker JT, LeBlanc AD, Fiorotto ML, Greenberg F, Klish WJ. Body Composition Studies in Prader-Willi Syndrome: Effects of Growth Hormone Therapy. In: (eds). Human Body Composition. Plenum Press, NY and London: Houston, Texas, 1993.

30. Salbe AD, Fontvieille AM, Harper IT, Ravussin E. Low levels of physical activity in 5-year-old children. J Pediatr 1997; 131: 423-429.

31. Goran MI, Reynolds KD, Lindquist CH. Role of physical activity in the prevention of obesity in children. Int J Obes 1999; 23: S18-S33.

32. Prentice AM, Goldberg GR, Murgatroyd PR, Cole TJ. Physical activity and obesity: problems in correcting expenditure for body size. Int J Obes 1996; 20: 688-691.

33. Bandini LG, Schoeller DA, Dietz WH. Energy Expenditure in Obese and Nonobese adolescents. Pediatr Res 1990; 27: 198-203.

34. Davies PSW, Evans S, Broomhead S, Clough H, Day JME, Laidlaw A, Barnes ND. Effect of growth hormone on height, weight, and body composition in Prader-Willi syndrome. Arch Dis Child 1998; 78: 474-476.

35. Lindgren AC, Hagenas L, Muller J, Blichfeldt S, Rosenborg M, Brismar T, Ritzen EM. Growth hormone treatment of children with Prader-Willi syndrome affects linear growth and body composition favourably. Acta Paediatr 1998; 87: 28-31.

36. Häusinger $D$, Roth $E$, Lang F, Gerok W. Cellular hydration state: an important determinant of protein catabolism in health and disease. Lancet 1993: 341: 1330-1332.

37. Waki M, Kral JG, Mazariegos M, Wang J, Pierson RN, Heymsfield SB. Relative expansion of extracellular fluid in obese vs. nonobese women. Am J Physiol 1991; 261-E: 199-203.

38. Battistini N, Virgili F, Severi S, Brambilla P, Manzoni P, Beccaria L Chiumello G. Relative expansion of extracellular water in obese vs. normal children.J Appl Physiol 1995: 79: 94-96.

39. Raison J, Achimastos A, Asmar R, Simon A, Safar M. Extracellular and interstitial fluid volume in obesity with and without associated systemic hypertension. Am J Cardiol 1986; 57: 223226.

40. Fomon SJ, Haschke F, Ziegler EE, Nelson SE. Body composition of reference children from birth to age 10 years. Am J Clin Nutr 1982; 35: 1169-1175.

41. Blum WB, Albertsson-Wikland K, Rosberg 5 , Ranke MB. Serum levels of insuline-like growth factor (ICF-I) and IGF-binding-protein 3 reflect spontaneous growth hormone secretion. J Clin Endocrinol Metab 1993; 76 : 1610-1616.

42. Smith W, Nam TJ, Underwood LE, Busby GH, Celnicker A, Clemmons DR. Use of insuline-like growth factor-binding protein-2 (IGFBP-2), IGFBP-3, and IGF-I for assessing growth hormone status in short children. J Clin Endocrinol Metab 1993; 7 : 1294-1299. 
43. Kristrom B, Jansson C, Rosberg S, Albertsson-Wikland K. Growth respons to growth hormone (GH) treatment relates to serum insuline-like growth factor-1 (IGF-I) and IGF-binding protein-3 in short children with various GH secretion capacities. J Clin Endocrinol Metab 1997; 82: 2889-2898.

44. Gelander L, Blum WF, Larsson L Rosberg S, Albertsson-Wikland K. Monthly measurements of insuline-Like Growth Factor I (IGF-I) and IGF-Binding Protein-3 in Healthy Prepubertal Children: Characterization and Relationship with Growth: The 1-Year Growth Study. Pediatr Res 1999: 45: $377-383$.

45. Cappa M, Grossi A, Borrelli P, Ghigo E, Bellone J, Benedetti S, Carta D, Loche S. Growth Hormone $(\mathrm{GH})$ Response to Combined Pyridostigmine and $\mathrm{GH}$-Releasing Hormone Administration in Patients with Prader-Labhart-Willi Syndrome. Horm Res 1993; 39: 51-55-

46. Eiholzer U, Stutz K, Weinmann C, Torresani T, Molinari L, Prader A. Low insulin, IGF-I and IGFBP-3 levels in children with Prader-Labhart-Willi syndrome. Eur J Pediatr 1998; 157: 890893.

47. Rubin K, Cassidy SB. Hypogonadism and osteoporosis. In: LR Greenswag and RC Alexander (eds). Management in Prader-Willi syndrome. Springer-Verlag: New York, NY, 1988.

48. Marcus R, Drinkwater B, Dalsky G, Dufek J, Raab D, Slemenda C, Snow-Harter C. Osteoporosis and exercise in women. Med Sci Sports Exerc 1992; 24: $\mathrm{S}_{301} \mathrm{O} 3307$.

49. Halioua L, Anderson JJB. Lifetime calcium intake and physical activity habits: independent and combined effects on the radial bone of healthy premenopausal Caucasian women. Am J Clin Nutr 1989; 49: 534-541. 
Chapter 5

Energy expenditure in adolescence:

a multicenter analysis of the effect of gender and body composition

Edgar G.A.H. van Mil, Klaas R. Westerterp, Arnold D.M. Kester, Wim H.M. Saris

From the Department of Human Biology, Nutrition Environment and Toxicology Research Institute Maastricht, the Department of Methodology and Statistics, Maastricht University

Accepted for: Archives of Disease in Childhood 


\section{Abstract}

Objective: To examine the relation between average daily metabolic rate (ADMR), basal metabolic rate (BMR), body composition and gender in adolescence, and to test current BMR prediction equations.

Study design: Twenty-four obese adolescents from The Netherlands (NL-O) were pooled with nonobese subjects from Northern Ireland (UK-N) and obese and nonobese subjects from the United States (US-O and US-N, respectively) $(n=90)$. Multiple regression models were used to calculate differences in BMR and ADMR. Results: Fat-free mass (FFM), BMR and ADMR were higher in the obese compared with the nonobese group $(53.2 \pm 10.7 \mathrm{~kg}, 8.35 \pm 1.57 \mathrm{M} /$ day, $13.64 \pm 2.78 \mathrm{MJ} /$ day, compared with $41.0 \pm 8.1 \mathrm{~kg}, 6.42 \pm 0.94 \mathrm{MJ} /$ day, $11.16 \pm 2.21 \mathrm{MJ} /$ day). BMR was also higher in the obese group when adjusted for FFM, age and gender, which were significant determinants in the analysis. WHO equations overestimated BMR in obese boys, and underestimated BMR in nonobese boys. The physical activity level (= ADMR/BMR) was lower in the obese group ( $1.64 \pm 0.19$ compared with $1.73 \pm$ $0.21)$, however $A D M R$ adjusted for $B M R$ was equal in both groups.

Conclusion: $B M R$, but not ADMR, is increased in obese and in male adolescents. Adult WHO BMR equations are recommended for obese adolescents. 


\section{Introduction}

The prevalence of overweight and obesity in children and adolescents is rapidly increasing in Western societies $(1,2,3,4)$. Obesity during adolescence is associated with elevated blood pressure and lipid profiles that increase the risk of obesityrelated disease and mortality $(5,6,7,8)$. Awareness is growing, that the long-term cardiovascular health of the next generation of adults is an issue of concern $(9,10$, 11). Moreover, the obese adolescent has the highest risk of becoming an obese adult (12), regardless of parental obesity (13). Since adult obesity remains difficult to treat (14), this age group is of increasing interest as a target for obesity treatment (15). Knowledge of energy metabolism in adolescents is therefore of vital importance for future obesity interventions.

Obesity is a condition of excess adipose tissue. The excess weight that results from this condition does not only consist of fat mass (FM), but also of fat-free mass (FFM). Generally, energy expenditure is increased, not only because the increased FFM results in a raise in basal metabolic rate (BMR), but also because of higher energy costs for weight bearing activities (16). During adolescence, however, growth spurts and biological maturation may have additional effects on body composition and energy expenditure $(17,18)$. As a result of these potential confounding factors, several studies measuring basal metabolism in obese adolescents $(19,20,21,22,23,24,25)$, have tested the validity of existing BMR prediction equations (26), often leading to new equations $(25,26)$. Only one study has addressed the effect of obesity on BMR as well as total energy expenditure, or average daily metabolic rate (ADMR) in this age group (27).

The aim of the study was to examine the relationship between ADMR, BMR and body composition in obese and nonobese male and female adolescents. Because of economic restraints, our objectives were achieved by using results from our own study center, pooled with data published in literature. The specific objectives were: 1) to examine the nature of the relationship between ADMR, BMR and FFM in adolescents; 2 ) to determine the effects of obesity and gender on ADMR and BMR in this age group; and 3) to assess whether existing FAO/WHO/UNU equations can be used to predict BMR in lean as well as obese adolescents.

\section{Methods}

A 'Medline' and cross-reference search was performed for existing data sets on $A D M R$ and $B M R$ in adolescents. Inclusion criteria were: 1) individually reported measures of FFM, BMR and ADMR from peer-reviewed journal articles; 2) subjects between 12 and 18 years of age and with no disease states other than obesity; 3 ) total body water (TBW) and ADMR had to be measured by labelled water (free liv. 
ing) and BMR by ventilated hood. FFM had to be calculated by TBW.

The results were extracted from each report and entered into a database. For each individual, information about gender, body weight, height, FFM, FM, BMR and $A D M R$ was extracted into the database. Subject characteristics are shown in Table 5.1.

\section{Subjects and protocol of study center Maastricht}

Twenty-four obese subjects (age 12.0 - 17.4y) with body mass index (BMI) and triceps skinfold thickness greater than or equal to the $97^{\text {th }}$ Percentile for age- and gender (28), were recruited from the regional public health department and paediatric outpatient clinic of the university hospital Maastricht. Subjects with endocrine causes or other secondary causes of obesity were excluded. Before the start of the study the parents gave written informed consent confirmed by an oral approval of the child. The study was approved by the medical ethical committee of Maastricht University.

Height, weight and BMR measurements have been described in detail previously (29), and TBW and ADMR were measured according to the Maastricht protocol for the measurement of body composition and energy expenditure with labelled water (30).

\section{BMR prediction equations}

BMR was calculated according to the prediction equations of the Food and Agriculture Organization of the United States, World Health Organization, and United Nations University (FAO/WHO/UNU) (18) on the basis of weight (WHO1), and weight in combination with height (WHO2) for age $10-18$ years, as well as 18 - 30 years (WHO1.a and $W H O 2 . a$, respectively):

\begin{tabular}{|c|c|c|}
\hline WHO1: $10-18 y$ & Males & $0.0732^{*}$ Weight +2.72 (M/day) \\
\hline & Females & $0.0510^{*}$ Weight $+3.12(\mathrm{MJ} /$ day $)$ \\
\hline WHO2: & Males & $69.4^{*}$ Weight $+322.2 *$ Height $+2392(\mathrm{~kJ} /$ day $)$ \\
\hline & Fem & $30.9^{*}$ Weight $+2016.6^{*}$ Height $+907(\mathrm{~kJ} /$ day $)$ \\
\hline WHO1.a: $18-30 y$ & Males & $0.0640^{*}$ Weight +2.84 (M/day) \\
\hline & Females & $0.0615^{*}$ Weight $+2.08(\mathrm{M} /$ day $)$ \\
\hline WHC & Males & $64.4^{*}$ Weight $-113.0^{*}$ Height $+3000(\mathrm{~kJ} /$ day $)$ \\
\hline & Females & 55.6* Weight + 1397.4 * Height $+146(\mathrm{~kJ} /$ day $)$ \\
\hline
\end{tabular}


Table 5.1

Subject characteristics of obese and nonobese adolescents'.

\begin{tabular}{|c|c|c|c|c|c|c|}
\hline Variable & NL-O & US-O & Obese & UK-N & US.N & Nonobese \\
\hline$n(F / M)$ & $24(11 / 13)$ & $27(12 / 15)$ & $51(23 / 28)$ & $16(8 / 8)$ & $23(10 / 13)$ & $39(18 / 21)$ \\
\hline Age $(y)$ & $13.9 \pm 1.3^{*}$ & $15.0 \pm 1.9$ & $14.5 \pm 1.7$ & $13.5 \pm 1.6$ & $14.3 \pm 1.3$ & $14.0 \pm 1.5$ \\
\hline Weight (kg) & $85.0 \pm 16.2^{* *}$ & $101.4 \pm 23.2$ & $93.7 \pm 21.7$ & $47.7 \pm 8.3$ & $55.3 \pm 9.5$ & $52.2 \pm 9.7$ \\
\hline $\mathrm{BMI}\left(\mathrm{kg} / \mathrm{m}^{2}\right)$ & $31.7 \pm 4.9^{*}$ & $36.3 \pm 7.7$ & $34.1 \pm 6.9$ & $19.0 \pm 2.9$ & $20.5 \pm 2.8$ & $19.9 \pm 2.9$ \\
\hline
\end{tabular}

1 mean \pm s.d

$\mathrm{NL}-\mathrm{O}$, obese group of the Maastricht area; US-O, obese group of the Boston area; UK-N, nonobese group of the Belfast area; US-N, nonobese group of the Boston area

$\because \quad$ Significantly different from US.0: ${ }^{*} p<0.05, \cdots p<0.01$

\#*\# Significantly different from nonobese: $p<0.001$

Significantly different form US-N: $\rho<0.05$ 


\section{Statistical analysis}

Firstly, all study samples were divided into the obese or nonobese group. Obesity was defined as BMI above the $95^{\text {th }}$ Percentile for age and gender according to the current recommendations (31). Differences in independent variables between the obese and nonobese groups and between the countries, as well as gender differences within the pooled groups, were analyzed by the two-sample $t$-test.

Differences in the mean of the measured and predicted BMR in males and females were determined with a paired $t$-test, as a measure of accuracy. The mean absolute error (MAE) for each subgroup was calculated to measure the precision of the BMR prediction.

Secondly, a multiple-linear-regression model with BMR as the dependent variable, and FFM, age, and gender as independent variables, was used to analyze the difference in BMR between the obese and nonobese adolescents, defined by the binary variable group. The regression coefficient indicates the difference in BMR between the groups, adjusted for the independent variables. The difference in regression slope, of the influence of FFM on BMR, was tested using an interaction variable of group and FFM, and group and gender after correction for the variables in the equation. Consequently, the difference between groups, corrected for these independent variables, was estimated and tested for significance using linear regression assuming equal slopes. The same procedure was done with ADMR as the dependent variable, again with FFM, age and gender as independent variables, and obesity as the grouping variable. This analysis was repeated with BMR instead of FFM as covariate.

Finally, to detect differences between centers these procedures were repeated within the obese as well as the nonobese group, with the study center as the grouping variable.

The significance level was chosen at $5 \%$. Data were expressed as mean \pm s.d. SPSS release 6.1 for Macintosh (SPSS Inc. Chicago, Illinois, USA) was used as the statistical package.

\section{Results}

Of the five BMR and ADMR studies in adolescents $(27,32,33,34,35)$ that were found in literature, two reports met the inclusion criteria: Bandini et al. (27) who measured obese (US-O) as well as nonobese adolescents (US-N) in the Boston region (MA, US) and Livingstone et al. (33) who measured children and adolescents of age 7,9,12 and 15 years in the Belfast area (Northern Ireland, UK). For the present analysis only the adolescent groups (12 and 15 years) of Livingstone's report were included (UK-N). Furthermore, FFM was indirectly calculated via 
weight and $F M$, the latter based on skinfold measurements. The results, however, were similar when FFM was measured by dilution technique (33). In the study by Bandini et al. (27), as well as in our own center, FFM was calculated by dividing TBW by 0.73 . Thus, two groups of US and Dutch obese (US-O and NL-O) and US and UK nonobese adolescents (US-N and UK-N) were formed, resulting in a total group of 90 subjects. There were no statistically significant differences between the groups for gender and height, while in the obese as well as the nonobese group, the US subjects were heavier than their European counterparts.

Furthermore, the US-O group had a higher age than the NL-O group (Table 5.1). FFM, FM, percentage fat mass (\%FM), BMR, ADMR and physical activity level (PAL (=ADMR/BMR)) were all higher in the obese adolescents. Within the obese group FFM and FM were higher in the US-O subjects compared with the NL-O group, while \%FM was similar. Additionally, BMR, ADMR and PAL were higher in US-O. Within the nonobese group, there was a higher FFM, BMR and ADMR in the US-N group compared with UK adolescents (Table 5.2).

Between males and females, there were no differences in age, height, weight or BMI within both groups (not shown). In addition, FFM was similar, while \%FM was lower in the males compared with the females, but only in the nonobese group $(17.1 \pm 5.4$ compared with $25.9 \pm 7.0 \%(p<0.0001))$. Furthermore, BMR was higher in males compared with females, for the obese as well as the nonobese group $(8.90 \pm 1.58$ compared with $7.69 \pm 1.31 \mathrm{MJ} /$ day $(p<0.01)$, and $6.95 \pm 0.84$ compared with $5.81 \pm 0.64 \mathrm{MJ} /$ day $(p<0.001)$, respectively). A significant difference between males and females was also found in ADMR for both the obese and the nonobese group $(14.45 \pm 2.69$ compared with $12.67 \pm 2.63 \mathrm{MJ} /$ day $(p<0.05)$, and $12.17 \pm 2.02$ compared with $9.98 \pm 1.83 \mathrm{M} /$ day $(p<0.01$, respectively). There were no gender differences in PAL.

The BMR of the obese subjects, plotted as a function of FFM, results in a regression line which is shown superimposed on the regression line of the nonobese group (Figure 5.1). BMR adjusted for FFM resulted in a higher BMR for the obese group compared with the nonobese group, even when adjusted for age and gender (Table 5.3). For the complete study sample FFM accounted for $80 \%$ of the observed variance. BMR adjusted for FFM was not different between US-N and UK-N, nor between US-O and NL-O (not shown). Other significant determinants in the prediction of $B M R$ were age and gender.

WHO1 as well as WHO2 overestimated the measured BMR in the obese males (MAE $=723$ and $562 \mathrm{~kJ}$, respectively), however, underestimated $B M R$ in the nonobese males (MAE $=405$ and $412 \mathrm{k}$, respectively), as was demonstrated by the differences in the means, which are shown in Table 5.4. Conversely, WHOz underestimated BMR in obese females (MAE $=591 \mathrm{~kJ}$ ), while the BMR of obese as well as nonobese females was adequately predicted by $\mathrm{WHO}_{1}(\mathrm{MAE}=189$ and $19 \mathrm{k}$, respectively).WHO1.a and WHO2.a underestimated BMR in the nonobese males 
Table 5.2

Energy expenditure and body composition of obese and nonobese adolescents'.

\begin{tabular}{|c|c|c|c|c|c|c|c|c|c|c|c|}
\hline Variable & NL-O & & $5-0$ & & bese & & $\mathrm{K}-\mathrm{A}$ & & & $S-N$ & Nonobese \\
\hline FFM (kg) & $49.0 \pm 8.5^{* *}$ & 56.8 & \pm 11.4 & 53.2 & $\pm 10.7^{\text {man }}$ & 36.6 & \pm & $6.4^{45}$ & 44.1 & \pm 7.8 & $41.0 \pm 8.1$ \\
\hline $\mathrm{FM}(\mathrm{kg})$ & $35.9 \pm 9.6^{\circ}$ & 44.6 & \pm 15.1 & 40.5 & \pm 13.4 " & 11.0 & \pm & 5.4 & 11.2 & \pm 5.0 & $11.1 \pm 5.1$ \\
\hline$\% F M(\%)$ & $42.0 \pm 4.9$ & 43.1 & \pm 6.8 & 42.6 & $\pm 6.0^{n a n}$ & 22.8 & \pm & 7.9 & 20.0 & \pm 7.2 & $21.2 \pm 7.6$ \\
\hline BMR (MJ/day) & $7.81 \pm 1.32^{*}$ & 8.83 & \pm 1.65 & 8.35 & $\pm \quad 1.57$ man & 6.02 & \pm & 0.86 & 6.71 & \pm 0.91 & $6.42 \pm 0.94$ \\
\hline $\operatorname{ADMR}(\mathrm{MJ} / \mathrm{day})$ & $12.14 \pm 2.19^{* * *}$ & 14.98 & \pm 2.58 & 13.64 & $\pm \quad 2.78$ san & 10.28 & \pm & 1.38 & 11.77 & \pm 2.49 & $11.16 \pm 2.21$ \\
\hline PAL & $1.56 \pm 0.18^{* *}$ & 1.71 & \pm 0.18 & 1.64 & \pm 0.19 & 1.72 & \pm & 0.18 & 1.75 & \pm 0.24 & $1.73 \pm 0.21$ \\
\hline
\end{tabular}

\section{mean \pm s.d.}

NL-O, obese group of the Mastricht area; US-O, obese group of the Boston area; UK-N, nonobese group of the Belfast area: US-N, nonobese group of the Boston area

$\cdots$ Significantly different from US-O: ${ }^{*} p<0.05 .{ }^{~} p<0.01, \cdots p<0.001$

", "n\#\# Significantly different from nonobese: " $p<0.05$, ${ }^{n * n} p<0.001$

4, 6 Significantly different form US-N: $9 p<0.05$. "5 $p<0.01$ 
and females (MAE $=773$ and $778 \mathrm{~kJ}$, and 517 and $136 \mathrm{~kJ}$, respectively), however, the measured BMR in obese males as well as females was best predicted by WHOr.a ( $M A E=33$ and $119 \mathrm{~kJ}$, respectively). Therefore, $\mathrm{WHO} 2$ had the least MAE for the nonobese males and females, while WHO1.a had the least MAE in the obese males and females. In Figure 5.2 BMR is a function of the BMR prediction of the $\mathrm{WHO}_{2}$ for the nonobese and WHO1.a for the obese adolescents, as these prediction equations had the smallest MAE in each group.

ADMR plotted as a function of FFM resulted in two similar regression lines for the obese and the nonobese group (not shown). This function was similar between the study centers within both groups (not shown), and when adjusted for age and gender, while only gender was a significant determinant in the analysis (Table 5.5). FFM accounted for $66 \%$ of the observed variance, which could be increased by including age and gender in the equation, adding $5 \%$ to the explained variance.

Fig.5.1

Basal metabolic rate (BMR, in $\mathrm{M} /$ day) as a function of fat-free mass (FFM, in $\mathrm{kg}$ ) plotted for the obese (filled symbols) and nonobese group (open symbols); Females are represented by triangles, males by circles. The regression line for the obese:

$B M R=0.12 F F M+1.99\left(R^{2}=0.67\right)$; for nonobese $B M R=0.08 F F M+3.05$ (dotted line, $R^{2}=$ $0.50)$. The regression line of the obese group is significantly different from the regression line of the nonobese group (Multiple-linear-regression analysis: $p<0.05$ ).

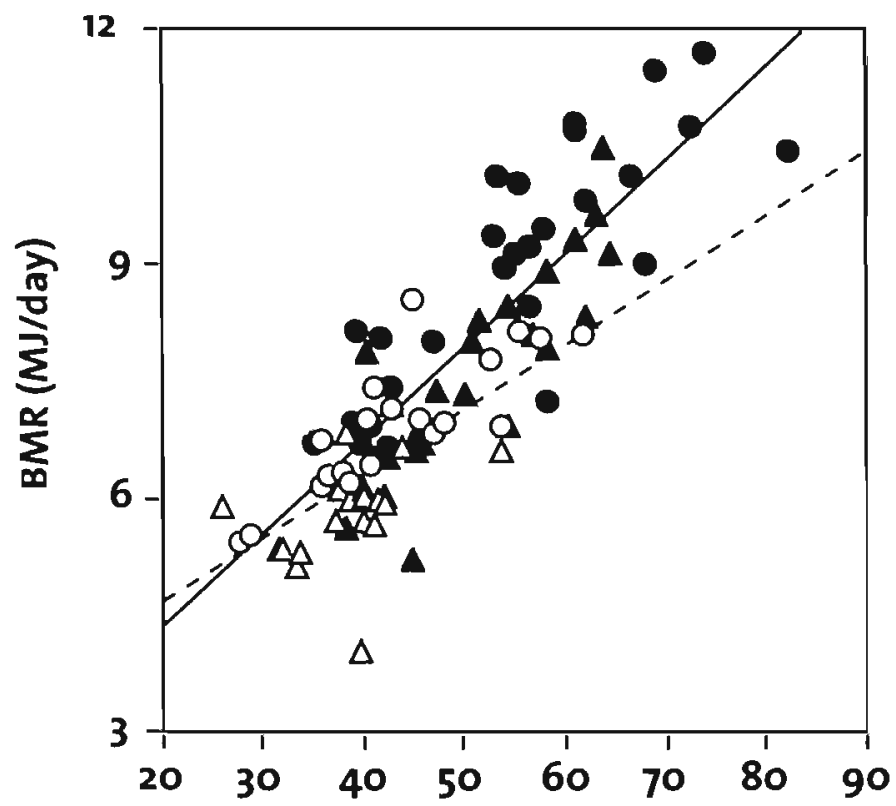

FFM (kg) 
Table 5.3

Results of multiple-linear-regression analysis of the influence of fat-free mass (FFM), age, gender and obesity, on basal metabolic rate (BMR).

\begin{tabular}{lrlrr} 
Variable & B Coefficient $^{1}$ & SE & $95 \% \mathrm{Cl}^{2}$ & $p$ \\
\hline FFM (kg) & 0.122 & 0.009 & $0.105-0.140$ & 0.000 \\
Age (y) & -0.238 & 0.053 & $-0.344--0.132$ & 0.000 \\
Gender & -0.627 & 0.149 & $-0.923--0.332$ & 0.000 \\
Group4 & 0.564 & 0.171 & $0.224-0.904$ & 0.001 \\
\hline
\end{tabular}

1 The partial regression coefficient which is the change in BMR for a change in a specific variable adjusted for the other independent variables in the equation

2 The range of values that includes the population value of the coefficient, with $95 \%$ probability

3 Gender was defined: Female $=1$, Male $=0$

4 Group was defined: Obese $=1$, Nonobese $=0$

Fig.5.2

Measured Basal metabolic rate (measured $B M R$, in $M /$ day) as a function of predicted $B M R$ by FAO/WHO/UNU equations (in M/day). The obese group (filled symbols) is predicted by adult $B M R$ equations based on weight, and the nonobese group (open symbols) is predicted by adolescent equations based on height and weight. Females are represented by triangles, males by circles. The dotted line represent the line of identity.

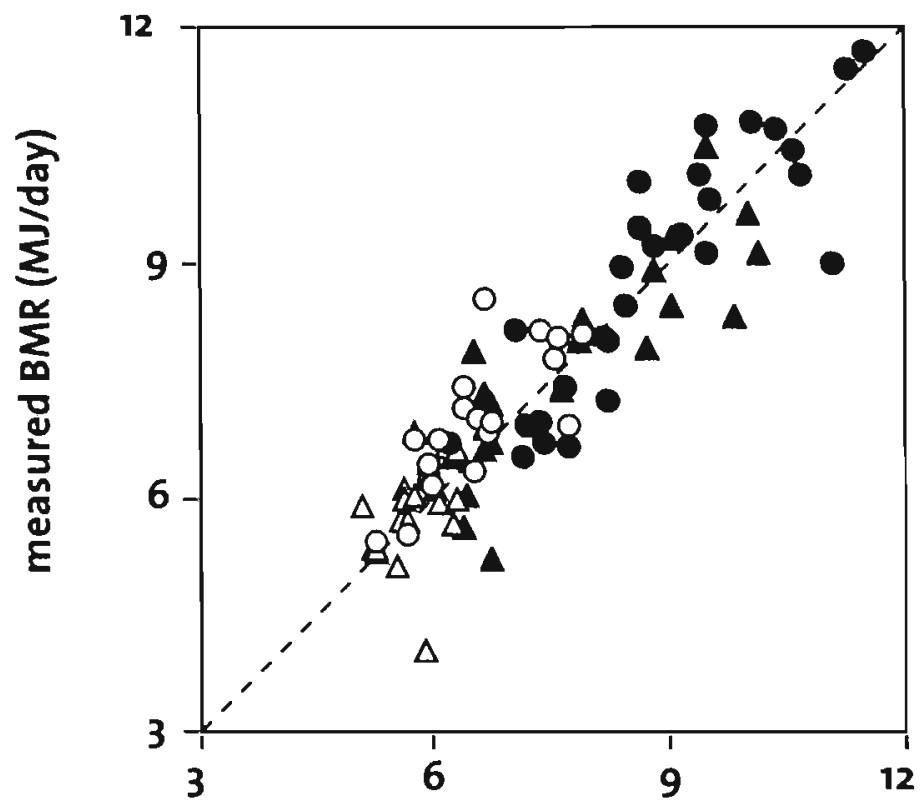


Table 5.4

FAO/WHO/UNU' prediction equations for basal metabolic rate (BMR) of males and females in the obese and nonobese group ${ }^{2 .}$

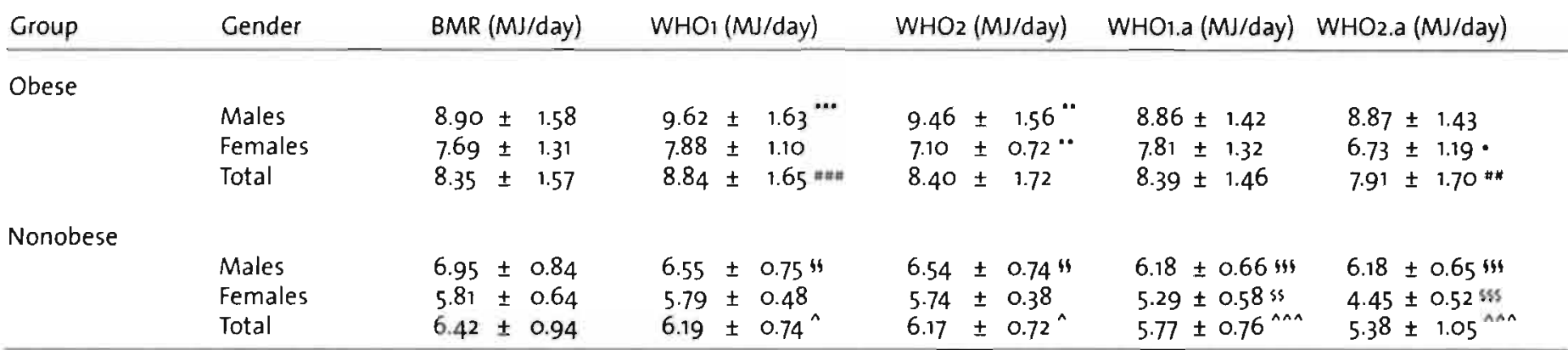

$1 \mathrm{FAO/WHO/UNU,} \mathrm{Food} \mathrm{and} \mathrm{Agriculture} \mathrm{Organization/World} \mathrm{Health} \mathrm{Organization/} \mathrm{United} \mathrm{Nations} \mathrm{University:}$ WHO1: equations based on weight for age $10-18$ years

WHO2: equations based on weight and height for age $10-18$ years

WhiO1.a: equations based on weight for age 18 - zo years

WHO2.a: equations based on weight and height for age 18-30 years

2 mean $\pm 5 . d$

$\because \quad$ Significantly different from BMR of obese males: ${ }^{*} p<0.01,{ }^{\cdots} p<0.001$

$\because \quad$ Significantly different from BMR of obese females. $" p<0.05 . " p<0.01$

"n, "n: Significantly different from BMR of obese group: " $p<0.01$, "n" $p<0.001$

(i), it Significantly different from BMR of nonobese males: $H p<0.01$, 51 p $p<0.001$

5s, s5s Significantly different from BMR of nonobese females: $55 p<0.01,355 p<0.001$

$\because \wedge$ Significantly different form BMR of nonobese group: ^ $p<0.05$, $^{\wedge \wedge} p<0.001$ 
Fig.5.3

Average daily metabolic rate (ADMR, in M/day) as a function of basal metabolic rate (BMR, in $M / d a y)$ plotted for the obese (filled symbols) and nonobese group (open symbols); Females are represented by triangles, males by circles. The regression line for the obese: $A D M R=1.46$ $B M R+1.44\left(R^{2}=0.68\right) ;$ for nonobese $A D M R=1.82 B M R-0.55$ (dotted line, $R^{2}=0.60$ ).

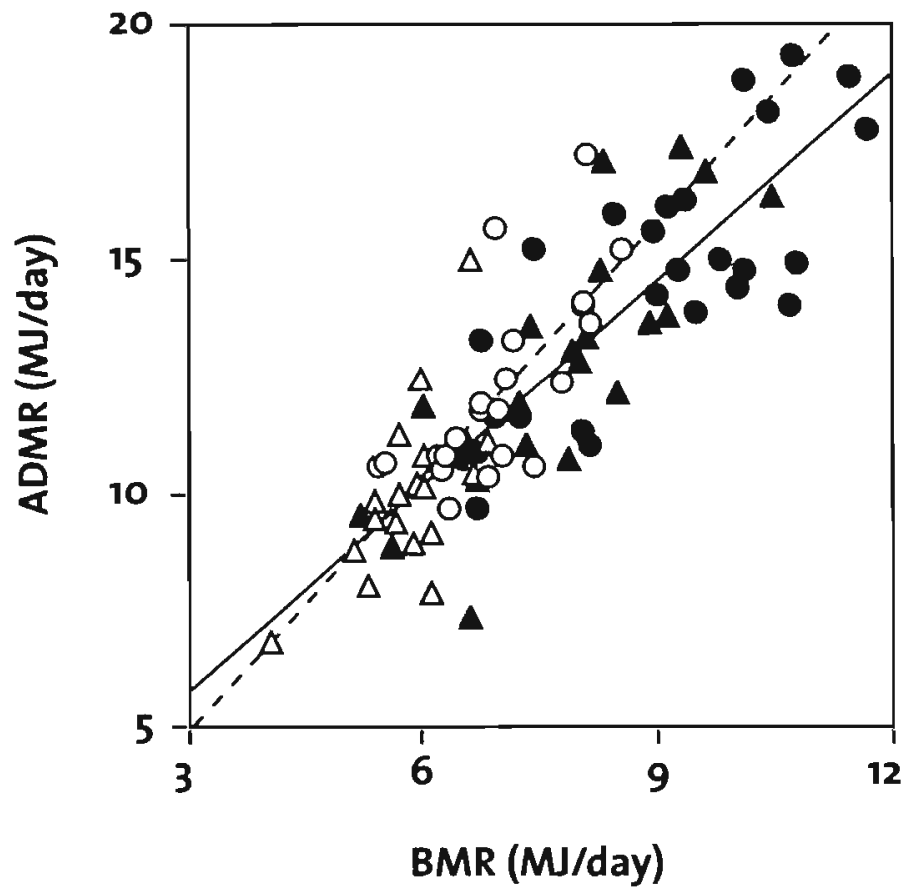

ADMR plotted as a function of BMR also resulted in similar regression lines for the obese and nonobese group ( $R^{2}=0.68$ and 0.60 , respectively) (Figure 5.3). Combining both groups, BMR accounted for $71 \%$ of the observed variance, while age, as the only other significant predictor for ADMR (Table 5.5), increased the explained variance to $72 \%$. 
Table 5.5

Results of multiple-linear-regression analysis of the influence of fat-free mass (FFM) or basal metabolic rate (BMR), adjusted for age, gender, obesity, on average daily metabolic rate (ADMR (M/day)).

\begin{tabular}{|c|c|c|c|c|c|c|}
\hline \multicolumn{2}{|c|}{ Variable } & \multirow{2}{*}{$\underbrace{\beta \text { Coefficient' }^{\prime}}_{0.211}$} & \multirow{2}{*}{$\frac{S E}{0.020}$} & \multicolumn{2}{|c|}{$95 \% \mathrm{Cl} \beta^{2}$} & \multirow{2}{*}{$\begin{array}{c}p \\
0.000\end{array}$} \\
\hline ADMR & $F F M(k g)$ & & & 0.170 & 0.252 & \\
\hline & Age $(y)$ & -0.241 & 0.121 & -0.483 & 0.001 & 0.050 \\
\hline & Gender3 & -1.069 & 0.339 & -1.744 & $-\quad-0.395$ & 0.002 \\
\hline & Group 4 & 0.044 & 0.390 & -0.731 & $-\quad 0.819$ & 0.910 \\
\hline \multirow[t]{4}{*}{ ADMR } & $\mathrm{BMR}$ (M/day) & y) 1.445 & 0.136 & 1.174 & 1.716 & 0.000 \\
\hline & Age $(y)$ & 0.215 & 0.102 & 0.012 & 0.418 & 0.038 \\
\hline & Gender 3 & -0.332 & 0.360 & -1.049 & 0.384 & 0.359 \\
\hline & Group4 & -0.419 & 0.407 & -1.230 & 0.392 & 0.307 \\
\hline
\end{tabular}

1 The partial regression coefficient which is the change in ADMR for a change in a specific variable adjusted for the other independent variables in the equation

2 The range of values that includes the population value of the coefficient, with $95 \%$ probability

3 Gender was defined: Female $=1$, Male $=0$

4 Group was defined: Obese $=1$, Nonobese $=0$

\section{Discussion}

Due to a scarcity of studies on total energy expenditure in obese as well as nonobese adolescents, the present study aimed to combine the energy expenditure and body composition data from obese adolescents from the Maastricht region with individual data from the US (Boston area) (27) and the UK (Belfast area) (33) to determine the effect of obesity and gender on energy metabolism in this age group.

$B M R$, adjusted for FFM, was higher in the obese group. Although gender and age, as known predictors for BMR, were significant parameters in the regression, a statistical difference between the obese and nonobese group remained. The difference in BMR was also consistent throughout the four study centers. These findings therefore confirm the conclusions by earlier reports $(19,27,36)$, although others did not find a difference between obese and nonobese adolescents (37). When FM was included in the analysis, the difference between obese and nonobese subjects was lost. However, this does not imply that in obese adolescents FM is (more) metabolically active. One explanation is that obesity causes changes in chemical composition of FFM $(38,39)$. Using theoretical calculations it was shown that the density of FFM, due to a relative increase in TBW, was decreased in the obese state leading to an overestimation of FM, when measured by underwater 
weighing (40). In the present study, however, TBW was measured directly by deuterium dilution, which cannot explain the increased BMR. Another explanation is that the increased BMR adjusted for FFM is not based on an underestimation of FFM, but on an increase in mass of metabolically active organs. Obesity might be related to a relative increase in internal organ mass compared with muscle mass. Since the major organs of the body (brain, heart, kidney and liver, including splanchnic bed) have high basal metabolism levels compared with skeletal muscle (41), a higher proportion of these organs in FFM would be reflected by an increase in BMR, even when adjusted for FFM.

In contrast with Katch et al.(19) but in agreement with Bandini et al. (27), this study showed a higher BMR in males, independent of body composition. The gender difference was also reflected by similar measures of FFM between the sexes of both groups, while BMR was higher in obese as well as nonobese males. As with the condition of obesity, one could speculate that the relative organ mass in females is smaller than in males or, as was shown in adults, that the $\mathrm{Na}^{+}-\mathrm{K}^{+}$ATPase activity is reduced in females (42), which is also related to a lower BMR (43). Another explanation comprises the effect of puberty. It is well-known that girls are starting puberty a few years earlier than boys, at approximately age 10 and ending at age 14 , compared with age 12.5 to 16 in boys (44). Since in the present study, the age ranges of boys and girls were similar ( $14.1 \pm 1.6$ compared with $14.5 \pm 1.6 \mathrm{y}$ ), it is likely that the girls are more advanced in their biological development than boys, and a greater proportion of them will be postpubertal, i.e. a greater proportion of boys were in their high metabolically active phase of puberty than girls, leading to a specific increase in BMR for boys. Moreover, Tanner stage (45), as a measure of sexual maturation, has shown to be a significant contributor in the explanation for the differences in BMR between the sexes $(26,27)$. On the other hand, Katch et al. (19) were not able to find a difference in BMR for puberty stage in 10-16 year old obese adolescents and the gender difference was also described in prepubescent children (46). Unfortunately, Tanner stage was not assessed in the UK-N group and therefore not included as a variable in the analysis. Additional determinants of energy expenditure, other than body composition, age and sex, are ethnicity, physical fitness and glucose tolerance (47). Apart from 2 boys and 1 girl with an impaired glucose tolerance test in the US-O group, there was again no information available regarding these issues. An important assumption to allow pooling of the data is therefore, that these determinants are not different between Ireland and the Netherlands, as these countries are only part of either the obese or the nonobese group.

Recently, existing equations to estimate BMR in nonobese children aged 10-15 have been thoroughly evaluated (26). The authors concluded that weight was the single most important factor in the equations for either gender and that the $\mathrm{FAO} / \mathrm{WHO}$ /UNU equations performed best in predicting BMR in this specific age 
group. In the present data, however, not all subgroups were well-predicted by $\mathrm{FAO} / \mathrm{WHO} / \mathrm{UNU}$ equations. WHO1 as well as $\mathrm{WHO}_{2}$ were good predictors of $\mathrm{BMR}$ in nonobese females, but underestimated the BMR in nonobese males, resulting in a general underestimation of energy expenditure in the whole nonobese group. The underestimation of energy requirements was in fact anticipated by the FAO expert committee, because their database included subjects who may have been on limited energy intakes before BMR measurement, as well as Indian subjects who were found to have BMR's approximately $10 \%$ below the average (18). The heavier nonobese group of the study of Bandini et al. is probably the reason that they did not find a difference using the WHO standards (27). Yet in the present obese group, the BMR in males was overestimated by WHO1 as well as WHO2, resulting in a general overestimation of $\mathrm{BMR}$ by $\mathrm{FAO} / \mathrm{WHO} / \mathrm{UNU}$-equations for obese males. For the total obese group the estimation by WHO2 seemed similar to the measured $B M R$, however, this was merely caused by a compensating effect of underestimated BMR in females. The overestimation of BMR by WHO standards in $10-16$ year old healthy child ren has been reported before, in obese as well as in nonobese subjects (24). We do not have an explanation for these conflicting findings, other than that the measurement of BMR is known to be subject of much error. Concluding from this data, the WHO1.a provides the best BMR prediction for the obese adolescents, while WHO1 adequately predicted BMR in obese as well as nonobese females, but provided the worst prediction for obese males. Thus, a combination of the use of $\mathrm{WHO}_{2}$ for nonobese and WHO1.a for obese adolescents results in the best fit along the line of identity (Figure 5.4), although the amount of variation around the same line shows, as already concluded by the FAO expert committee, that equations cannot substitute for the direct BMR measurements. The gender effect on ADMR is also based on BMR differences, since gender has only a negative effect on ADMR, when corrected for age and FFM, however, not when adjusted for BMR. Therefore, in concordance with data of $4-10$ year old children (48), the present study showed no effect of gender on activity related energy expenditure. Conversely, in a meta-analysis of adult data (49), the gender difference was demonstrated for ADMR, also when adjusted for BMR and independent from $F M$. The latter may indicate that the gender effect in activity related energy expenditure does not surface before adulthood.

Despite the effect of obesity on BMR, ADMR is not directly influenced by an excess of FM, when adjusted for FFM. This would suggest that the increase in BMR would be compensated by a decrease in nonbasal energy expenditure, mainly consisting of activity induced energy expenditure. The ratio of ADMR/BMR (PAL) provides a measure of activity related energy expenditure, corrected for $B M R$, assuming that diet induced energy expenditure is a constant proportion of ADMR (18). In the present study, the PAL of the male adolescents was within the range of $1.6-1.75$, as suggested by the FAO/WHO/UNU. The average PAL of female adolescents was 
higher than suggested $(1.5-1.65)(18)$, resulting in an underestimation of the calculated ADMR in this subgroup by the FAO/WHO/UNU, as was reported earlier (34).

The obese group had a lower PAL, indicating a lower activity level, which would be in contradiction with the literature that is generally in agreement that obese and nonobese subjects have similar total energy expenditure levels after normalizing for differences in body composition (49). Surprisingly, the low PAL of the NL-O group was the reason for this difference. Since many Dutch adolescents rely on their bicycles for transportation and spend only about $1.5 \mathrm{hr}$ per day watching television (50), a higher PAL might have been anticipated. In fact, in a previous study in 7-10 year old children of the Maastricht area a mean PAL of $1.83 \pm 0.23$ was found (51). Furthermore, the low PAL cannot be explained by an overestimation of the BMR, because the BMR, adjusted for FFM, was similar between the NL-O and US-O group. In this context, an alternative way of measuring differences in activity related energy expenditure, is by analysis of covariance based on multiple regression (52). Using this technique, which is most valuable in adjusting data with non-zero intercepts, such as the present data (Fig.5.3), the relationship of $A D M R$ with $B M R$ in obese and nonobese male and female subjects was compared using BMR as a covariate. In fact, this analysis showed that the activity related energy expenditure is indeed similar in both groups. It also demonstrates that, in this age group, physical activity increases with age. Although the positive effect of age on ADMR, after adjustment for BMR, was marginal, it might in part explain the low PAL in the younger NL-O group and the high PAL that was found in 15year-old Swedish adolescents (35). On the other hand it is remarkable that studies have shown that physical activity decreases both in boys (53) and girls (54) just before puberty, while this study demonstrates that activity, adjusted for gender and body composition, further increases during adolescence towards adulthood.

In conclusion, an attempt to combine sparse data on energy metabolism in obese and nonobese adolescents has been made. The present study combined energy expenditure and body composition data from different centers, and indicates that, during adolescence, BMR is increased in the obese state and in males, which is independent from differences in body composition. The FAO/WHO/UNU equations underestimate $B M R$ in nonobese, and overestimate $B M R$ in obese male adolescents. For the obese subgroup the adult FAO/WHO/UNU BMR prediction equations, based on weight, are recommended. ADMR of obese adolescents, adjusted for body composition or BMR, is comparable with that of their nonobese peers, indicating that activity related energy expenditure is not different between obese and nonobese adolescents. 


\section{References}

1. Prentice AM, Jebb SA. Obesity in Britain: gluttony or sloth? BM/ 1995; 311: 437-439.

2. Seidell JC. Obesity in Europe: scaling an epidemic. Int J Obes 1995; 19: S1-S4.

3. Troiano RP, Flegal KM. Overweight children and adolescents: Description, epidemiology, and demographics. Pediatrics 1998; 101: S497-5504.

4. Reilly JJ, Dorosty AR, Emmett PM. Prevalence of overweight and obesity in British children: cohort study. BM 1999; 319: 1039.

5. Hoffmans MDA, Kromhout D, Lezenne Coulander DC. The impact of body mass index of 78,612 18-year old Dutch men on 32-year mortality from all causes. J Clin Epidemiol 1988; 41 : 749-756.

6. DiPietro L, Mossberg HO, Stunkard AJ. A 40-year history of overweight children in Stockholm: life-time overweight, morbidity, and mortality. Int J Obes 1994; 18: 585-590.

7. Owens S, Gutin B, Ferguson M. Allison J, Karp W, Le NA. Visceral adipose tissue and cardiovascular risk factors in obese children. J Pediatr 1998; 133: 41-45.

8. Luepker RV, Jacobs DR, Prineas RJ, Sinaiko AR. Secular trends of blood pressure and body size in a multi-ethnic adolescent population: 1986 to 1996. J Pediatr 1999; 134: 668-674.

9. Himes JH, Dietz WH. Guidelines for overweight in adolescent preventive services: recommendations from an expert committee. The Expert Committee on Clinical Guidelines for Overweight in Adolescent Preventive Services. Am J Clin Nutr 1994: 59: 307-316.

10. Daniels SR. Is there an epidemic of cardiovascular disease on the horizon? / Pediatr 1999; 134: 665-666.

11. Van Mil ECAH, Goris AHC, Westerterp KR. Debate: Physical activity and the prevention of childhood obesity - Europe versus the United States. Int J Obes 1999; 23: S41-S44.

12. Guo SS, Roche AF, Chumlea WC, Gardner JD, Siervogel RM. The predictive value of childhood body mass index values for overweight at age 35 y. Am J Clin Nutr 1994; 59: 810.819.

13. Whitaker RC, Wright JA, Pepe MS, Seidell KD, Dietz WH. Predicting obesity in young adulthood from childhood and parental obesity. N Eng/ J Med 1997; 337: 869-873.

14. Basdevant A, Boute D, Borys JM. Who should be educated? Education strategies: could chil. dren educate their parents. Int J Obes 1999; 23: S10-S13.

15. Freedman DS, Dietz WH, Srinivasan SR, Berenson GS. The relation of overweight to cardiovas: cular risk factors among children and adolescents: The Bogalusa Heart Study. Pediatrics 1999; 103: 1175-1182.

16. Westerterp KR. Obesity and physical activity. Int J Obes 1999; 23: 59-64.

17. Cheek DB, Mellits D, Elliott D. Body Water, Height, and Weight During Growth in Normal Children. Am J Dis Child 1966; 112: 312-317.

18. Energy and protein requirements: report of a joint FAO/WHO/UNU Expert Consultation. World Health Organization, Geneva, 1985.

19. Katch V, Rocchini A, Becque D, Marks C, Moorehead K. Basal metabolism of obese adolescents: age, gender and body composition effects. Int J Obes 1985; 9: 69-76. 
20. Katch VL, Marks CC, Bexque MD, Moorehead C, Rocchini A. Basal metabolism of obese adolescents: Evidence for energy conservation compared to normal and lean adolescents. Am J Human Biol 1990; 2: 543-551.

21. Dietz WH, Bandini LG, Schoeller DA. Estimates of metabolic rate in obese and nonobese adolescents. J Pediatr 1991; 118: 146-149.

22. Molnár D. Estimates of metabolic rate of obese and nonobese adolescents.J Pediatr 1992; 120: 660-661.

23. Firouzbakhsh S, Mathis RK, Dorchester WL, Oseas RS, Groncy PK, Grant KE, Finklestein JZ. Measured resting energy expenditure in children. J Pediatr Gastroenterol Nutr 1993; 16: 136142.

24. Molnár D, Jeges S, Erhardt E, Schulz Y. Measured and predicted resting metabolic rate in obese and nonobese adolescents. J Pediatr 1995; 127: 571-577.

25. Molnár D, Schutz Y. Fat oxidation in nonobese and obese adolescents: effect of body composition and pubertal development. J Pediatr 1998; 132: 98-104.

26. Henry CIK, Dyer S, Ghusain-Choueiri A. New equation to estimate basal metabolic rate in children aged 10-15 years. Eur I Clin Nutr 1999; 53:134-142

27. Bandini LG, Schoeller DA, Dietz WH. Energy Expenditure in Obese and Nonobese adolescents. Pediatr Res 1990; 27: 198-203.

28. Gever WJM, De Bruin R. Paediatric Morphometrics. Wetenschappelijke uitgevery Bunge, The Netherlands, Utrecht, 1996.

29. Van Mil EGAH, Westerterp KR, Gerver WJ, Curfs LM, Schrander-Stumpel CT, Kester AD, Saris WH. Energy expenditure at rest and during sleep in children with Prader-Willi syndrome is explained by body composition. Am J Clin Nutr 2000;71:752-756.

30. Westerterp KR, Wouters L, Marken-Lichtenbelt WDV. The Maastricht Protocol for the Measurement of Body Composition and Energy Expenditure with Labeled Water. Obes Res 1995: 3: 49-57.

31. Barlow SE, Dietz WH. Obesity evaluation and treatment: expert committee recommendations. Pediatrics 1998; 102: E29 (available at http://www.pediatrics.org).

32. Davies PSW, Livingstone MBE, Prentice AM, Coward WA, Jagger SE, Steward C, Strain J, Whitehead RG. Total energy expenditure during childhood and adolescents. Proc Nutrition Soc 1991; 50: 14A.

33. Livingstone MB, Coward WA, Prentice AM, Davies PS, Strain J, McKenna PG, Mahoney CA, White JA, Stewart CM, Kerr M. Daily energy expenditure in free-living children: comparison of heart-rate monitoring with the doubly labeled water method. Am I Clin Nutr 1992; 56 : $343-352$.

34. Wong WW. Energy expenditure in female adolescents. J Am Coll Nutr 1994; 13: 332-337.

35. Bratteby LE, Sandhagen B, Fan H, Enghardt H, Samuelson G. Total energy expenditure and physical activity as assessed by the doubly labeled water method in Swedish adolescents in whom energy intake was underestimated by 7-d diet records. Am J Clin Nutr 1998; 67: 905911.

36. Luke A, Schoeller DA. Basal metabolic rate, fat-free mass, and body cell mass during energy restriction. Metabolism 1992; 41: 450-450. 
37. Elliot DL, Goldberg L, KuehI KS, Hanna C. Metabolic evaluation of obese and nonobese siblings. J Pediatr 1989; 114: 957-962.

38. Halliday D, Hesp R, Stalley SF, Warwick P, Altman DG, Garrow JS. Resting metabolic rate, weight, surface area and body composition in obese women. Int J Obes 1979; 3: 1-6.

39. Lohman TG. Skinfolds and body density and their relation to body fatness: a review. Hum Biol 1981; 53: 181-225.

40. Deurenberg $P$, Leenen $R$, Van der Kooy $K$, Hautvast JGAJ. In obese subjects the body fat percentage calculated with Siri's formula is an overestimation. Eur f Clin Nutr 1989; 43: 569-575.

41. Holliday MA. Metabolic rate and organ size during growth from infancy to maturity and during late gestation and early infancy. Pediatrics 1971; 47: 169-179.

42. Simat BM, Morley JE, From AHL, Briggs IE, Kaiser FE, Levine AS, Ahmed K. Variables affecting measurement of human red cell $\mathrm{Na}^{*}, \mathrm{~K} \cdot$ ATPase activity: technical factors, feeding, aging. Am J Clin Nutr 1984; 40: 339-345.

43. Poehlman ET, Toth MJ, Webb GD. Erythrocyte $\mathrm{Na}^{\prime}-\mathrm{K}^{*}$ pump activity contributes to the agerelated decline in resting metabolic rate. J Clin Endocrinol Metab 1993; 76: 1054-1057.

44. Tanner JM. Growth at adolescence. Blackwell Scientific Publications L.td., London, 1962.

45. Tanner JM, Whitehouse RH, Marshall WA, Healy MR, Goldstein H. Assessment of skeletal maturity and prediction of adult height (TW2 Method). Academic Press, London, 1983.

46. Goran $\mathrm{MI}$, Kaskoun $\mathrm{M}$, Johnson $\mathrm{R}$. Determinants of resting energy expenditure in young children. J Pediatr 1994; 125: 362-367.

47. Weyer C, Snitker S, Rising R, Bogardus C, Ravussin E. Determinants of energy expenditure and fuel utilization in man: effects of body composition, age, sex, ethnicity and glucose tolerance in 916 subjects. Int J Obes 1999; 23: 715-722.

48. Goran MI, Carpenter WH, Poehlman ET. Total energy expenditure in 4- to 6-yr-old children. Am J Physiol 1993; 264: E706-E7n1.

49. Goran MI, Carpenter WH, McGloin A, Johnson R, Hardin JM, Weinsier RL Energy expenditure in children of lean and obese parents. Am J Physiol 1995;

50. Wekke JS-vd, Meulmeester JF, Radder JJ, Hirasing RA, Verloove-Vanhorick SP. PGO-peiling 1992/ 1993. TNO Preventie en Gezondheid, Leiden, 1994.

51. Van den Berg-Emons HJG, Saris WHM, De Barbanson DC, Westerterp KR, Huson A, Van Baak MA. Daily physical activity of school children with spastic diplegia and of healthy control subjects. J Pediatr 1995; 127: 578-584.

52. Goran MI. Variation of total energy expenditure in humans. Obes Res 1995; 3:59-66.

53. Brown DC, Kelnar CJH, Wu FCW. Energy metabolism during male puberty. I. Changes in energy expenditure during onset of puberty in boys. Ann Hum Biol 1996; 23: 273-179.

54. Goran MI, Gower BA, Nagy TR, Johnson RK. Developmental changes in energy expenditure and physical activity in children: evidence for a decline in physical activity in girls before puberty. Pediatrics 1998; 101: 887-891. 
Chapter 6

\section{Sibutramine prevents the decrease in basal metabolic rate associated with restriction of energy intake in obese adolescents}

Edgar G.A.H. van Mil, Klaas R. Westerterp, Arnold D.M. Kester, Wouter D. van Marken Lichtenbelt, Willem J.M. Gerver, Wim H.M. Saris

From the Department of Human Biology, Nutrition Environment and Toxicology Research Institute Maastricht, the Department of Methodology and Statistics, Maastricht University; and the Department of Paediatrics, University Hospital Maastricht, The Netherlands

Submitted for publication 


\section{Abstract}

Background: The increasing prevalence and the disappointing results in the treatment of paediatric obesity, urges the need for new treatment strategies.

Objective: To measure the effect of sibutramine on body composition and energy expenditure in obese adolescents.

Design: A randomized, double-blind, placebo-controlled study of 24 obese adolescents (age 12 - 17 years) treated either with sibutramine or placebo in combination with an energy restricted diet and exercise plan for 12 weeks, followed by a followup period of 12 weeks with the same diet and exercise plan, however, without the study medication. Basal metabolic rate was measured by ventilated hood and adjusted for gender, fat mass and fat-free mass $\left(B M R_{\text {adj }}\right)$. Average daily metabolic rate (ADMR) was measured by doubly labeled water. The change in BMI was the principal measure of efficacy.

Results: During intervention, $B M R_{\text {adj }}$ was decreased in the placebo group, and significantly different compared with the sibutramine group. The changes in ADMR were not significant between both groups. Although only the sibutramine group had a significant amount of weight loss, the change in BMI or FM was not significantly higher in the sibutramine group compared with the placebo group $(-3.3 \pm$ $1.5 \mathrm{vs}-1.3 \pm 1.5 \mathrm{~kg} / \mathrm{m}^{2}$, respectively). The difference in reported adverse events between both groups was not significant.

Conclusion: Sibutramine prevents the decrease in BMR associated with energy restriction and is therefore of potential support in the treatment of obesity in adolescence. 


\section{Introduction}

Obesity in childhood and adolescence is increasing worldwide and now considered an epidemic in many industrialized countries. Although children and especially adolescents suffer from the psychosocial consequences, public health professionals are above all concerned for the increase in cardiovascular diseases and diabetes in the coming generation $(1,2,3,4,5)$. While obese children below the age of six have about $25 \%$ chance of becoming an obese adult, up to $75 \%$ of the obese adolescents will stay obese when they enter adulthood (6). Moreover, obesity during adolescence compared with before adolescence is more predictive of morbidity and mortality later in life (7). Aiming to prevent adult obesity, and minimizing the risk of treating children who are in no need of intervention, there is an increasing emphasis on treatment of obese adolescents. Increasing prevalence of 'unhealthy' dietary practices or even eating disorders, particularly among adolescent girls and young women $(8,9)$, demonstrates the vulnerability of this age period and forces the physician even more to seek effective medical care for the appropriate target group.

Recently, an expert committee (10) recommended that adolescents whose BMI is above the $95^{\text {th }}$ percentile for age and gender should be considered overweight (11) and treated. The primary goal of the treatment program should be healthy eating and increased physical activity, eventually leading to weight loss. The treatment should focus on family based behavioral changes. Pharmacological therapy of obesity is only recommended if complications require rapid weight loss and should only be used in specialized paediatric obesity treatment centers. The effect of drug treatment on energy metabolism during adolescence, therefore, has never been studied. In recent years, pharmacological treatment was of low supportive value. A recently developed anti-obesity agent, sibutramine hydrochloride (Meridia ${ }^{\top M}$, Knoll Pharmaceutical Company, Mount Olive, NJ, USA), has been shown to be effective in achieving long-term weight loss in adults $(12,13,14)$. The metabolites of sibutramine are serotonin and noradrenalin reuptake inhibitors with no releasing activity $(15,16)$.

In adults, sibutramine is well-tolerated in doses up to $20 \mathrm{mg}$ administered as a single morning dose $(17,18,19)$, while weight loss was seen up to 24 weeks with a minimal dose of $5 \mathrm{mg}(20)$. The anti-obesity activity of sibutramine results from its dual mode of action: it reduces energy intake by increasing satiety (21), and it increases energy expenditure by stimulating thermogenesis (22). Whether sibutramine has the same weight reducing and thermogenic effects in obese adolescents has not been investigated.

The present study was designed for obese adolescents to evaluate the efficacy and safety of sibutramine, in combination with an energy restricted diet and exercise program, on body composition and energy expenditure. 


\section{Methods}

\section{Subjects}

Adolescents with primary obesity from the regional public health department and paediatric outpatient clinic of the university hospital Maastricht participated in the study. Participants were between 12 and 18 years of age, had a BMI and triceps skinfold thickness greater than or equal to the $97^{\text {th }}$ Percentile for age- and gender (23) and failed to lose or maintain weight after at least one supervised attempt of weight loss. Patients with endocrine causes or other secondary causes of obesity were excluded as well as patients with any significant physical or medical illness, that could influence the results of the study. Subject characteristics are shown in Table 6.1. Before the start of the study the parents gave written informed consent confirmed by an oral approval of the child. The study was approved by the medical ethical committee of Maastricht University.

Table 6.1

Subject characteristics'.

\begin{tabular}{|c|c|c|c|c|c|c|}
\hline \multirow{3}{*}{$\frac{n(F / M)}{\text { Age }(y)}$} & \multicolumn{3}{|c|}{ Sibutramine } & \multicolumn{3}{|c|}{ Controls } \\
\hline & \multicolumn{3}{|c|}{$12(6 / 6)$} & \multicolumn{3}{|c|}{$12(5 / 7)$} \\
\hline & 14.1 & \pm & 1.0 & 13.8 & \pm & 1.5 \\
\hline Bone age $(y)$ & 15.5 & \pm & 0.9 & 15.1 & \pm & 1.3 \\
\hline Tanner $(0-5)$ & 3.7 & \pm & 1.2 & 3.6 & \pm & 1.8 \\
\hline Height (m) & 1.63 & \pm & 0.05 & 1.63 & \pm & 0.08 \\
\hline Weight (kg) & 80.8 & \pm & 15.6 & 89.2 & \pm & 16.4 \\
\hline BMI $\left(\mathrm{kg} / \mathrm{m}^{2}\right)$ & 30.1 & \pm & 4.5 & 33.3 & \pm & 5.0 \\
\hline FFM (kg) & 46.6 & \pm & 8.2 & 48.6 & \pm & 9.0 \\
\hline$\% F M(\%)$ & 42.1 & \pm & 5.2 & 45.5 & \pm & 3.9 \\
\hline BMR (MJ/day) & 7.74 & \pm & 1.23 & 7.89 & \pm & 1.45 \\
\hline ADMR (MJ/day) & 12.12 & \pm & 1.93 & 12.55 & \pm & 2.10 \\
\hline
\end{tabular}

1 mean + s.d.; Tanner, sexual development stage according to Tanner (25); FFM, fat-free mass; \%FM, percentage fat mass; $B M R$, basal metabolic rate; $A D M R$, average daily metabolic rate

There were no significant differences between the sibutramine group and placebo group

\section{Methodology and treatment}

The trial was a randomized, double-blind, placebo-controlled, parallel-group comparison of two treatment regimens and conducted between April and October 1998. The study was divided into two phases. The first phase included a random- 
ized treatment period of 12 weeks, which included of an energy restricted diet, an exercise plan and either placebo or sibutramine $5 \mathrm{mg}$, taken once daily in the morning. After two weeks the dose was increased to $10 \mathrm{mg}$ daily. The second phase consisted of a follow-up period of 12 weeks with continuation of the diet and exercise plan. Throughout the study the emphasis was put on lifestyle modification. The study medication was provided by Knoll Pharma BV (Amsterdam, the Netherlands). The study complied with Good Clinical Practice guidelines (24).

\section{Study schedule}

At screening, a complete medical history and physical examination, including Tanner staging (25), was performed.

During the double-blind treatment period, subjects visited the center at: o (baseline), 1, 2, 3, 4, 6, 8, 10 and 12 weeks. At baseline, laboratory assessment, ECG, boneage, vital signs, dietary assessment, body composition and total energy expenditure were measured. At each following visit, the subject and parent(s) were invited by the physician for determination of vital signs and compliance of the treatment and exercise plan. The subject with parent(s) were asked to keep a daily record of the use of the trial medication and time spent on physical activity. The compliance was assessed by counting returned capsules and checking the medication and activity record. In addition, the subject with parent(s) was seen by the study dietician for dietary evaluation, except for the visit on week 3 that only included an appointment with the physician. At the end of the treatment period body composition and energy expenditure measurements were repeated. During the follow-up period the subjects visited the center at weeks: 13, 14, 16, 18, 20, 22, 24 , undergoing the same treatment and measurements as during the treatment period, however, without sibutramine or placebo. The follow-up period also ended with body composition and energy expenditure measurements. Unfortunately, due to a temporary world wide scarcity of doubly labeled water (26), total energy expenditure could not be measured in the second phase.

\section{Dietary and exercise advice}

Dietary advice was based on energy requirements. The energy prescription was calculated from measured basal metabolic rate multiplied by an estimated physical activity level minus $500 \mathrm{kcal}$. The dietary intake could not be lower than 18-20 $\mathrm{kcal}$ per kilogram of ideal body weight with a minimum of $25 \%$ of calories provided by fat. The estimated physical activity level was determined using an activity questionnaire (27). 
Physical activity was prescribed, based on individual preferences as well as information obtained by the activity questionnaire. The prescription contained a daily bout of exercise of at least 30 minutes of moderate to vigorous levels of exertions, however, the participants were encouraged to do more. Furthermore, emphasis was put on the implementation of additional physical activities, regardless of intensity, in the daily routine $(28,29)$.

\section{Measurements}

\section{Vital signs}

Blood pressure $(\mathrm{mm} \mathrm{Hg})$ and heart rate ( $\mathrm{HR}$, beats/minute) was measured after sitting for five minutes, using a regular adult cuff for an arm circumference of 23 $33 \mathrm{~cm}$ or a large adult cuff for an arm circumference of $34-41 \mathrm{~cm}$. Systolic blood pressure (SBP) was determined by the first Korotkoff sound and diastolic blood pressure (DBP) by the fifth Korotkoff sound.

\section{Bone age assessment}

Bone age was determined by assessing epiphysal maturation by the same paediatric endocrinologist using an $\mathrm{X}$-ray of the mid portion of the left hand and standard growth data (30).

\section{Dietary assessment}

A 7 days weighed dietary record form was handed to the parent(s) and subject, after the dietician gave instructions on how to measure portion size. They were asked to record brand names, methods of preparation, and ingredients of mixed dishes. The dietician reviewed the record with the parent(s) and subject and calculated the energy intake and macronutrients. The outcome of daily energy intake and macronutrient consumption will be the topic of a separate report. For the present analysis only the food quotient (FO) was needed for assessment of the respiratory exchange ratio (RER) to calculate total energy expenditure (31).

\section{Body composition}

In the morning, before the subjects consumed any food or drink, after voiding and whilst wearing under-clothing, total body weight was measured on an electronic 
scale (E1200, Mettler Instrumente AG, Greifensee, Switserland). Height of subjects without shoes was measured using a stadiometer. Body composition was assessed using a four-component (UC) reference model: Total body weight = fat mass (FM) + total body water (TBW) + total bone mineral content (TBMC) and remaining fat-free mass (32).

This multicompartment model is based on the classical two compartment model, determined by densitometry, measured by underwater weighing with simultaneous lung volume measurement. Furthermore, the fat-free mass (FFM) compartment is divided into three subcompartments, two of which are separately measured, namely TBW and TBMC.

TBW was measured with deuterium dilution according to the Maastricht protocol for the measurement of body composition and energy expenditure with labelled water (31). TBMC was assessed by dual-X-ray absorptiometry (DXA) (DPX-L, Lunar Corp., Madison, WI, USA). The $4 \mathrm{C}$ - model is considered one of the most accurate methods of estimating \%FM (33).

\section{Energy expenditure}

Total energy expenditure or average daily metabolic rate (ADMR) is divided into basal metabolic rate (BMR), diet-induced energy expenditure (DEE), and activity induced energy expenditure. DEE was calculated as $10 \%$ of ADMR. ADMR was measured according to the Maastricht protocol for the measurement of body composition and energy expenditure with labelled water (31). BMR was measured by ventilated hood, as been previously described (34). BMR consists of sleeping metabolic rate (SMR) and arousal. SMR was measured during a 12 h overnight stay in the respiration chamber which was described in detail previously (35). The respiration chamber, an open-circuit indirect calorimeter $(14 \mathrm{~m} 3)$ was maintained at a constant air temperature of $18^{\circ} \mathrm{C}$ during the night. The chamber was ventilated with fresh air at about $40 \mathrm{l} / \mathrm{min}$. Activity of the subject was measured by a modified analog ultrasound radar system. $5 M R$ was calculated automatically according to Weir (36), between $23.00 \mathrm{~h}$ and $6.30 \mathrm{~h}$ over the 3 -hour interval with the lowest radar count.

The physical activity level (PAL) was calculated as ADMR/BMR. As an alternative measure for physical activity, ADMR was adjusted for BMR using the residuals of $A D M R$ when plotted as a function of $B M R\left(A D M R_{a d j}\right)$. BMR was adjusted for gender, FFM and FM (BMR adj $)$. 


\section{Statistical analysis}

Differences in continuous variables between the sibutramine group and the placebo group at baseline were analyzed by the two-sample $t$-test. The number of patients required per treatment group to detect a difference between treatment groups in mean change in BMI at endpoint of $1.0 \mathrm{~kg} / \mathrm{m}^{2}$, based on an estimate of variance (s.d.) of 0.65 , an overall significance level of $5 \%$, and a power of $90 \%$ (37), was 9 . Allowing a drop-out rate of $30 \%$, the number of patients needed in each group was 12. The principal measure of efficacy was the change in BMI during the intervention period. The difference between both groups, in changes in BMI, as well as other continuous variables of vital signs, body composition and energy expenditure, was evaluated by analysis of covariance. For each variable the change from endpoint to baseline was used as the dependent variable in the analysis with group and the baseline value as explanatory variables. Similar analyses were performed for the change from endpoint intervention to endpoint follow-up. Furthermore, an efficacy analysis on an intention-to-treat basis was performed according to the last observation carried forward method (38). Thus, for subjects who dropped out, the last weight constituted the endpoint of intervention or follow-up. The change from baseline to endpoint interwention for continuous ustables within each group was assessed by paired t-test. Continuous data are reported as mean \pm s.d. The significance level was chosen at $5 \%$. 5 s s release 6. for Macintosh (SPSS Inc. Chicago, Minois, USA) was used as the statistical package.

\section{Results}

Subject characteristics at baseline are shown in Table 6. . There were no statistical differences in age, biological matumty, energy expenditure or body composition, in spite of a clinically relevant dfference in weight and Dw between the sibutramine and placebo group.

\section{Effects on body composition and energy expenditure}

\section{Intervention period}

None of the changes in body composition and energy expenditure were signifcantly different between the sibutramine and the placebo group, except for PAL and $B M R_{\text {adj }}$ (Table 6.2). BMR adj remained constant in the stbutramine group, but tended to decrease in the placebo group, leading to a significant difference between both groups (Figure 6.1) Vice versa, PAL remained constant in the sibu- 
Table 6.2

Changes from baseline to endpoint intervention in body composition and energy expenditure for completers of intervention.

Baseline

\begin{tabular}{|c|c|c|c|c|}
\hline Group & Sibutramine & Placebo & Sibutramine & Placebo \\
\hline $\mathrm{n}(\mathrm{F} / \mathrm{M})$ & $11(6 / 5)$ & $12(5 / 7)$ & $11(6 / 5)$ & $12(5 / 7)$ \\
\hline Height $(m)$ & $1.63 \pm 0.06$ & $1.63 \pm 0.08$ & $1.65 \pm 0.06$ & $1.64 \pm 0.07$ \\
\hline Weight (kg) & $82.2 \pm 15.6$ & $89.2 \pm 16.4$ & $79.0 \pm 16.3$ & $87.2 \pm 15.1$ \\
\hline $\mathrm{BMI}\left(\mathrm{kg} / \mathrm{m}^{2}\right)$ & $30.6 \pm 4.4$ & $33.3 \pm 5.0$ & $29.0 \pm 4.7$ & $32.2 \pm 4.2$ \\
\hline FFM (kg) & $47.4 \pm 8.0$ & $48.6 \pm 9.0$ & $46.8 \pm 8.3$ & $48.7 \pm 9.0$ \\
\hline$\% F M(\%)$ & $42.0 \pm 5.4$ & $45.5 \pm 3.9$ & $40.4 \pm 5.6$ & $44.2 \pm 4.0$ \\
\hline SMR (MJ/day) & $6.96 \pm 0.65$ & $7.24 \pm 1.17$ & $6.60 \pm 0.64$ & $6.96 \pm 1.03$ \\
\hline BMR (MJ/day) & $7.70 \pm 1.28$ & $7.89 \pm 1.45$ & $7.60 \pm 1.26$ & $7.37 \pm 1.25$ \\
\hline ADMR (MJ/day) & $12.23 \pm 1.99$ & $12.88 \pm 1.84$ & $12.03 \pm 2.68$ & $13.63 \pm 1.92$ \\
\hline PAL & $1.57 \pm 0.16$ & $1.60 \pm 0.42$ & $1.56 \pm 0.17$ & $1.86 \pm 0.30^{*}$ \\
\hline $\mathrm{BMR}_{\text {adj }}$ (M/day) & $7.96 \pm 1.67$ & $7.67 \pm 1.79$ & $7.96 \pm 1.90$ & $7.04 \pm 1.86^{*}$ \\
\hline$A D M R_{\text {adj }}(M / d a y)$ & $12.08 \pm 2.87$ & $12.86 \pm 2.80$ & $11.04 \pm 3.96$ & $14.53 \pm 3.22$ \\
\hline
\end{tabular}

FFM, fat-free mass; FM, fat mass; \%FM, percentage FM, SMR, sleeping metabolic rate; BMR, basal metabolic rate; ADMR, average daily metabolic rate; PAL physical activity level (ADMR/BMR); $B M R_{\text {adj, }}$ BMR adjusted for gender. FM and FFM; ADMR adj, ADMR adjusted for BMR

" Significantly different from Sibutramine group ( $p<0.05)$

tramine, but increased in the placebo group ( $p<0.01$ ), resulting in a significant group difference. The change in $A D M R_{\text {adj }}$, however, was not significant between both groups.

The change in $\mathrm{BMI}$ from baseline to intervention in the sibutramine and placebo group, adjusted for the BMl at baseline, was -3.3 and $-1.3 \mathrm{~kg} / \mathrm{m}^{2}$, respectively (SE = 1.5 in both groups). However, even without the correction for initial BMI, the decrease in $\mathrm{BMI}$ reached a higher level of significance in the sibutramine group $(p<0.001)$ than in the placebo group $(p<0.05)$. This is explained by an increase in height in both groups (Sibutramine: $p<0.01$; Placebo; $p<0.05$ ), while only the sibutramine group significantly lost weight during the intervention period ( $p<$ $0.05)$. The decrease in \%FM, however, was comparable in both groups $(p<0.05)$ (Table 6.2).

One subject of the sibutramine group discontinued the intervention period prematurely. Inclusion of this subject at intervention endpoint did not alter the results (last observation carried forward method) (Table 6.4). In both groups, SMR decreased significantly during intervention $(p<0.05)$, while BMR only tended to decrease in the placebo group $(p=0.057)$. The respiratory exchange ratio (RER), 
however, increased significantly in the sibutramine group (from $0.82 \pm 0.04$ to $0.85 \pm 0.05 ; p<0.05$ ), but not in the placebo group (from $0.81 \pm 0.03$ to $0.84 \pm$ $0.05 ; \mathrm{p}=0.11$ ). The changes in $A D M R$ and $A D M R_{\text {adj }}$ were not significant in both groups, however, PAL did increase significantly in the placebo group $(p<0.01$; Table 6.2).

Figure 6.1

Basal metabolic rate adjusted for fat-free mass, fat mass and gender (BMR adj), at Baseline (B), Intervention endpoint (I) and Follow-up endpoint (F). The change from baseline to intervention and from intervention to follow-up was significantly different between the sibutramine and the placebo group $(p<0.05)$.

\section{Sibutramine Placebo}

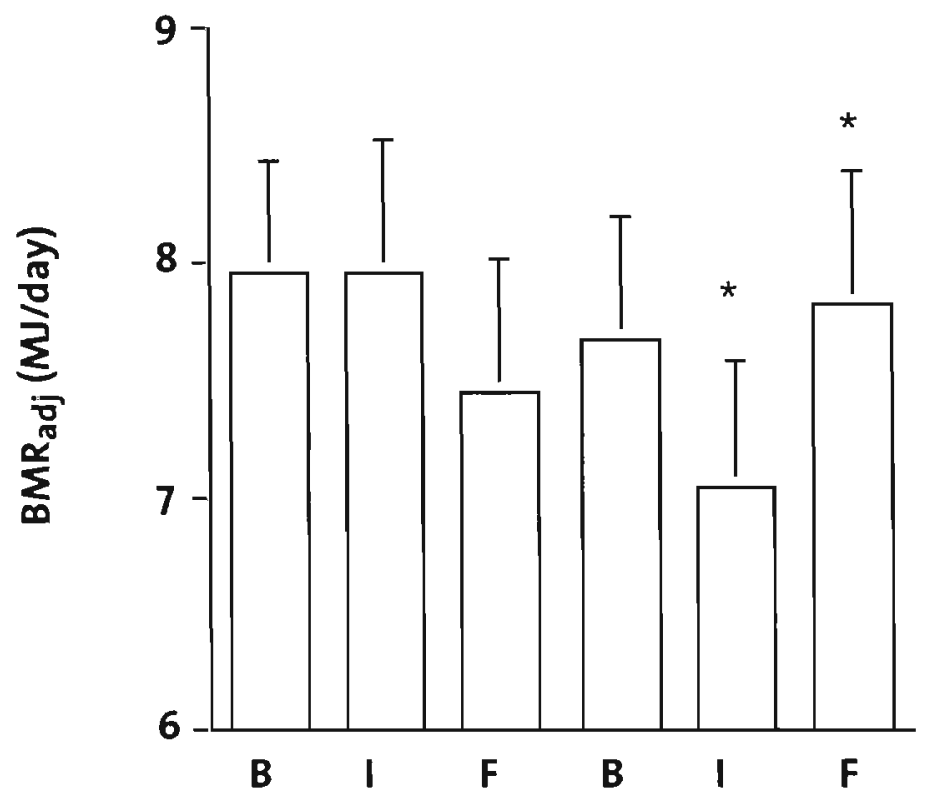

\section{Follow-up period}

None of the changes in body composition and energy expenditure were significantly different between the sibutramine and the placebo group, except for $\mathrm{BMR}_{\mathrm{adj}}$, which tended to decrease in the sibutramine group and increase in the placebo group, leading to a significant difference between both groups (Figure 6.1). 
Table 6.3

Changes from endpoint intervention to endpoint follow-up in body composition and energy expenditure for completers of follow-up.

Intervention

\begin{tabular}{lcccc}
\hline Group & Sibutramine & Placebo & Sibutramine & Placebo \\
\hline $\mathrm{n}(\mathrm{F} / \mathrm{M})$ & $11(6 / 5)$ & $9(3 / 6)$ & $11(6 / 5)$ & $9(3 / 6)$ \\
Height $(\mathrm{m})$ & $1.65 \pm 0.06$ & $1.64 \pm 0.06$ & $1.65 \pm 0.06$ & $1.65 \pm 0.06$ \\
Weight $(\mathrm{kg})$ & $79.0 \pm 16.3$ & $87.7 \pm 14.7$ & $81.6 \pm 16.8$ & $87.9 \pm 15.1$ \\
BMI (kg/m²) & $29.0 \pm 4.7$ & $32.6 \pm 4.7$ & $29.7 \pm 4.7$ & $32.3 \pm 5.1$ \\
FFM (kg) & $46.8 \pm 8.4$ & $48.2 \pm 8.2$ & $49.3 \pm 8.6$ & $49.9 \pm 8.0$ \\
$\% F M(\%)$ & $40.4 \pm 5.6$ & $45.0 \pm 3.6$ & $39.1 \pm 6.4$ & $42.9 \pm 4.8$ \\
SMR (MJ/day) & $6.60 \pm 0.64$ & $6.91 \pm 0.96$ & $6.94 \pm 1.09$ & $7.19 \pm 1.03$ \\
BMR (MJ/day) $_{\text {BMR }}$ (MJ/day) & $7.60 \pm 1.26$ & $7.36 \pm 1.27$ & $7.41 \pm 1.44$ & $7.86 \pm 1.25$ \\
BMdj $_{\text {(M }}$ & 7.90 & $6.95 \pm 2.02$ & $7.44 \pm 1.88$ & $7.82 \pm 1.69^{*}$ \\
\hline
\end{tabular}

FFM, fat-free mass; FM, fat mass; \%FM, percentage FM; SMR, sleeping metabolic rate: BMR, basai metabolic rate; $B M R_{\text {adj, }} B M R$ adjusted for gender, FM and FFM

- Significanly different from Sibutramine group ( $p<0.05$ )

During follow-up, body weight increased significantly in the sibutramine group ( $p$ $<0.05)$, which was mainly the result of an increase in FFM $(p<0.01)$. The increase in BMI, however, was not significant, partly due to a small increase in height (1.645 compared with $1.653 \mathrm{~m}$ ) in the sibutramine group. Adjusted for initial BMI, the increase in BMI in the sibutramine group was $0.6 \mathrm{~kg} / \mathrm{m}^{2}(\mathrm{SE}=0.4)$ compared with a decrease of $0.2 \mathrm{~kg} / \mathrm{m}^{2}(\mathrm{SE}=0.4)$ in the placebo group. The \%FM tended to decrease during the follow-up period in both groups (Table 6.3).

At the beginning of the follow-up period, 3 subjects from the placebo group dropped out of the study because of lack of efficacy during the intervention period. Inclusion of these subjects at endpoint of follow-up did not affect the outcome (last observation carried forward) (Table 6.4).

BMR tended to increase in the placebo group $(p=0.057)$, while the lower mean RER did not change significantly in both groups.

\section{Safety}

In the placebo group the DBP dropped significantly during intervention ( $p<0.001$ ), while the HR tended to increase in this period $(p=0.05$ ) as well as the SBP (Table 6.6). In the sibutramine group the changes in HR and blood pressure from baseline to intervention endpoint were not significantly different. None of 
Table 6.4
Changes from baseline to endpoint intervention and follow-up in body composition for all subjects (last observation carried forward-method).

\begin{tabular}{|c|c|c|c|c|c|c|}
\hline \multirow[b]{2}{*}{ Group } & \multicolumn{2}{|c|}{ Baseline } & \multicolumn{2}{|c|}{ Intervention } & \multicolumn{2}{|c|}{ Follow-up } \\
\hline & Sibutramine & Placebo & Sibutramine & Placebo & Sibutramine & Placebo \\
\hline$n(F / M)$ & $12(6 / 6)$ & $12(5 / 7)$ & $12(6 / 6)$ & $12(5 / 7)$ & $12(6 / 6)$ & $12(5 / 7)$ \\
\hline $\begin{array}{l}\text { Height }(\mathrm{m}) \\
\text { Weight }(\mathrm{kg})\end{array}$ & $\begin{aligned} 1.63 & \pm 0.05 \\
80.8 & \pm 15.6\end{aligned}$ & $\begin{aligned} 1.63 & \pm 0.08 \\
89.2 & \pm 16.4\end{aligned}$ & $\begin{array}{l}1.65 \pm 0.06 \\
78.0 \pm 15.9 \\
28.7 \pm 4.6\end{array}$ & $\begin{array}{l}1.64 \pm 0.07 \\
87.2 \pm 15.1 \\
32.2 \pm 4.2\end{array}$ & $\begin{array}{c}1.65 \pm 0.06 \\
80.4 \pm 16.5 \\
29.3 \pm 4.6\end{array}$ & $\begin{array}{c}1.65 \pm 0.07 \\
87.3 \pm 15.3 \\
32.0 \pm 4.5\end{array}$ \\
\hline
\end{tabular}

Weight $(\mathrm{kg}) \quad 80.8 \pm 15$.

$33.3 \pm 5.0$

$28.7 \pm 4.6$

$87.2 \pm 15.1$

$29.3 \pm 4.6$

$87.3 \pm 15.3$

BMI $\left(\mathrm{kg} / \mathrm{m}^{2}\right)$

$30.1 \pm 4.5$

The changes in body composition between baseline, intervention and follow-up were not statistically significant between the sibutramine and placebo group 
the changes in HR or blood pressure were significantly different between the sibutramine or placebo group. There were no statistically or clinically significant electrocardiographical changes between both groups. During the follow-up period no significant changes in HR or blood pressure were recorded.

During the whole study period 41 adverse events were reported in the sibutramine group compared with 22 in the placebo group, however, the difference was not significant.

The most common events are summarized in Table 6.5. One subject, who was on sibutramine, dropped out prematurely because of symptoms of clinical depression. After discontinuation of study medication the symptoms disappeared. No serious adverse events were recorded.

Table 6.5

Adverse events by treatment group for intervention and follow-up period.

Sibutramine $(n=12)$ Placebo $(n=12)$

Total no. of adverse events reported Total no. of subjects reporting adverse events 22 Total no. of withdrawals due to adverse events

$\begin{array}{rr}41 & 22 \\ 12 & 9 \\ 1 & 0\end{array}$

Most commonly reported events

(no. of patients reporting)

Flu syndrome

Headache

Abdominal complaints

Agitation

Increased appetite*

Rash

Dizziness

9

Dysmenorrhea Joint problem

$\begin{array}{ll}6 & 6 \\ 2 & 3 \\ 7 & 0 \\ 3 & 1 \\ 4 & 2 \\ 2 & 0 \\ 3 & 1 \\ 3 & 0 \\ 2 & 2\end{array}$

The total number of adverse events reported was not significantly different between the sibutramine and the placebo group (Mann-Whitney $U$ test: $p=0.16$ )

* At the start of the follow-up period 
Table 6.6

Effect of sibutramine on heart rate (HR), diastolic (DBP) and systolic (SBP) blood pressure in obese adolescents.

\section{Baseline}

Intervention

Follow-up

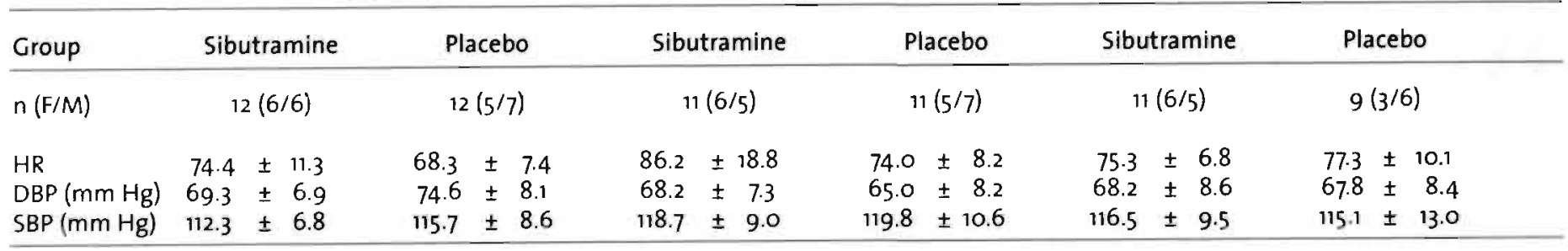

The changes in HR, DBP and SBP between the sibutramine and the placebo group were not statistically significant 


\section{Discussion}

The present study demonstrates that, in obese adolescents, sibutramine prevents the decrease in BMR that normally occurs during weight loss caused by energy restriction. BMR, adjusted for changes in body composition, decreased $8 \%$ in the placebo group, resulting in a $0.65 \mathrm{M} /$ day decrease in energy expenditure during rest. In the sibutramine treated subjects no change in BMR was seen during weight loss.

Both groups significantly lost weight during the three month intervention, based on energy restriction and physical activity. The mean initial weight of the sibutramine group was on average $8.4 \mathrm{~kg}$ lower than the initial weight of the placebo group, however, this difference was not statistically significant, because of the high variation in weight within both groups. Despite this finding, the weight loss in the sibutramine group tended to be greater. The difference between both groups in terms of mean change of BMI (the principal measure of efficacy) during intervention was $2.0 \mathrm{~kg} / \mathrm{m}^{2}$ in favour of the sibutramine treated subjects, but was not significant.

Since the present study is the first to measure the effect of sibutramine in adolescents, it is difficult to compare the results with other reports. A comparable study in adolescents (15.4 \pm 0.2 years of age), using a different central acting compound for a period of nine weeks, also reported no significant change in body composition between the treatment and placebo group (39). In adults, previous reports on sibutramine intervention did demonstrate significant weight loss for the sibutramine group compared with placebo $(17,19,40)$, sometimes after only two weeks of intervention (18). Moreover, our own center used a similar, albeit open study protocol, conducted by the same study personnel in a clinical trial with adults, which resulted in an average weight loss of $7.3 \%$ compared with $3.8 \%$ in the present study. Even if the knowledge to be supported by an anti-obesity drug might have influenced the outcome in the adult group, the difference between adults and adolescents was striking.

Although it is tempting to compare adolescents with adults, energy metabolism in adolescents is different because of the element of body growth. A practical con. sequence therefore, is that BMI should be used as a measure of efficacy, instead of weight, in order to correct for possible differences in growth rate. Indeed, both groups had a significant and comparable increase in height. The similar bone age and Tanner stage in both groups also indicate that it is unlikely that one of the groups has a lower in biological maturation compared with the other group, which, consequently, might result in a difference in growth rate between the groups. Furthermore, in the age range from 12 to 17 years the BMI curve is close to a straight line, which makes BMI a valid measure of efficacy.

From a theoretical point of view, one could speculate that, in order to protect 
growth, energy restriction in adolescents would be more likely to result in a decrease in energy expenditure than in weight loss. The decrease in BMR in the placebo group could be an indication of this metabolism lowering mechanism and may partly explain the generally high failure rate of obesity treatment in obese adolescents. This finding is in agreement with a recent study in obese adolescent girls (41). Even when adjusted for FFM and FM, the BMR remained decreased as long as the energy restriction was continued. A point of criticism raised by the authors was the use of skinfold measurements for the assessment of body composition, which may not detect certain changes in body composition, e.g. water loss. In the present study, a 4C-model was used for the measurement of body composition, allowing an adjustment of the assumptions of tissue density by separately measuring water as well as bone mass. Furthermore, in a previous study on BMR in adolescents, BMR was shown to be higher in the obese compared with the non-obese subjects. When adjusted for FFM, FM, and gender, however, BMR was comparable (unpublished observations, E.G.A.H. Van Mil, 1999), which is why BMR was adjusted for these factors in the present study. Recently, the thermogenic effect of sibutramine at rest, both in the fasted as in fed state has been demonstrated using a single dose of $30 \mathrm{mg}$ of the compound (22). Interestingly, the authors reported no significant thermogenic effects in the first 3 hours after intake, while in the present study, a significant increase in BMR was found within 45 minutes after intake of only $10 \mathrm{mg}$ of the compound. Presumably, the BMR effect is the result of a constant plasma concentration of sibutramine throughout the intervention period. On the other hand, in an intervention study in obese women using sibutramine $10,30 \mathrm{mg}$ or placebo, sibutramine did not result in a significant change in BMR, adjusted for FFM and FM. Unfortunately, the number of subjects in the present study was too small to assess the effect of gender within the sibutramine group.

The mechanism that explains the prevention of a decrease in BMR in humans with sibutramine is not yet elucidated. Studies in animals have shown that sibutramine, due to its combined re-uptake inhibition of both noradrenaline and serotonine, increases energy expenditure via the central nervous system. The central effect is mediated via $\beta_{3}$ receptors as blocking of these receptors inhibits sibutramine's effect on energy expenditure $(16,42)$. The mode of action of sibutramine is most likely to be related to the arousal component, because SMR was not influenced in the sibutramine treated subjects. Although it is accepted that the increase in heart rate and blood pressure suggests that the thermogenic properties of sibutramine in humans are likely related to a stimulatory effect on the sympathicoadrenal system, Hansen et al.(22) were not able to find consistent increases in plasma noradrenalin. Moreover, in the present study, the increase in heart rate was not significant between both study groups. In fact, the heart rate in the placebo group increased throughout the trial. Possibly, the subjects were 
nervous during the visits, which also could explain the tendency of an increased systolic blood pressure. On the other hand, the systolic blood pressure returned to normal in the follow-up period, while the heart rate tended to increase further in the placebo group. Another factor that is inconsistent with a rise in plasma noradrenalin is the increased RER that was found in the sibutramine treated adolescents. An increased RER would suggest an increase in carbohydrate oxidation, while noradrenaline is associated with increased free fatty acid oxidation. In contrast, the placebo group seemed to become more physically active during the intervention period, reflected by an increased PAL The increase in PAL, howev$\mathrm{er}$, was mainly the result of the decrease in BMR in this group, which explains why the seemingly increased physical activity did not lead to a significant change in $A D M R$. Indeed, the increase in $A D M R_{\text {adj }}$ was not significant, which is a more valid approach to assess physical activity in cases with data with non-zero intercepts (43). Sibutramine prevented the decrease in BMR, which consequently did not lead to an artificially increased activity level. Furthermore, if the activity level in the placebo group would have been higher, and the increase in ADMR in the placebo group was a trend that would have been significant in a larger study, it is difficult to explain why the weight loss in the sibutramine group tended to be higher. The most reasonable explanation is that the sibutramine group lost weight because of a decreased energy intake, whereas the placebo group was mainly successful as a result of an increased activity level. A future longer trial might shed light to the most effective strategy for intervention of adolescent obesity.

In terms of safety, the average heart rate as well as the blood pressure were well within the limits, according the second task force on blood pressure control in children (44). Four subjects treated with sibutramine had a heart rate of more than 100 beats $/$ min on 2 occasions, while in 2 of these subjects one of the visits was during the follow-up period. Furthermore, 2 subjects, one receiving sibutramine, the other placebo, had a diastolic blood pressure higher than $85 \mathrm{~mm} \mathrm{Hg}$ on 2 occasions. The highest measured systolic blood pressure was $155 \mathrm{~mm} \mathrm{Hg}$, observed in the heaviest subject of the placebo group.

The most frequently reported adverse event in the sibutramine group was 'abdominal complaints'. Six of the 7 subjects mentioned these problems during the intervention period, one during follow-up. In contrast to the symptoms reported in sibutramine treated adults, only one adolescent reported constipation, while most of the complaints could be grouped under ' abdominal discomfort'. In general, recurrent abdominal pain is experienced in $10 \%$ of healthy school children between 5 and 15 years of age, severe enough to affect daily routine (45). In the present study, the abdominal problem was considered to be mild and did not result in study withdrawal. 
Often abdominal pain in children is a reaction to emotional stress. This may explain the high rate of abdominal complaints and no reports of nervousness, which is another known complaint in treated adults. Anxiety, however, was reported in the present study and did lead to a dose reduction in one of the sibutramine treated subjects. Interestingly, none of the subjects reported dry mouth, which is one of the most frequent adverse events in adults. Four subjects treated with sibutramine mentioned increased appetite at the start of the follow-up period. Average weight increase of these subjects, however, tended to be lower than the average weight increase of the whole sibutramine group (1.1 kg compared with $2.6 \mathrm{~kg}$ )

One adverse event in the sibutramine group, 'symptoms of clinical depression', led to a withdrawal before the end of intervention. The symptoms consisted of insomnia, headache and loss of interest and loss of appetite, while the subject, a 12 year old boy, gained weight during this period. Although the boy himself reported no problems, his mother noticed that he was not 'his normal self', which is why it was decided to stop the treatment. After the termination of the study, the symptoms disappeared, as was confirmed by both mother and son.

Overall, the adverse events during this study were mild and mostly transitory throughout the intervention period, as evidenced by only one drop-out in the sibutramine treated subjects compared with 3 withdrawals in the placebo group. Each of these 3 subjects withdrew at the beginning of the follow-up period, because of lack of efficacy during previous intervention period (average weight gain: $2.1 \mathrm{~kg}$, compared with $0.2 \mathrm{~kg}$ in the whole group).

In conclusion, the present study demonstrates that sibutramine is of potential support in the treatment of obese adolescents. In a once daily dosing of $10 \mathrm{mg}$, sibutramine prevented the significant decrease in BMR that was seen in the placebo group during energy restriction. Treatment with a daily dose of $5 \mathrm{mg}$ for 2 weeks, followed by $10 \mathrm{mg}$ for 10 weeks, in combination with an energy restricted diet and physical activity, resulted in a significant weight loss, however, the change in BMI or FM was not different compared with placebo. Sibutramine probably ensures a better individual compliance towards a hypocaloric diet, which may lead to a significant higher weight loss in a longer trial.

\section{Acknowledgements}

We thank Dr. F.J.M. Feron and his colleagues from the School Health Service Department, Maastricht, the Netherlands, for their valuable cooperation in this study.

This study was sponsored by Knoll BV, Amsterdam, the Netherlands 


\section{References}

1. Gidding SS, Bao W, Srinivasan SR, Berenson GS. Effects of secular trends in obesity on coronary risk factors in children: the Bogalusa Heart Study. J Pediatr 1995; 127: 868-874.

2. Pinhas-Hamiel O, Dolan ML, Daniels SR, Standiford D, Khoury PR, Zeitler P. Increased incidence of non-insuline-dependent diabetes mellitus among children and adolescents. $J$ Pediatr 1996; 128: 608-615.

3. Daniels SR. Is there an epidemic of cardiovascular disease on the horizon? J Pediatr 1999; 134: 665-666.

4. Luepker RV, Jacobs DR, Prineas RJ, Sinaiko AR. Secular trends of blood pressure and body size in a multi-ethnic adolescent population: 1986 to 1996. J Pediatr 1999; 134: 668-674.

5. Must A, Strauss RS. Risks and consequences of childhood and adolescent obesity. Int $J$ Obes 1999; 23: S2-S11.

6. Klish WJ. Childhood obesity: pathophysiology and treatment. Acta Paediatr Jpn 1995; 37: 1-6.

7. Must A, Jacques PF, Dallal GE, Bajema CI, Dietz WH. Long-term morbidity and mortality of overweight adolescents. N Engl J Med 1992; 327: 1350-1355.

8. French SA, Jeffrey RW. Consequences of dieting to lose weight: effects on physical and mental health. Health Psychol 1994; 13: 195-212.

9. Brugman E, Meulmeester JF, Van de Wekke SS, Beuker RJ, Zaadstra BM, Radder JJ, VerlooveVanhorick PS. Dieting, weight and health in adolescents in the Netherlands. Int J Obes 1997: 21: $54-60$.

10. Barlow SE, Dietz WH. Obesity evaluation and treatment: expert committee recommendations. Pediatrics 1998; 102: E29 (available at http://www. pediatrics.org).

11. Himes JH, Dietz WH. Guidelines for overweight in adolescent preventive services: recommendations from an expert committee. The Expert Committee on Clinical Guidelines for Overweight in Adolescent Preventive Services. Am J Clin Nutr 1994; 59: 307-316.

12. Jones SP, Smith IG, Kelly F, Gray JA. Long-term weight loss with sibutramine. Int J Obes 1995: 19: 41 .

13. MCNeely W, Goa KL Sibutramine. A review of its contribution to the management of obesity. Drugs 1998; 56:1093-1124.

14. Apfelbaum $M$, Vague $P$, Ziegler $O$, Hanotin $C$, Thomas $F$, Leutegger $E$. Long-term maintenance of weight loss after a very-low-calorie diet: a randomized blinded trial of efficacy and tolerability of sibutramine. Am J Med 1999; 106: 179-184.

15. Gundlah C, Martin KF, Heal DJ, Auerbach SB. In vivo criteria to differentiate monoamine reuptake inhibitors from releasing agents: sibutramine is a reuptake inhibitor. J Pharmacol Exp Therap 1997; 283: 581-591.

16. Stock M. Sibutramine: a review of the pharmacology of a novel anti-obesity agent. Int J Obes 1997; 21 Suppl 1: $\$ 25-29$.

17. Bray GA, Ryan DH, Gordon D, Heidingsfelder S, Cerise F, Wilson K. A double-blind randomized placebo-controlled trial of sibutramine. Obes Res 1996; 4:263-270.

18. Hanotin C, Thomas F, Jones SP, Leutenegger E, Drouin P. Efficac.y and tolerability of sibutramine in obese patients: a dose-ranging study. Int J Obes 1998; 22: 32-38. 
19. Bray GA, Blackburn GL, Ferguson JM, Greenway FL, Jain AK, Mendels J, Ryan DH, Schwartz SL, Scheinbaum ML, Seaton TB. Sibutramine produces dose-related weight loss. Obes Res 1999; 7: 189-198.

20. Weintraub M, Rubio A, Golik A, Byrne L, Scheinbaum ML Sibutramine in weight control: A dose-ranging, efficacy study. Clin Pharmacol Ther 1991; 50: 330-337.

21. Rolls BJ, Shide DJ, Thorwart ML Ulbrecht JS. Sibutramine reduces food intake in non-dieting women with obesity. Obes Res 1998; 6:1-11.

22. Hansen DL, Toubro S, Stock MU, Macdonald IA, Astrup A. Thermogenic effects of sibutramine in humans. Am J Clin Nutr 1998; 68: 1180-1186.

23. Gerver WJM, De Bruin R. Paediatric Morphometrics. Wetenschappelijke uitgeverij Bunge, The Netherlands, Utrecht, 1996.

24. Group IEW. ICH Harmonised Tripartite Guideline. ICH-International conference on harmonisation of technical requirements for registration of pharmaceuticals for human use, Geneva, Switserland, 1996.

25. Tanner IM. Growth at adolescence. Blackwell Scientific Publications Ltd., London, 1962.

26. Schoeller D. The shortage of O-18 water. Obes Res 1999; 7: 519.

27. Baecke JAH, Burema J, Frijters JER. A short questionnaire for the measurement of habitual physical activity in epidemiological studies. Am J Clin Nutr 1982; 36: 936-942.

28. Sallis JF. Physical Activity Guidelines for Adolescents: Consensus Statement. The International Consensus Conference on Physical Activity Guidelines for Adolescents. 1993.

29. Epstein LH. Family-based behavioural intervention for obese children. Int J Obes 1996; 20: S14 $-521$.

30. Tanner JM, Whitehouse RH, Marshall WA, Healy MUR, Goldstein H. Assessment of skeletal maturity and prediction of adult height (TW2 Method). Academic Press, London, 1983.

31. Westerterp KR, Wouters L, Marken-Lichtenbelt WDv. The Maastricht Protocol for the Measurement of Body Composition and Energy Expenditure with Labeled Water. Obes Res 1995: 3: 49-57.

32. Fuller NJ, Jebb SA, Laskey MA, Coward WA, Elia M. Four-component model for the assessment of body composition in humans: comparison with alternative methods, and evaluation of the density and hydration of fat-free mass. Clin Sc: 1992; 82: 687-693.

33. Van Marken Lichtenbelt W, Fogelholm M. Body composition. In: MS Westerterp-Plantenga, $A B$ Steffens and A Tremblay (eds). Regulation of food intake and energy expenditure. EDRA: Milano, 1999.

34. Van Mil EGAH, Westerterp KR, Gerver WJ, Curfs LM, Schrander-Stumpel CT, Kester AD, Saris WH. Energy expenditure at rest and during sleep in children with Prader-Willi syndrome is explained by body composition. Am J Clin Nutr 2000;71: 752-756.

35. Schoffelen PFM, Westerterp KR, Saris WHM, Ten Hoor F. A dual-respiration chamber system with automated calibration. J Appl Physiol 1997; 83: 2064-2072.

36. Weir JBdV. New methods for calculating metabolic rate with special reference to protein metabolism. J Physiol 1949: 612: 511-521.

37. Colton T. Statistics in Medicine. Little, Brown and Company, Boston, 1974. 
38. Gillings $D$. The application of the principle of intention-to-treat to the analysis of clinical trials. Drug Information J 1991; 24: 411-424.

39. Grugni G, Guzzaloni G, Ardizzi A, Moro D, Morabito F. Dexfenfluramine in the treatment of juvenile obesity. Minerva Pediatr 1997; 49: 109-117.

40. Seagle HM, Bessesen $\mathrm{DH}$, Hill JO. Effects of sibutramine on resting metabolic rate and weight loss in overweight women. Obes Res 1998; 6: 115-121.

41. Tounian P, Frelut M-L, Parlier G, Abounaufal C, Aymard N, Veinberg F, Fontaine J-F, Girardet J-P. Weight loss and changes in energy metabolism in massively obese adolescents. Int J Obes 1999; 23 : $830-837$.

42. Connoley IP, Liu YL, Frost I, Reckless IP, Heal DJ, Stock MJ. Thermogenic effects of sibutramine and its metabolites. Br J Pharmacol 1999; 126: 1487-1495.

43. Ravussin E, Bogardus C. Relationship of genetics, age, and physical fitness to daily energy expenditure and fuel utilization. Am J Clin Nutr 1989; 49: 968-975.

44. Report on the Second Task Force on Blood Pressure Control in children - 1987. Pediatrics 1987; 79: 1-25.

45. Sondheimer JM, Silverman A. Gastrointestinal tract. In: WW Hay, JR Groothuis, AR Hayward and MJ Levin (eds). Current-Pediatric diagnosis and treatment. Appleton \& Lange: Norwalk, Connecticut, USA, 1995. 

Chapter 7

General discussion 



\section{General discussion}

Obesity is a condition of excess fat mass (FM) and is defined as a body mass index (BMI, $\mathrm{kg} / \mathrm{m}^{2}$ ) above the $95^{\text {th }}$ percentile for age and gender. Despite the current consensus on the diagnosis of obesity in children and adolescents, the actual measurement of FM is challenging, because, in vivo, FM cannot be measured directly. The validity of BMI as an individual measure of adiposity is discussed with regard to the findings in the present thesis.

Obesity is caused by a positive energy balance, which is the result of increased energy intake, decreased energy expenditure, or a combination of both. The research presented in this thesis focuses on whole body energy expenditure in children and adolescents, susceptible to obesity (i.e., patients with Prader-Willi syndrome (PWS)), and obese adolescents. In both groups, the major components of average daily metabolic rate (ADMR) were studied in relation to body composition. This chapter integrates and discusses the results from the different studies to come to a general conclusion about the implications of this thesis to the aetiology and treatment of obesity in the paediatric age group

\section{The diagnosis of paediatric obesity}

Obesity in adulthood is associated with increased risk of morbidity and mortality. To diagnose paediatric obesity, a measure of overweight is used, namely BMI. By choosing BMI to diagnose obesity, obesity during childhood can be tracked into adulthood. This is of importance, since the risk of becoming an obese adult is a major health implication of paediatric obesity.

Nonetheless, a measure of adiposity is needed to evaluate the effect of obesity interventions. Although BMI correlates well with measures of adiposity in children and adolescents on a population level, resulting in correlation coefficients ranging from 0.39 to $0.90(1,2,3,4,5)$, BMI has been reported not to be an appropriate measure to assess fat mass on an individual level (3). This is especially true for child ren with secondary causes of obesity, since in these cases the relationship between fat mass (FM) and fat-free mass (FFM), with regard to age and gender, is often changed. Chapters 2 to 4 have handled aspects of body composition in children and adolescents with Prader-Willi syndrome (PWS). Although several of these young subjects were not obese according to the current definition, their adiposity level ranged from 29 to $60 \%$. For example, one girl with PWS with a bone age of 16 years and BMI 27, had an adiposity level of $38 \%$, whereas her non-PWS peer who had the same bone age and BMI 28 , had an adiposity level of $32 \%$. In chapter 5 , the current definition of obesity was used to divide the pooled group of adolescents reported in the literature, into obese and nonobese. The Dutch par- 
ticipants of this study, who were the same subjects as in chapter 6 , were selected upon the $97^{\text {th }}$ percentile of the age and gender specific BMI curves of a selection of the Dutch population (6). A triceps skinfold thickness above the $97^{\text {th }}$ percentile was used as an additional selection criterion, in order to ensure that the participants were not only overweight, but also had excess adiposity. Thus, \%FM in the selected subject group ranged from 33 to 52 , where FM was measured by the fourcomponent $(4 \mathrm{C})$ model. Although the methods used in the ${ }_{4} \mathrm{C}$-model are time consuming, expensive, and laboratory based, the $4 \mathrm{C}$-model is increasingly accepted as a reference in adults (7) and recently in children as well (8). In a study using the $4 \mathrm{C}$-model as a reference model, it was demonstrated that skinfold measures, which is currently the most widely used method of assessing fatness in the paediatric practice, underestimated FM in a sample of 8 to 12 year-old children, and produced individual values that were not accurate. In situations in which the $4 \mathrm{C}$ model could not be used, deuterium dilution was the most appropriate method for assessing FM in children (8).

In conclusion, the current $95^{\text {th }}$ percentile cut-off level for BMI, although well suited as a measure for screening groups on obesity (9), is not valid as an individual measure of adiposity. Indeed, the cut-off percentile of the current BMI definition was defined as a screening measure for paediatric obesity with high specificity rather than sensitivity, thus minimizing the proportion of children and adolescents who would be incorrectly considered obese. The measurement of adiposity in children and adolescents, therefore, especially with secondary or syndromal causes of obesity, like PWS, is still limited to specialized laboratories.

\section{Energy balance and the aetiology of paediatric obesity}

Excessive accumulation of fat, as a consequence of a positive energy balance, is due to interactions between genetic factors and environmental conditions. The positive energy balance can be studied from two angles: energy intake and energy expenditure.

\section{Energy intake}

Most food intake measurements conducted in the paediatric age range, tend to underestimate the actual energy intake $(10,11)$, especially in the obese $(12)$ and in adolescents $(13,14,15)$. On the contrary, one study in children has shown that a food frequency questionnaire also can overestimate total energy intake, even up to $50 \%(16)$. Repeated 24 -hour recalls (17), dietary history and weighed diet records (14), however, provide reasonably accurate group mean values for energy intake in 
young children up to 9 years of age (EI/EE : about $105 \pm 18 \%$ ). Unfortunately, the values are not accurate on an individual basis, when compared with doubly labelled water (18).

This leaves the question of whether the under-reporting of energy intake is in fact caused by under-recording or under-eating. By assessing water loss by deuterium labelled water, Goris et al. (19) were able to measure the amount of under-recording by comparing water intake (reported and metabolic water) with water loss. Mean body mass loss was used to measure under-eating, while the total amount of under-reporting was determined using doubly labelled water (DLW) by measuring total energy expenditure. The study demonstrated that $38 \pm 15 \%$ under-reporting of food intake was explained by $25 \%$ under-recording and $14 \%$ under-eating (19). Although this study was performed in obese adults rather than children, the data shows that current measurements of energy intake are unreliable for the assessment of energy balance on an individual and probably also on a group level. In a dietary survey that was carried out on an Antarctic base, Acheson et al. (20) demonstrated that, although the measurements of food intake were underestimating the actual energy intake, one week is a valid period to measure habitual food intake for assessment of the macronutrient composition of the diet. The macronutrient composition is necessary for calculating the food quotient, thereby estimating the respiratory exchange ratio for the calculation of $\operatorname{ADMR}(20,21)$. In the present thesis, therefore, data from 7-day food questionnaires, filled out by parents and subjects, were used to determine the macronutrient composition of the diet, whereas the calculations of energy intake were not used in any further analyses.

\section{Energy expenditure}

Each of the components of ADMR can form the basis of a decreased energy expenditure and thus help to identify the basis of a positive energy balance, in order to understand the aetiology or aetiologies of obesity. In chapter 2 , we have seen that basal metabolic rate (BMR, MJ/day) as well as sleeping metabolic rate (SMR, MJ/day) is lower in children and adolescents with PWS. Furthermore, it was demonstrated that fat-free mass (FFM, kg) was lower compared with obese controls (chapter 2). The deficit in FFM seems to play a key role in understanding the lower energy expenditure in PWS. First of all, the under-development of FFM is the direct cause of the reduced resting energy expenditure in children and adolescents with PWS, thereby decreasing ADMR, as resting energy expenditure is the main component of ADMR. Secondly, ADMR is decreased further, by a decrease in physical activity related energy expenditure. Moreover, as an increase in adiposity is associated with a relative decrease in FFM as a proportion of body mass (chap- 
ter 2), physical activity related energy expenditure may decrease further in patients with PWS with increasing levels of adiposity, as indicated in chapter 4. Unfortunately, it is not possible to draw conclusions on cause and effect in the current study, as the data in these chapters were obtained cross-sectionally. This leaves unanswered the question of whether the decreased physical activity is the cause of the decreased FFM in PWS, thereby suggesting that the high adiposity in PWS is the result of a low physical activity level, or, vice versa, whether the deficit in FFM is in fact the reason for the decreased physical activity.

The relationship between adiposity and energy costs of physical activity in the general population has been discussed in several meta-analyses (22). Westerterp et al. (23) analyzed 96 existing data sets with observations on body composition and physical activity level (PAL) in adults. Their conclusion confirmed that adiposity is related to a low PAL, however, only in males. Schulz en Schoeller (24) analyzed 259 existing data sets with observations on body composition and physical activity, the latter defined as non-basal energy expenditure divided by body mass (ADMR-BMR)/kg. Again the relationship between adiposity and physical activity was highly significant, which led to the suggestion that low physical activity is a permissive factor for obesity. As discussed in chapter 3 , however, activity induced energy expenditure per kg body weight incorrectly assumes that all physical activity is weight dependent, which over-corrects for body weight in obese individuals, thus making them appear less active (25).

Prentice et al.(26) analyzed 319 sets of healthy subjects according to four categories of BMI, and demonstrated similar levels of physical activity in the three lowest BMI groups. Only in the highest BMI was there a trend that suggested a negative relationship between adiposity and physical activity. Westerterp and Goran (27) quantified physical activity by analysis of covariance, adjusting ADMR for BMR (28). This regression-based approach has been suggested as an alternative statistical technique to adjust data when non-zero intercepts are apparent (29). Their findings confirmed the inverse relationship between physical activity related energy and adiposity, which was most apparent in males.

From the combination of these approaches, based on different precepts, the unified conclusion can be drawn that, at least in males, adiposity is associated with lower levels of physical activity related energy expenditure. Despite this relationship, the literature on the causal relationship between exercise and FFM is still ambiguous. There is one major difference, however, between patients with PWS and nonsyndromal obese individuals, namely the deficit of FFM in PWS for increasing levels of adiposity (chapter 2 ). In nonsyndromal individuals a positive energy balance results in an increasing body mass and, therefore, an absolute increase in resting metabolism by a compensatory increase in FFM. Additionally, absolute non-resting energy metabolism will increase, by increased physical activity associated energy expenditure, due to higher energy costs of weight bearing 
activities, until the subject comes back into energy balance at an increased weight and adiposity level (24).

If a patient with PWS is subjected to a positive energy balance, the deficit in growth of FFM in this syndrome will lead to an increase in resting metabolic rate that is reduced compared with the increase in an nonsyndromal person. The nonresting metabolic rate will also be lower compared with nonsyndromal individuals, because the deficit in FFM in combination with an increased FM is likely to result in a reduction in weight bearing activities. The impaired increase in resting and non-resting energy expenditure further leads to a lower absolute ADMR compared with people without PWS. Consequently, the increase in energy expenditure as a compensatory effect of the increased energy intake will take place at a higher adiposity level.

Therefore, if anything, it seems more likely that physical activity is decreased as a result of increased adiposity, rather than the reverse causal relationship would exist in PWS - i.e. low levels of physical activity are the cause of increased adiposity in this syndrome. The fact that FM did not negatively influence measures of physical activity related energy expenditure in chapter 3 , seems contradictory to the statement above. In the obese control group, however, FM will most likely increase energy expenditure, as a result of increased energy costs for weight bearing activities, which might have compensated the negative effect of FM on energy costs of physical activity in children and adolescents with PWS, leading to a nonsignificant effect of FM on physical activity related energy expenditure in the analysis of both groups combined. Unfortunately, because of the small number of subjects, the analysis could not be performed for the PWS and control group separately.

Finally, the present conclusions about whole body energy expenditure in PWS do not hold necessarily for all syndromal obesities. In a study children with Down's syndrome, for example, no significant differences were found in total and nonresting energy expenditure compared with nonsyndromal controls (30). Although Down's syndrome is also characterized by with stunted growth, the deficit in the development of FFM does not seem to play an important role in the susceptibility to obesity.

In children with PWS, the study of whole body energy expenditure has identified components that form the basis of a decreased metabolic rate, thereby at least partly explaining the pathophysiological background of the susceptibility to obesity in this syndrome. Assuming that the deficit in FFM is indeed the key to the understanding of the decrease in total energy expenditure, this finding will have significant implications for the management of obesity in PWS.

Nonsyndromal obesity has been associated with decreased BMR $(31,32,33)$ as observed in the studies with PWS. Here, the decreased BMR is defined in terms of 
scatter about the regression line between metabolic rate and metabolic body size, suggesting that a person with a low adjusted metabolic rate is at greater risk of gaining weight than one with a normal or high adjusted metabolic rate. Using this approach, which is similar to the analysis of covariance used in this thesis, some studies showed reduced resting energy expenditure in $6-16$ year old and 19 year old African American girls $(34,35)$. After correction for differences in FFM and $\mathrm{FM}$, resting energy expenditure was $318 \mathrm{~kJ} /$ day lower compared with Caucasian girls (34), with no race by FFM or FM interaction. Similarly, Griffith et al. (33) reported that a low energy expenditure in girls age 5 years correlated negatively with BMI in adolescence. Other authors reported decreased energy expenditure in 3 month-old infants from overweight mothers (32). Total adjusted energy expenditure was even $20.7 \%$ lower in infants who later became overweight. These results, however, were not confirmed in a more recent study, demonstrating that adjusted resting energy expenditure was only $0.21 \mathrm{M} /$ day ( $3 \%$ of TEE) lower in children with one obese parent compared with children without obese parents (36). Moreover, not all studies in children support the concept that obesity is associated with reduced energy expenditure. In a group of children, divided into tertiles by FM, and matched for FFM, there was no significant difference in total, resting or activity related energy expenditure between the groups (37). In a similar study, measuring energy expenditure in obese and nonobese prepubertal girls, energy expenditure was not different, when adjusted for body composition (38). Even in a recent longitudinal study in children of obese and nonobese parents, none of the components of energy expenditure were related to a change in fat adjusted for FFM (39).

Therefore, despite some of these intriguing findings in at risk populations, the question of whether the development of obesity can be related to variations in the components of whole body energy expenditure is still unanswered. In response to this question, Goran et al. (39) have calculated that, theoretically, a daily imbalance of less than 0.11 MJ would be sufficient to cause $1 \mathrm{~kg}$ fat gain, adjusted for FFM, during one prepubertal year. The best test-retest precision for the measurement of average daily metabolic rate (ADMR) by doubly labelled water (DLW), however, is $8 \%$ (27), resulting in an average error in total daily energy expenditure of $0.57 \mathrm{MJ}$ and $1.09 \mathrm{MJ}$ for our groups of PWS patients and obese adolescents, respectively. Although most subjects in both groups were older than the subjects in the study of Goran et al. (39), these small amounts of daily imbalance put the level of sensitivity of the current standard in indirect calorimetry into question. Another limitation to the measurement of indirect calorimetry is that the time span in which total energy expenditure by DLW is measured (e.g. 1-3 weeks) is quite short when compared with the prolonged period for the development of childhood obesity. A possible solution could be to measure energy expenditure over a longer period. Indeed, if a small daily imbalance cannot be detected, 
it may be identified when the effect will accumulate over a prolonged period. Moreover, it is conceivable that a prolonged positive energy imbalance in obesity susceptible individuals, is in fact a failure to compensate periodic reductions in energy expenditure (40). Unfortunately, at present, no method of indirect calorimetry measures energy expenditure over a period longer than 3 weeks in a free-living situation. For the time being, therefore, ADMR measured by DLW, remains the most accurate technique to measure imbalances in whole body energy expenditure.

The current literature illustrates inconsistencies regarding the role of energy expenditure in the aetiology of primary, nonsyndromal paediatric obesity. Although methods of indirect calorimetry are reasonably accurate, research based on whole body energy expenditure may be not sensitive enough to detect small periodic changes in whole body energy expenditure. Unless an approach is developed to determine energy expenditure accurately over intervals of months or longer, instead of weeks, it is unlikely that the causes of a prolonged positive energy imbalance will be detected by only measuring ADMR.

\section{Treatment of paediatric obesity}

The primary goal of paediatric obesity treatment is regulation of body weight and fat with adequate growth and development, thereby preventing interruption of linear growth, minimizing loss of FFM, and preventing endocrine disturbances (41). The underlying mechanisms for the onset of obesity appears to be different between syndromal obesity (i.e., children and adolescents with PWS) and nonsyndromal, primary obesity. Thus, the treatment of these two distinct forms of paediatric obesity will also differ.

In the obesity treatment of patients with PWS, it is not possible to reach a physiological proportion of FM in relation to FFM, if the only focus is prevention of excess weight gain by restriction of energy intake. Since the endogenous stimulation of FFM growth is dysfunctioning, the PWS child will most likely maintain the relatively high level of adiposity, even at a low body weight. The primary goal in the treatment of PWS children, therefore, should be to increase FFM. In nonsyndromal subjects, FFM can be increased by increasing physical activity, especially by moderate to strenuous levels of exercise $(42,43)$ and resistance training $(44)$. Since normal development of FFM is deficient in PWS, it is questionable whether increased exercise training can give a substantial increase in FFM in children with this syndrome. An alternative way of increasing FFM is by exogenous administration of recombinant human growth hormone $(\mathrm{GH})$. Previous studies have shown that intervention with $\mathrm{GH}$ has led to a significant increase in $\operatorname{FFM}(45,46,47,48$, 49), a finding that has been confirmed by the positive relationship between ICF-I 
and FFM in chapter 4 . Furthermore, the concentration of serum IGF-I was also positively correlated with bone mass density in the limbs. Assuming that FFM indeed plays a key role in the altered whole body energy expenditure in PWS, as suggested above, then the increased FFM would increase ADMR, by increasing BMR as well as by facilitating physical activity. Several short-term studies have already showed a positive effect of GH on body composition in PWS. Long term trials are currently being undertaken, which will hopefully result in a better treatment regimen for young PWS patients in the future.

Although the condition of obesity during adolescence is associated with absolute increases in BMR and ADMR, increasing energy expenditure by physical activity is considered an important cornerstone in the treatment of obesity (50). Physical activity is hypothesized to protect from the development of obesity not only through an increase in energy expenditure, but also through beneficial effects on substrate metabolism $(51,52,53)$. Studies in children demonstrated that physical activity has led to maintenance of weight loss (54), a decrease in FM in relation to FFM (55), attainment of psychological well-being, and optimal bone health (56, 40). Epidemiological studies suggest that spontaneous activity decreases with age (57). Thus, preventing this decrease in physical activity will reduce sedentary behaviour, which is a major risk factor for obesity (40). Unfortunately, obesity intervention solely based on exercise is not effective (58). For example, extra physical activity had no significant effect on weight in overweight boys $(59,60)$. On the other hand, targeting weight loss by strongly reducing energy intake may compromise growth and necessary energy acquisition, and exacerbate the risk of introducing eating disorders (40). Paediatric obesity treatment should therefore combine exercise with dietary intervention. As stated by Epstein et al. (41), obesity intervention in children and adolescents should modify eating and exercise behaviours along with the factors that regulate these behaviours, so that the new, healthier behaviours persist throughout development. Treatment should therefore be focussed on small but permanent changes in this behaviour (9).

Some conditions that are associated with morbidity and mortality during childhood and adolescence, however, require more rapid weight loss (61).

In chapter 6, physical activity in combination with a moderate energy restricted diet was demonstrated to be an effective weight-reducing regimen in obese ado lescents. Although after 3 months the average decrease in $B M I$ in this group was $1.3 \mathrm{~kg} / \mathrm{m}^{2}$, it is questionable whether this rate of weight loss could have been extended for a longer period. Like in adults, obese adolescents, who are undergoing restriction in energy intake, demonstrate a compensatory decrease in BMR that may prevent further weight loss and even facilitate weight relapse. In adults, the decreased BMR is mainly caused by a decrease in FFM. In chapter 6 , however, 
obese adolescents demonstrated a decrease in BMR when adjusted for body com. position and gender. This decrease in adjusted $B M R$, which is also demonstrated in adults (62) and regarded as a metabolic opposition to reduced body weight $\left(6_{3}\right)$, is not well understood but probably caused by decreased sympathetic nervous system activity. Compounds that compensate this energy saving mechanism during weight loss (i.e. sibutramine) can be a valuable tool in enhancing the chance of success for weight reducing regimens during adolescence and adulthood. In formerly obese adults $(62,63,64)$, metabolic opposition to the reduced body weight continued, even after maintenance of reduced weight for several years, indicating that long-lasting changes in metabolic efficiency constitute an important part of the mechanism by which systems of energy homeostasis in adults oppose the maintenance of an altered body weight (65). A critical question, therefore, is whether the compensatory changes opposing weight loss and maintenance of an altered body weight, that occur in adults and adolescents also occur in children. Maffeis et al. (66) studied the effect of 6 months weight loss on BMR in obese prepubertal children and concluded that changes in BMR paralleled the changes in FFM, measured by anthropometry. This may suggest that aggressive treatment of obesity, early in childhood, may be accompanied by permanent downward resetting of the regulatory systems controlling body weight (65). Although this hypothesis needs further testing, it does indicate the importance of early obesity intervention, i.e., before puberty.

\section{Research needs in paediatric obesity}

Several problems have been encountered when studying the energy balance in the child or adolescent with regard to obesity. First of all, there is a need for a generally applicable measure of $F M$ that can be obtained in a variety of clinical and field settings, in order to evaluate the management of obese children and adolescents. Now that the $4 \mathrm{C}$-model increasingly is regarded as a reference for estimation of FM (40), research should be aiming at finding an easy to use, relatively inexpensive, but valid measurement of adiposity. Some studies have presented bioelectrical impedance as an alternative technique for the assessment of body composition in children and adolescents (40), as well as children with PWS (67). The technique is based on the measurement of electrical resistance in the body to a small imperceptible current (18) or on a series of measurements at different frequencies (bio-impedance spectrometry). A major limitation, however, is that equations are needed to convert measurements of impedance to body composition, that should be validated for specific populations (68). Although the accuracy and usefulness are still under debate, the technique holds promise for the future (40). Ideally, the broader applicability of such a measure in the daily paediatric practice 
will result in a large body of data on adiposity in children and adolescents that, in the long term, can be associated with morbidity and mortality outcome variables. Consequently, appropriate adiposity cut-off levels will be determined, in order to develop obesity intervention protocols to approach at risk groups.

To study the role of decreased energy expenditure in the development of obesity in high-risk groups, longitudinal data are needed. Physical activity associated energy expenditure plays a key role in energy balance, as the most variable and the best influential component of daily energy expenditure. Valid longitudinal assessment of physical activity in the paediatric age group, therefore, will give insight to the periodic fluctuation in energy expenditure. Furthermore, several studies $(69,70,71)$ have suggested that the time devoted to physical activity may have an additional role on energy regulation, supporting the notion that qualitative assessment of physical activity would be of additional importance in the study of development of paediatric obesity (40). Indeed, a limitation to the measurement of physical activity associated energy expenditure is that it does neither provide any qualitative information on physical activity pattern, nor does it differentiate between different types of physical activity. Therefore, the ideal measure of physical activity should provide quantitative information about type, intensity, duration and frequency of the activity performed (18). A promising technique that does allow measurements in free field is movement registration by a tri-axial accelerometer (72). The advantage of movement registration over energy expenditure measurements is that the first is capable of measuring activity patterns, addressing the question of whether time devoted to physical activity can be of additional importance in the susceptibility to obesity. Before studies can be conducted, however, this technique needs to be validated for different subgroups with respect to age, race an gender. In the search for the most appropriate method, average daily metabolic rate, in combination with resting energy expenditure can be used as a standard reference, to verify the combined energy costs of physical activity derived by other techniques. Finally, with regard to the study of energy metabolism, there is a need for valid measurements of energy intake. In the situation of energy balance, energy intake can be estimated well by measurements of energy expenditure (e.g. doubly labelled water), however, in situations when body weight is not stable (i.e. weight loss), it is unclear to what extend metabolic mechanisms may influence energy expenditure and how the composition of FFM might alter total energy expenditure, making it impossible to assess energy intake. Furthermore, the doubly labelled water validation approach does not provide any validity of macronutrient intake. Measurement of habitual food intake, therefore, remains one of the most challenging aspects of human obesity research (18), especially since development of new techniques for dietary intake are hindered by the inability to cross-validate instruments with any known standard technique.

Until energy intake can be measured accurately, the assessment of energy balance 
will not be of much use when studying the aetiology of obesity. Even in the situation of energy balance, the variation of the activity component of ADMR is too large to detect daily imbalances. Furthermore, as discussed earlier, the precision of $A D M R$ still is relatively large compared with the small imbalances to be detected. Methods with a lower (around 2-3\%) test-retest precision are BMR by ventilated hood, or, respiration chamber and body composition by labelled water $(27,40)$. Unfortunately, these techniques cannot measure energy expenditure in a free-living situation and are not suitable to calculate the energy balance. On the other hand, resting energy expenditure analyzed by analysis of covariance using gender, maturation and body composition, allows the measurement of metabolic predictors for body weight gain, thereby helping to identify new pathways involved in the pathophysiology of obesity.

Although we know that obesity is a complex phenotype with genetic, environmental and developmental determinants, the limitations in measuring energy intake and energy expenditure over time have prevented a complete understanding of the pathophysiology of the positive energy balance in the aetiology of paediatric obesity. Furthermore, the increasing prevalence of obesity in the western world illustrates the incapacity of treating obesity with maintenance of weight loss regardless of age.

We have seen in the last chapter of this thesis that weight reduction during adolescence is at least as difficult as during adulthood. Therefore, as stated by the expert consultation on obesity, concentrating on children and adults who have a high BMI and associated health problems will not stem the escalating numbers of people entering the medically defined categories of ill health (73). It is thus essential to develop new preventive public health strategies, which affect the entire society. Research is needed to develop strategies for modifying the environment to increase physical activity and to discourage sedentary behaviour in children and adolescents in general.

An approach that has proven its success was developed by Epstein et al. $(50,54)$, and uses behavioural modification techniques to modify diet and physical activity in children and adolescents, which is a strategy not substantially different from that used often in adults. Especially with respect to physical activity, this so-called 'lifestyle' exercise has proved successful in maintaining weight loss for more than 10 years. Since it is clear that physical activity will have a crucial role in the life-long prevention of obesity (74), the biggest challenge is to incorporate spontaneous physical activity, as much as healthy eating, back into the daily lives of children again. Schools, families, and communities must provide an atmosphere that encourages a physically active existence in combination with sound nutritional practices, in order to instill a general and permanent appreciation for this obesity preventing behaviour. 


\section{Conclusions}

Daily energy expenditure is decreased in children and adolescents with PraderWilli syndrome (PWS) compared with obese controls

The decreased energy expenditure in PWS is explained by a decreased basal metabolic rate as well as a decreased physical activity related energy expenditure

The decreased basal metabolic rate in PWS is explained by a deficit in fat-free mass (FFM), probably caused by endocrine growth dysfunction

Physical activity related energy expenditure in PWS is inversely related to fat mass (FM), corrected for height (FMI, $\mathrm{kg} / \mathrm{m}^{2}$ )

The extracellular water compartment in children and adolescents with PWS is enlarged even when adjusted for FMI and bone age

Daily energy expenditure is increased in obese adolescents compared with nonobese peers and is caused by increased basal metabolic rate

Basal metabolic rate in obese adolescents is increased, even when adjusted for FFM, age and gender

Basal metabolic rate in male adolescents is increased, even when adjusted for body composition and age

Physical activity related energy expenditure in obese adolescents is comparable to nonobese adolescents, when adjusted for metabolic body size

During adolescence, physical activity related energy expenditure increases with age

Sibutramine compensates for an energy intake restriction induced decrease in basal metabolic rate in obese adolescents 


\section{References}

1. Kileen J, Vanderburg D, Harlan WR. Applications of weight-height ratio and body indices to juvenile population: the National Health Examination Survey data. J Chron Dis 1978: 31: 529537.

2. Deurenberg P, Weststrate JA, Seidell JC. Body mass index as a measure of body fatness: ageand sex-specific prediction formulas. Br J Nutr 1991; 65: 105-114.

3. Daniels SR, Khoury PR, Morrison JA. The utility of body mass index as a measure of body fatness in children and adolescents: differences by race and gender. Pediatrics 1997; 99 : 804807.

4. Dietz WH, Robinson TN. Use of body mass index (BMI) as a measure of overweight in children and adolescents. J Pediatr 1998; 132: 191-193.

5. Pietrobelli A, Faith MS, Allison DB, Gallagher D, Chiumello $G$, Heymsfield SB. Body mass index as a measure of adiposity among children and adolescents: a validation study. $J$ Pediatr 1998; 132: 204-210.

6. Gerver WJM, De Bruin R. Paediatric Morphometrics. Wetenschappelijke uitgevery Bunge, The Netherlands, Utrecht, 1996.

7. Fuller NJ, Jebb SA, Laskey MA, Coward WA, Elia M. Four-component model for the assessment of body composition in humans: comparison with alternative methods, and evaluation of the density and hydration of fat-free mass. Clin Sci 1992; 82: 687-693.

8. Wells JCK, Fuller NJ, Dewit O, Fewtrell MS, Elia M, Cole TJ. Four-component model of body composition in children: density and hydration of fat-free mass and comparison with simpler models. Am J Clin Nutr 1999; 69: 904-912.

9. Barlow SE, Dietz WH. Obesity evaluation and treatment: expert committee recommenda-

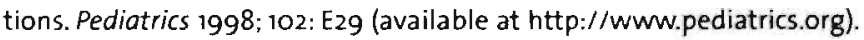

10. Livingstone MBE, Prentice AM, Strain JJ. Accuracy of weighed dietary records in studies of diet and health. Br Med J 1990; 300: 708-72.

11. Schoeller D, Bandini LG, Dietz WH. Inaccuracies in self-reported intake identified by comparison with the doubly labeled water method. Can J Physiol Pharmacol 1990; 68: 941-949.

12. Maffeis $C$, Schutz $Y$, Zaffanello M, Piccoli R, Pinelli L. Elevated energy expenditure and reduced energy intake in obese prepubertal children: paradox of poor dietary reliability in obesity? J Pediatr 1994: 124: 348-354.

13. Bandini LG, Schoeller DA, Dietz WH. Energy Expenditure in Obese and Nonobese adolescents. Pediatr Res 1990; 27: 198-203.

14. Livingstone MBE, Prentice AM, Coward WA, Strain JJ, Black AE, Davies PSW, Stewart CM, McKenna PG, Whitehead RG. Validation of estimates of energy intake by weighed dietary record and diet history in children and adolescents. Am J Clin Nutr 1992; 56: 29-35.

15. Bandini LG, Vu D, Must A, Cyr H, Goldberg A, Dietz WH. Comparison of high-calorie, lownutrient-dense-food consumption among obese and non-obese adolescents. Obes Res 1999; $7: 438-443$. 
16. Kaskoun MC, Johnson RK, Goran MI. Comparison of energy intake by semiquantitative foodfrequency questionnaire with total energy expenditure by the doubly labeled water method in young children. Am J Clin Nutr 1994; 60: 43-47.

17. Johnson RK, Driscoll P, Goran MI. Cross-calibration of energy intake by 24 hour recall against total energy expenditure by doubly labeled water in young children. J Am Diet AssoC 1996; 96: 1140-1144.

18. Goran MI. Measurement issues related to studies of childhood obesity: assessment of body composition, body fat distribution, physical activity, and food intake. Pediatrics 1998; 101: 505518.

19. Goris AHC, Westerterp-Plantenga MS, Westerterp KR. Underreporting of food intake in obese men is explained by undereating and underrecording, and characterized by a selective underreporting of fat intake. Am J Clin Nutr 2000; in press.

20. Acheson KJ, Campbell IT, Edholm OG, Miller DS, Stock M. The measurement of daily energy expenditure-an evaluation of some techniques. Am J Clin Nutr 1980; 33: 1155-1164.

21. Black AE, Prentice AM, Coward WA. Use of food quotients to predict respiratory quotients for the doubly-labelled water method of measuring energy expenditure. Human Nutrition: Clinical Nutrition 1986; 40C: 381-391.

22. Westerterp KR. Obesity and physical activity. Int J Obes 1999; 23: 59-64

23. Westerterp KR, Meijer GAL, Kester ADM, Wouters L, Ten Hoor F. Fat-free mass as a function of fat mass and habitual activity level. Int I Sport Med 1992; 13: 163-166.

24. Schultz LO, Schoeller DA. A compilation of total daily energy expenditure and body weights in healthy adults. Am J Clin Nutr 1994; 60: 676-681.

25. Prentice AM, Goldberg GR, Murgatroyd PR, Cole TJ. Physical activity and obesity: problems in correcting expenditure for body size. Int J Obes 1996; 20: 688-691.

26. Prentice AM, Black AE, Coward WA, Cole TJ. Energy expenditure in overweight and obese adults in affluent societies: an analysis of 319 doubly-labeled water measurements. Eur J Clin Nutr 1996; 50: 93-97.

27. Westerterp KR, Goran MI. Relationship between physical activity related energy expenditure and body composition: a gender difference. Int J Obes 1997; 21: 184-188.

28. Carpenter WH, PoehIman ET, O'Connell M, Goran MI. Influence of body composition and resting metabolic rate on variation in total energy expenditure: a meta-analysis. Am J Clin Nutr 1995; 61: 4-10.

29. Goran MI. Variation of total energy expenditure in humans. Obes Res 1995; 3: 59-66.

30. Luke A, Roizen NJ, Sutton M. Schoeller DA. Energy expenditure in children with Down syndrome: correcting metabolic rate for movement. J Pediatr 1994: 125: 829-838.

31. Ravussin E, Lillioja S, Knowler WC, Christin PHL, Freymont D, Abott WGH, Boyce V, Howard BV, Bogardus C. Reduced rate of energy expenditure as a risk factor for body-weight gain. N Engl I Med 1988; 318: 467-472.

32. Roberts SB, Savage J, Coward WA, Chew B, Lucas A. Energy expenditure and intake in infants born to lean and overweight mothers. N Engl J Med 1988; 318:461-466.

33. Griffiths M, Payne PR, Stunkard AJ, Rivers JPW, Cox M. Metabolic rate and physical development in children at risk of obesity. Lancet $1990 ; 336: 76-78$. 
34. Morrison JA, Alfaro MP, Khoury P, Thornton BB, Daniels SR. Determinants of resting energy expenditure in young black and young white girls. J Pediatr 1996: 5: 637-642.

35. Weyer C, Snitker S, Rising R, Bogardus C, Ravussin E. Determinants of energy expenditure and fuel utilization in man: effects of body composition, age, sex, ethnicity and glucose tolerance in 916 subjects. Int J Obes 1999; 23: 715-722.

36. Goran MI, Carpenter WH, McGloin A, Johnson R, Hardin IM, Weinsier RL. Energy expenditure in children of lean and obese parents. Am J Physiol 1995; 0054:

37. DeLany JP, Harsha DW, Kime J, Kumler J, Melancon L, Bray GA. Energy expenditure in lean and obese pre-pubertal children. Obes Res 1995; S67-S72.

38. Treuth MS, Figueroa-Colon R, Hunter GR, Wensier RL, Butte NF, Goran MI. Energy expenditure and physical fitness in overweight vs non-overweight prepubertal girls. Int J Obes 1998; 22: 440-447.

39. Goran MI, Shewchuk R, Gower BA, Nagy TR, Carpenter WH, Johnson RK. Longitudinal changes in fatness in white children: no effect of childhood energy expenditure. Am J Clin Nutr 1998; 67: 309-316.

40. Westerterp-Plantenga MS, Steffens AB, Tremblay A. Regulation of food intake and energy expenditure. Edra, Milano, 1999.

41. Epstein LH, Myers MD, Raynor HA, Saelens MA. Treatment of pediatric obesity. Pediatrics 1998; 101: 554-570.

42. Bar-Or O. Pediatric sports medicine for the practioner. Springer-Verlag, New York, 1983.

43. Poehlman ET. A review: exercise and its influence on resting energy expenditure in man. Med Sci Sports Exer 1989; 21: 515-525

44. Van Etten LMLA. Weight training: implications for energy metabolism. Department of Human Biology. Maastricht, Maastricht University, 1997.

45. Lee PD, Hwu K, Henson H, Brown BT, Bricker JT, LeBlanc AD, Fiorotto ML Greenberg F. Klish WJ. Body Composition Studies in Prader-Willi Syndrome: Effects of Growth Hormone Therapy. In: (eds). Human Body Composition. Plenum Press, NY and London: Houston, Texas, 1993.

46. Eiholzer $U$, Weber $R$, Stutz K, Steinert $H$. Effect of 6 months of growth hormone treatment in young children with Prader-Willi syndrome. Acta Paediatr Supp/ 1997; 423: 66-68.

47. Lindgren AC, Hagenäs L, Müller J, Blichfeldt $S$, Rosenborg M, Brismar T, Ritzen EM. Effect of growth hormone treatment on growth and body composition in Prader-Willi syndrome: a preliminary report. Acta Paediatr Supp/ 1997; 423: 60-62.

48. Davies PSW, Evans S, Broomhead S, Clough H, Day JME, Laidlaw A, Barnes ND. Effect of growth hormone on height, weight, and body composition in Prader-Willi syndrome. Arch Dis Child 1998; 78: 474-476.

49. Lindgren AC, Hagenas L, Muller J, Blichfeldt S, Rosenborg M, Brismar T, Ritzen EM. Growth hormone treatment of children with Prader-Willi syndrome affects linear growth and body composition favourably. Acta Paediatr 1998; 87: 28-31.

50. Epstein LH, Wing RR, Koeske R, Valoski A. Long-term effects of family-based treatment of childhood obesity. J Consult Clin Psychol 1987; 55: 91-95.

51. Almèras N, Lavallée N, Després J-P, Bouchard C, Tremblay A. Exercise and energy intake: effect of substrate oxidation. Physiol Behav 1995; 57: 995-1000. 
52. Hill JO, Peters JC. Environmental contributions to the obesity epidemic. Science 1998; 280 : 1371-1374.

53. Hunter GR, Weinsier RL Bamman MM, Larson DE. A role for high intensity exercise on energy balance and weight control. Int J Obes 1998; 22:489-493.

54. Epstein LH, Valoski A, Wing RR, McCurley J. Ten-year outcomes of behavioral family-based treatment for childhood obesity [see comments]. Health Psychol 1994; 13: 373-383.

55. Treuth MS, Hunter GR, Pichon C, Figueroa-Colon R, Goran MI. Strength, fitness, and energy expenditure after resistance training in obese prepubertal girls. Med Sci Sports Exerc 1998; 30: $1130-1136$.

56. Ulrich C, Georgiou C, Snow-Harter C, Gillis D. Bone mineral density in mother-daughter pairs: relation to lifetime exercise, lifetime milk consumption, and calcium supplements. Am J Clin Nutr 1996; 63: 72-79.

57. Sallis JF, Simons MB, Stone EJ, Corbin CB, Epstein LH, Faucette N, lannotti RJ, Killen JD, Klesges $R C$, Petray CK, et al. Determinants of physical activity and interventions in youth. Med SCi Sports Exerc 1992.

58. Seltzer CD, Mayer J. An effective weight control program in a public school system. Am J Public Health 1970; 60: 679-689.

59. Blomquist B, Borjeson $M$, Larsson $Y$, Persson B, Sterky $G$. The effect of physical activity on the body measurements and work capacity of overweight boys. Acta Paediatr Scand 1965: 54 : 566-572.

60. Blaak EE, Westerterp KR, Bar OO, Wouters $\sqcup$, Saris WH. Total energy expenditure and spontaneous activity in relation to training in obese boys. Am J Clin Nutr 1992; 55: $777-782$.

61. Dietz WH. Health consequences of obesity in youth: childhood predictors of adult disease. Pediatrics 1998; 101: S518-S525.

62. Van Gemert WG, Westerterp KR, Greve JWM, Soeters PB. Reduction of sleeping metabolic rate after vertical banded gastroplasty. Int J Obes 1998; 22: 343-348.

63. Leibel RL, Rosenbaum $M$, Hirsch J. Changes in energy expenditure resulting from altered body weight. N Engl J Med 1995; 332: 621-628.

64. Leibel R, Hirsch J. Diminished energy requirements in reduced-obese patients. Metabolism 1984; 33: 164-170.

65. Rosenbaum $M$, Leibel $R$. The physiology of body weight regulation: Relevance to the etiology of obesity in children. Pediatrics 1998; 101: 525-539.

66. Maffeis $C$, Schutz $Y$, Pinelli L. Effect of weight loss on resting energy expenditure in obese prepubertal children. Int J Obes 1992; 16: 41-47.

67. Davies PSW, Joughin C. Assessment of Body Composition in the Prader-Willi Syndrome Using Bioelectrical Impedance. Am J Med Cenet 1992; 44: 75-78.

68. Rombeau JL, Yanovski SE, Van Hubbard S, Heymsfield SB, Lukaski HC. Bioelecrical impedance analysis. Consensus Conference NIH - Bethesda 1994. Am J Clin Nutr 1996; 64:

69. Craig SB, Bandini LC, Lichtenstein AH, Schaefer EJ, Dietz WH. The impact of physical activity on lipids, lipoproteins and blood pressure in preadolescent girls. Pediatrics 1996; 98: 389-395.

70. Goran MI, Hunter $G$, Johnson R. Physical activity related energy expenditure and fat mass in young children. Int J Obes 1997; 21: 171-178. 
77. Maffeis C, Zaffanello M, Schultz Y. Relationship between physical activity and adiposity in prepubertal boys. J Pediatr 1997: 131: 288-292.

72. Bouten CVC. Assessment of daily physical activity by registration of body movement. Technical University Eindhoven, 1995.

73. World Health Organisation. Obesity, Preventing and Managing the Global Epidemic. Report of a WHO consultation on Obesity. WHO, Geneva, 1998.

74. Epstein LH, Valoski AM, Vara LS, MCCurley J, Wisniewski L, Kalarchian MA, Klein KR, Shrager LR. Effects of decreasing sedentary behavior and increasing activity on weight change in obese children. Health Psychol 1995; 14: 109-115. 


\section{Summary}

The prevalence of paediatric obesity is increasing world-wide and is now considered an epidemic in many industrialized countries. The exact consequences on public health are not clear. The current opinion is that a large number of today's obese children and adolescents will remain obese during adulthood, which is associated with an increased risk for cardiovascular diseases and diabetes mellitus, leading to increased morbidity and mortality. Additionally, even a young child, if severely obese, can suffer serious morbidity.

The aetiology of paediatric obesity is based on the interaction between genetic predisposition with regard to the energetic efficiency to store body fat, and an environment that is permissive to the expression of that genetic tendency. Although the relative influence of each of these factors is unclear and may vary at certain periods during growth, together they result in a prolonged positive energy balance. When measuring energy balance, energy intake is difficult to assess because most available methods rely on self report. Energy expenditure, however, can be validly measured by indirect calorimetry.

A group of children with high susceptibility to the development of obesity, are children with the Prader-Willi syndrome (PWS). In addition to an almost insatiable appetite, the obesity of children with PWS has been associated with a decreased basal energy metabolism. The pathophysiological background of impaired metabolism, as well as the main features of PWS (mental retardation, hypotonia in early childhood, hypogonadism and short stature) are still poorly understood but are most likely based on dysfunction of various hypothalamic centres.

In this thesis, energy expenditure and body composition were measured in a group of 17 children and adolescents with PWS, and were compared with 17 nonsyndromal obese controls, matched for gender and bone age. In chapter 2 , it was demonstrated that energy expenditure at rest as well as during sleep is $21 \%$ and $23 \%$ lower in children with PWS compared with controls, respectively. The low basal metabolic rate was explained by a low fat-free mass, in absolute terms as well as when adjusted for height and, therefore, could not be the result of an impaired energy metabolism at cellular level. Furthermore, it was shown that fatfree mass was reduced in relation to fat mass in this syndrome. The fat-free mass contains the metabolically active tissues in the body, such as organs and muscle. The reduced growth of the fat-free tissues in children with PWS may well be related to an abnormality of the hypothalamic-pituitary-gonadal axis that has been suggested in the literature. Together with a possible functional growth hormone $(\mathrm{GH})$ deficiency, the decreased levels of gonadotropins might take away the natural urge to be lively and playful.

Physical activity induced energy expenditure is a major component of average 
daily metabolic rate, along with basal metabolic rate. Although physical activity induced energy expenditure can be validly measured by combining measurements of average daily metabolic rate and basal metabolic rate, the best way to correct for body weight is still debated. In chapter 3 , various methods for correcting differences in body size were discussed, based on the results obtained in the PWS and control groups. All methods support the same conclusion, namely that activity related energy expenditure is lower (up to $38 \%$ ) in children with PWS compared with obese controls. Adjusted for biological maturation, gender and body composition, the difference between groups was $18 \%$.

Not only the reduced fat-free mass but also the pattern of adiposity in children with PWS, in combination with an impaired bone mineral content, especially in the limbs, have a close resemblance to the body composition present in children with $\mathrm{GH}$ deficiency. Since not all children with PWS develop a diagnosed $\mathrm{GH}$ deficiency, it has been suggested in the literature that PWS might be associated with a functional $\mathrm{CH}$ deficiency. By using serum Insulin-like Growth Factor-I as a measure of $\mathrm{GH}$ function, fat-free mass as well as bone mineral density of the limbs, were positively related to GH function in children with PWS (chapter 4).

Furthermore, in contrast to nonsyndromal obese children, adiposity was inversely related to physical activity in these children. Finally, an increased extracellular-tointracellular water ratio was found, even when corrected for the higher adiposity and lower biological maturation, which are characteristic of children with PWS.

It is still debated whether the development of obesity during adolescence (one of the critical periods in the development of paediatric obesity) is associated with a reduction in energy expenditure. In chapter 5 , energy expenditure and body composition data of a group of nonsyndromal obese adolescents of the Maastricht region were combined with individual data of obese and nonobese adolescents reported in the literature. Contrary to children with PWS, nonsyndromal obese adolescents showed a $15 \%$ increase in basal metabolic rate compared with their nonobese peers, even when corrected for age, gender and fat-free mass differences. It was speculated that the increased basal metabolic rate in the obese state was not caused by a metabolically more active fat mass, but by a shift in the composition of the fat-free mass towards a relatively higher contribution of internal organ tissues compared with muscle mass. This change in fat-free mass composition would then lead to a higher basal energy expenditure per unit fat-free mass. Furthermore, basal metabolic rate was $12 \%$ higher in adolescent boys compared with adolescent girls, independent of body composition and age. Activity related energy expenditure, however, when appropriately adjusted for body size, was similar in both groups. Furthermore, the Food and Agriculture Organisation of the United Nations, the World Health Organisation, and United Nations University 
(FAO/WHO/UNU)-equations for prediction of BMR overestimated energy expenditure in obese male adolescents by $8 \%$, whereas the adult FAO/WHO/UNU-equa tions, based on weight, did predict the measured basal energy expenditure correctly. For obese adolescents, therefore, the adult FAO/WHO/UNU-equations were recommended.

Treatment of paediatric obesity is primarily based on dietary advice and stimulation of physical activity. Pharmacological therapy is only recommended when complications of obesity require rapid weight loss. The increasing prevalence of paediatric obesity and the disappointing results in the traditional treatment of obesity, however, urges the need for new treatment strategies. In chapter 6 of this thesis, the effect of sibutramine on body composition and energy expenditure, in combination with an energy restricted diet and exercise programme, was evaluated in a double blind, placebo-controlled, randomised trial. During an intervention period of three months, sibutramine, which is a recently developed satiety enhancing drug, prevented the decrease in basal metabolic rate, that occurred in the placebo group. Furthermore, sibutramine probably ensured a better individual compliance towards a hypocaloric diet.

In conclusion, the studies described in the present thesis demonstrate that children and adolescents with PWS have a low average daily metabolic rate, based on an impaired growth of fat-free mass, leading to a low basal metabolic rate as well as a low physical activity related energy expenditure. These altered components in energy expenditure may be related to an impaired function of various hypothalamic centres. The basal metabolic rate in nonsyndromal obese adolescents is, however, increased compared with their nonobese peers, which is not only caused by an increase in fat-free mass, but also, most likely, by a shift in fat-free tissue composition. During energy intake restriction, however, basal metabolic rate decreases in obese adolescents, impairing the effect of the obesity intervention. Sibutramine can prevent the decrease in basal metabolic rate and, therefore, can be of potential support in the treatment of obese adolescents. Nonetheless, drug therapy in the management of paediatric obesity should only be used if conventional treatment has failed. 


\section{Samenvatting van het proefschrift 'Energiemetabolisme in kinderobesitas'}

De huidige toename in de wereldwijde prevalentie van kinderobesitas geeft aan dat er sprake is van een epidemie. De exacte gevolgen voor de volksgezondheid zijn nog onduidelijk. De verwachting is dat een groot aantal van de hedendaagse obese kinderen en adolescenten obees zal blijven op volwassen leeftijd, hetgeen is geassocieerd met een toegenomen risico voor hart- en vaatziekten en diabetes mellitus. Dit zal een toename van de morbiditeit en mortaliteit tot gevolg hebben. Tevens is bekend dat extreme obesitas, zelfs bij jonge kinderen, tot ernstige morbiditeit kan leiden.

De etiologie van kinderobesitas vindt zijn basis in de interactie tussen enerzijds een genetische predispositie met betrekking tot de energetische efficiëntie om lichaamsvet op te slaan, en anderzijds een omgeving die de expressie van de genetische predispositie toestaat. De relatieve invloed van elk van deze processen is nog niet opgehelderd en lijkt beïnvloed te worden door bepaalde perioden tijdens de groei. Het uiteindelijke resultaat is een langdurige positieve energiebalans. Een positieve energiebalans kan het gevolg zijn van een verhoogde energieinname of een verlaagd energiegebruik. Een verhoogde energie-inname is moeilijk te bepalen omdat de meest gebruikte methoden gebaseerd zijn op zelfrapportage. Het energiegebruik echter, kan met behulp van indirecte calorimetrie wel valide worden gemeten.

Een voorbeeld van kinderen met een verhoogde predispositie voor het ontwikkelen van obesitas zijn kinderen met het Prader-Willi syndroom (PWS). Naast een vrijwel onstilbare honger, is obesitas in dit syndroom geassocieerd met een verlaagd basaal energiemetabolisme. De pathofysiologie van het verlaagd metabolisme, evenals van de hoofdkenmerken van PWS (mentale retardatie, hypotonie op vroege kinderleeftijd, hypogonadisme en klein gestalte), is nog onduidelijk, maar hoogstwaarschijnlijk gebaseerd op dysfunctioneren van hypothalame centra. In dit proefschrift werden energiegebruik en lichaamssamenstelling gemeten in een groep van 17 kinderen en adolescenten met PWS en vergeleken met 17 nietsyndromale obese controle kinderen van hetzelfde geslacht en met dezelfde botleeftijd. In hoofdstuk 2 werd aangetoond dat het energiegebruik in rust en tijdens de slaap respectievelijk 21 en $23 \%$ lager is bij kinderen met PWS in vergelijking met obese controles. Het lage basaal energiegebruik kon worden verklaard door een lagere vetvrije massa bij deze kinderen, zowel in absolute zin als gecorrigeerd voor lengte, en bleek daarmee niet het gevolg te zijn van een afgenomen energiemetabolisme op cellulair niveau. Tevens werd bij kinderen met PWS aangetoond dat de vetvrije massa lager was in relatie tot vetmassa.

De vetvrije massa omvat de metabool actieve weefsels van het lichaam, zoals 
organen en spieren. Volgens de huidige wetenschappelijke literatuur is de verminderde groei van vetvrije weefsels bij kinderen met PWS waarschijnlijk gerelateerd aan afwijkingen in de hypothalamo-hypofysaire-gonadale as. Het is denkbaar dat verlaagde gonadotrofiene spiegels, mogelijk in combinatie met een functionele groeihormoon $(\mathrm{CH})$ deficiëntie, een remmend effect hebben op de spontane lichamelijke activiteit.

Het energiegebruik voor lichamelijke activiteit behoort, samen met het basaal energiegebruik, tot de hoofdbestanddelen van het totale dagelijkse energiegebruik. Lichamelijke activiteit kan worden bepaald door een meting van het totaal dagelijkse energiegebruik te combineren met een meting van het basaal energiegebruik. Er bestaat echter nog geen consensus over hoe lichamelijke activiteit gecorrigeerd dient te worden voor lichaamsgewicht. In hoofdstuk 3 worden de gangbare methoden om te corrigeren voor lichaamsgewicht behandeld, gebaseerd op waarnemingen bij kinderen met PWS en controles. Alle methoden komen tot dezelfde conclusie, namelijk dat het energiegebruik voor lichamelijke activiteit lager is (tot $38 \%$ ) bij kinderen met PWS in vergelijking met obese controles. Na correctie voor de mogelijke effecten van biologische rijping, geslacht en lichaamssamenstelling, was het verschil tussen beide groepen $18 \%$.

Niet alleen de lage vetvrije massa, maar ook de vetverdeling bij kinderen met PWS, samen met de afgenomen hoeveelheid botmineralen, met name in de ledematen, hebben een sterke gelijkenis met de lichaamssamenstelling van kinderen met $\mathrm{GH}$ deficiëntie. Aangezien niet alle kinderen met PWS een gediagnostiseerde $\mathrm{GH}$ deficiëntie hebben, wordt PWS ook wel geassocieerd met een functionele GH deficiëntie. In hoofdstuk $\mathbf{4}$ werd gevonden dat zowel de vetvrije massa als de botdichtheid positief gecorreleerd is aan GH functie bij kinderen met PWS, waarbij $\mathrm{GH}$ functie werd gemeten aan de hand van de concentratie somatomedine-C (IGF-I) in het serum. In tegenstelling tot niet-syndromaal obese kinderen, bleek de vetmassa bij deze kinderen negatief gecorreleerd met lichamelijke activiteit. Tenslotte werd een toegenomen ratio extracellulair-intracellulair water aangetoond, zelfs na correctie voor de hogere mate van adipositas en lagere biologische rijping, welke karakteristiek zijn voor kinderen met PWS.

Over het ontstaan van obesitas tijdens de adolescentie (één van de kritische perioden in de ontwikkeling van kinderobesitas) en de relatie met verlaagd energiegebruik is nog veel onduidelijk. In hoofdstuk 5 werden de energiegebruik en lichaamssamenstelling gegevens van een groep van 24 niet-syndromaal obese adolescenten uit de regio Maastricht gecombineerd met individuele gegevens van obese en niet-obese adolescenten uit de literatuur. In tegenstelling tot kinderen met PWS, hadden de obese adolescenten vergeleken met hun niet-obese leeftijdsgenoten 
een $15 \%$ hoger basaal energiegebruik, zelfs nadat gecorrigeerd was voor verschillen in leeftijd, geslacht en vetvrije massa. Waarschijnlijk is het verhoogde basaal energiegebruik niet het gevolg van een metabool actievere vetmassa, maar van een verschuiving in de samenstelling van de vetvrije massa naar een relatief hogere bijdrage van weefsels van interne organen (zoals de lever) ten koste van spierweefsel. Deze verandering in de vetvrije massa samenstelling leidt vervolgens tot een hoger basaal energiegebruik per eenheid vetvrije massa. Tevens was het basaal energiegebruik bij adolescente jongens $12 \%$ hoger dan bij adolescente meisjes, onafhankelijk van lichaamssamenstelling en leeftijd. Het energiegebruik voor lichamelijke activiteit, gecorrigeerd voor verschillen in lichaamssamenstelling, was vergelijkbaar tussen alle groepen. Tenslotte bleken de berekeningsformules voor basaal energiegebruik, opgesteld door de 'Food and Agriculture Organisation of the United Nations, the World Health Organisation, and United Nations University (FAO/WHO/UNU)' en gebaseerd op gewicht, het energiegebruik bij obese adolescenten met $8 \%$ te overschatten, terwijl de FAO/WHO/UNUvergelijkingen voor volwassenen, tevens gebaseerd op gewicht, het gemeten basaal energiegebruik wel goed voorspelden. De FAO/WHO/UNU-vergelijkingen voor volwassenen werden aanbevolen voor het berekenen van het basaal energiegebruik van obese adolescenten.

De behandeling van kinderobesitas is primair gericht op dieet advisering en stimulering van lichamelijke activiteit. Farmacologische therapie wordt alleen toegepast indien door complicaties snel gewichtsverlies noodzakelijk is. De toenemende prevalentie van kinderobesitas en de teleurstellende resultaten van traditionele behandeling, nopen tot de ontwikkeling van nieuwe behandelingsstrategiëen. In hoofdstuk 6 van dit proefschrift werd in een dubbel-blind, placebo-gecontroleerd, gerandomiseerd onderzoek het effect geëvalueerd van sibutramine op lichaamssamenstelling en energiegebruik, in combinatie met een energiebeperkt dieet en een activiteitenprogramma. Gedurende een interventieperiode van 3 maanden voorkwam sibutramine, een recent ontwikkeld geneesmiddel dat het verzadigingsgevoel langer doet aanhouden, de daling van het basaal energiegebruik die optrad in de placebo groep. Tevens leek de sibutramine groep het energiebeperkt dieet beter vol te houden.

Concluderend tonen de studies die beschreven worden in dit proefschrift aan dat kinderen en adolescenten met PWS een lager dagelijks energiegebruik hebben, gebaseerd op een afgenomen groei van vetvrije massa, hetgeen zowel een verlagd basaal energiegebruik als een verlaagd energiegebruik voor lichamelijke activiteit tot gevolg heeft. De veranderingen in energiegebruik zijn mogelijk gerelateerd aan dysfunctionele hypothalame centra. Het basaal energiegebruik in nietsyndromaal obese adolescenten is echter toegenomen vergeleken met hun niet- 
obese leeftijdsgenoten. De oorzaak hiervan ligt niet alleen in een toegenomen vetvrije massa, maar hoogstwaarschijnlijk ook in een verschuiving in de vetvrije massa samenstelling. Indien obese adolescenten echter energie-inname restrictie ondergaan, zal het basaal energiegebruik dalen, hetgeen het effect van de obesitas interventie voor een deel teniet zal doen. Sibutramine kan deze compensatoire verlaging tegengaan en heeft daarmee de potentie om ondersteuning te bieden tijdens de behandeling van obese adolescenten. Onveranderd blijft het standpunt dat farmacologische therapie in de behandeling van kinderobesitas alleen geindiceerd is als conventionele therapie heeft gefaald. 


\section{Nawoord}

Wetenschap, zoals beschreven in de hoofdstukken van dit proefschrift, richt zich op het heden en vormt de basis voor de toekomst. Er gelden strikte regels waarbinnen veilige uitspraken kunnen worden gedaan. Aangekomen bij het nawoord wordt de promovendus plots geconfronteerd met de behoefte een retrospectieve beschouwing te geven van het recente verleden. De geschiedenis wordt echter beïnvloed door persoonlijke interpretaties uit een selectief geheugen en vormt daarmee een schril en gewaagd contrast met de vorige hoofdstukken. Ironisch genoeg is het nawoord juist het meest gelezen hoofdstuk van een wetenschappelijke verhandeling. Ook door onderzoekers. Zij weten als geen ander dat de vorming tot zelfstandig onderzoeker niet alleen gebaseerd is op de oefening in de wetenschap, maar ook in het leren omgaan met tijdsdruk, de variabele viscositeit van de universitaire bureaucratie, de media, de wispelturigheid van editorial boards, professionele proefpersonen, en zeker ook je collega's.

Het voert te ver om al deze facetten uitvoerig te beschrijven. Wat nu volgt is enkel een korte en ongetwijfeld onvolledige opsomming van diegenen die direct of indirect een bijdrage hebben geleverd aan de totstandkoming van dit proefschrift.

Mijn interesse in de kindergeneeskunde en daarmee de allereerste aanzet van dit proefschrift werd iets meer dan 10 jaar geleden gewekt bij Dr. Van Drumpt. Als eerstejaars student geneeskunde kreeg ik de mogelijkheid kennis te maken met de kinderafdeling van het voormalige St. Nicolaas ziekenhuis in mijn geboortestad.

Mijn eerste schreden in het wetenschappelijk onderzoek zijn echter moeilijker te traceren. De eerste pogingen werden weliswaar gedaan in het oude Annadal, bij Jaap Schrander, destijds nog werkzaam aan zijn eigen promotieonderzoek naar koemelkeiwitintolerantie bij zuigelingen, maar het werkelijk zelfstandig opzetten en uitvoeren van onderzoek vond het eerste plaats onder de bezielende leiding van professor Oded Bar-Or, aan het Children's Exercise and Nutrition Centre in Canada. Dear Oded, if you would have told me that it would take until the next millenium to do my PhD I wouldn't have believed you. Please believe me, when I tell you, that my stay at the CENC was a very beneficial experience, both as a future scientist and as a person. As often said, written or mailed - Let's keep each other posted!

Tijdens de periode in Canada was professor Wim Saris mijn interne begeleider en dat is de hele promotietijd zo gebleven. 'Kom maar met een voorstel', is de eerste zin die in me opkomt, 'in principe is alles mogelijk'. Wim, je was getuige van mijn eerste bokkensprongen in de wetenschap en gaf me de vrijheid om mijn eigen richting te bepalen. Je sterke gerichtheid op de nieuwste ontwikkelingen in de wetenschap werkte telkens enthousiasmerend. Uiteindelijk is de beslissing over mijn pro- 
motie-onderwerp gevallen in de metro van Barcelona, terugkomend van een 'social evening'. Dit geeft enerzijds duidelijk aan dat er niet altijd voldoende tijd was voor overleg, maar dat je anderzijds altijd open stond voor discussie op wat voor tijdstip of plaats dan ook.

Helaas leidde deze afspraak niet meteen tot een daadwerkelijke start van mijn promotie-onderzoek. Het viel dan ook zwaar om, na eindelijk officieel gestart te zijn bij Humane Biologie, de eerste twee jaar als promovendus volledig opgeslokt te zijn in een multicentre studie, waarin eigen wetenschappelijke inbreng vrijwel niet mogelijk was. In deze tijd werden diverse studies besproken o.a. met professor James O'Hill van de Universiteit van Denver, Colorado (VS) en professor Carlos Blanco van de vakgroep Kindergeneeskunde van het academisch ziekenhuis Maastricht (azM). Carlos, van meet af aan heb je je opgesteld als een duidelijke voorstander van wetenschappelijke scholing van toekomstige kinderartsen, hetgeen ik altijd als een sterke stimulans heb ervaren. De komende jaren zullen leren in hoeverre deze scholing ook in de kliniek zijn vruchten zal afwerpen.

Ondanks verwoede pogingen kwamen er in deze periode geen additionele studies van de grond. Achteraf bezien, blijkt een dergelijke lange start dan toch een hele leerzame geweest te zijn, waar ik nu met plezier aan terugdenk. Tanja, jij was heel duidelijk de spil van de SibuTrial en ik beschouw mezelf nog altijd als een geluksvogel dat we samen hieraan hebben kunnen werken. Mede door jouw grote gevoel voor verantwoordelijkheid was het mogelijk naast de SibuTrial mijn eigen werk op te zetten. Margot, je opgewektheid en interesse maakte je altijd een graag geziene gast, je daadkracht en begrip voor onze 'niet-klinische' klinische trial, een echte teamgenote. Later zou Lenke je taak overnemen, hetgeen ze op heel eigen wijze deed. En dan natuurlijk niet te vergeten, Ellen, mijn redster in diëtistische nood, die vrijwel vanaf de eerste dag de draai in ons team wist te vinden. Ook Marleen van Baak wil ik graag langs deze weg bedanken voor de prettige samenwerking en betrokkenheid in mijn studies, ook al vielen die de laatste twee jaar niet meer onder haar hoede.

De eerste praktische uitvoerbare studie voorstellen kwamen tot stand nadat contact was gelegd met Paul Curfs en Connie Schrander, van de Stichting Klinische Genetica Limburg. Paul en Connie, het multidisciplinaire karakter dat jullie aan het Prader-Willi onderzoek geven zou voor veel vakgroepen als model kunnen fungeren. Het gevolg is wel dat er nog veel werk op ons ligt te wachten. Marleen Manders, mijn allerbeste en enige stagiaire. Marleen, ons gezamelijke artikel laat nog altijd op zich wachten, maar ooit zal het er echt van komen! Vanwege het statistiek onderwijs (met name na de cursus), is Arnold Kester onmisbaar gebleken in de opzet en de latere rapportage van het onderzoek. Arnold, ik vond onze besprekingen niet alleen erg leerzaam, maar ook erg plezierig. Bedankt voor je tijd en de hulp bij de stellingen! Ook Wouter van Marken Lichtenbelt mag in dit rijtje niet ontbreken. Wouter, naast je onuitputtelijke hulp bij het puzzelen naar goede 
literatuur over lichaamssamenstelling van kinderen, wist je me ook altijd met een brede grijns je kantoor uit te sturen. Je brede biologische kennis gecombineerd met je sterke relativeringsvermogen en gevoel voor humor maakte het overleg altijd weer een prettig intermezzo. Ook Willem-Jan Gerver verstaat de kunst om moeilijke materie zo simplistisch uit te leggen dat je bijna gaat geloven dat je het daadwerkelijk begrijpt. Na enige tijd klaart de euforie op en niet zelden bleek daarna de oorspronkelijke vraag nog niet beantwoord. Gelukkig heeft de toekomst nog vele vragen in het verschiet...

Als dan, na een periode van twee jaar, in de zomer van '97, eindelijk 'mijn eigen' proefpersonen druppelsgewijs in het lab worden uitgenodigd, bleek het soms moeilijk het hoofd koel te houden, beseffend dat de resterende onderzoekstijd zo efficiënt mogelijk benut diende te worden. Vanaf dat moment is de begeleiding van professor Klaas Westerterp van essentieel belang geworden. Klaas, telkens wist je me weer op het juiste spoor te zetten als ik de rode draad kwijt was.

Meerdere malen hebben je heldere blikken op de data me wakker geschud en je ontnuchterende opmerkingen me de ogen doen openen. Zonder jouw begeleiding zou dit schrijven nu niet voor ons liggen.

Ondanks de hoge tijdsdruk waren er gelukkig collega's die je met beide benen op de grond weten te zetten. Jos, een man van weinig woorden, dus.. moet ik hier nog iets aan toevoegen? Truus, met al jouw mensenkennis kun je makkelijk zelf eens een boekje schrijven. Joan, gelukkig gingen onze gesprekken zelden over onderzoek. Jouw enthousiasme voor sport heeft altijd een stimulerende invloed op me gehad. Het zal alleen nog wel even duren voordat ik voor je in de Messcher Bergloop zal eindigen. Desirée en later zeker ook Claudia en Peggy, ondanks jullie drukke secretariële werkzaamheden kon ik jullie altijd storen met mijn lastige vragen, nogmaals bedankt daarvoor! Paul en Loek, de werkpaarden annex wizz-kids ofwel willi-wortels van HB. Kortom, zonder jullie is wetenschap niet meer mogelijk op planet-HB. Trouwens over bedanken gesproken... Arjen, waar bliff ons Lancet artikel nou?

Dan is er natuurlijk nog de grote groep promovendi en overig voetvolk, zoals Luc, the barbarian, 'Frolijke Freddy, de ritselaar, 'leptine'Chris, 'Enkhuizer-irritantje'Erwin, 'Beaker'-Joost, 'Professor' P. Schrauwen, met dank voor het lezen van de Nederlandse samenvatting, snelle Marco, 'big' Bert, mijn bevallige vrouwelijke collega's Sandra, Dorien, Annelies, Eva en Marleen en de immer 'brave ende oprechte' collega's van de voormalige divisie 2 . In het begin voelde ik me als enige arts een vreemde eend in de bijt, maar al snel werd duidelijk dat het hele gezelschap uit exotisch pluimvee bestond, dat van 's ochtends vroeg tot 's avonds laat en vaak in de weekenden aardig wat veren kon doen opwaaien (om maar niet te spreken over het kakelende kippenhok bij het koffiezetapparaat). Het valt niet mee om van zo'n gemeleerde bende afstand te moeten nemen, dus vandaar dat ik ongevraagd 
nog af en toe mijn gezicht zal laten zien op de laatste donderdag van de maand. Inmiddels ben ik weer aan een nieuwe uitdaging begonnen, die zeker zo groot is. Weer ben ik enigszins een vreemde eend, nu vanwege mijn absolute non-ervaring op klinisch gebied. Maar gelukkig heb ik het weer getroffen met mijn collega's, ditmaal van het azM, die de landing in de kliniek wisten te verzachten: Clarry, Rony, Annemiek, Singrid, Ingrid, Maartje, Eric, Henriëtte, Monique, Phillip, Colleen, Paola, Derek-lan en Jaap houd moed, met jullie hulp ben ik binnenkort een echte dokter.

Tenslotte wil ik dit betoog beeindigen met enkele personen die de afgelopen periode een bijzondere rol hebben gespeeld. Dean, forgive me that l address these few words to you in English instead of Dutch, which is your -almost- second language. During these last few months you have been a tremendous help to me, both by inviting me to stay at your house so I could look for my own appartment, as well as correcting my Dutch-English in my thesis. You have become a real friend and I hope that I can return the favour in the near future. In the mean while stay the positivelythinking and genuine Scientist, that you are, and let's stay in touch no matter where your enviable department may need you.

Michiel, collega! Je behoort tot een zeldzame groep mensen die duidelijke keuzes durft te maken en zich daar ook aan weten te houden. Ik ben blij dat je op mijn verzoek koos mijn paranimf te worden, en ik weet dat ik op je kan rekenen.

Steven (wereldwijd beter bekend als Dr. Damink), tijdens mijn promotietijd heb je voor mij als een bron van inspiratie gefungeerd. Je hebt me niet alleen betrokken bij de atletiekvereniging DDS, waaraan ik nieuwe vrienden, Rogier, Dennis en Michiel, heb overgehouden, maar je hield me ook regelmatig een spiegel voor als ik weer eens te hard van stapel liep. Ik ben niet alleen verheugd, maar ook trots dat je mijn paranimf wilt zijn. En, Rogier, bedankt voor je altijd beschikbare luisterend oor. De kwaliteit van de schaatscursussen mag dan wisselend zijn, de heenen terugreis was altijd van grote klasse!

Pap en Mam, al vanaf het prilste begin gelden jullie, samen met Harald en Annabelle, als mijn fanatiekste supporters. Nog altijd beschouw ik jullie als mijn grote voorbeeld, al zal het niet makkelijk zijn om dit te evenaren. Dankzij jullie steun vond ik het vertrouwen terug als ik dat soms even kwijt was.

Sandra, nu het moment eindelijk daar is dat er een punt achter deze promotie kan worden gezet, schieten woorden tekort. Ondanks mijn matige voorspellingen over de afronding van het proefschrift en de gepaard gaande perioden van vorst in ons sociale leven, kon ik tijdens de moeilijkste momenten altijd op je steun rekenen. De laatste jaren heb je er veel alleen voor moeten staan en 'onze' beslissingen vaak grotendeels zelf moeten nemen. Telkens kon je weer begrip opbrengen voor mijn afwezigheid tijdens belangrijke gebeurtenissen. Ik heb er grote bewondering voor dat je altijd achter me bent blijven staan. San, dit boekje is klaar, maar óns laatste hoofdstuk is nog lang niet geschreven! 


\section{Curriculum vitae}

Name:

van Mil, (Edgar) Gerardus Antonius Henricus

Date of Birth:

September 13,1969

Place of Birth:

Waalwijk, The Netherlands

Education:

- Gymnasium B, dr. Mollercollege, Waalwijk

- Medicine, Maastricht University, Maastricht, the Netherlands

- Graduate Program in Medical Sciences: Fundamentals in Clinical Epidemiology and Biostatistical Topics in Clinical Epidemiology, MCMaster University, Hamilton, Ontario, Canada

- M.D. degree in 1995, Maastricht University, the Netherlands

- Clinical Research Fellow at the Department of Human Biology, Nutrition Toxicology and Environment Research Institute Maastricht, under the guidance of Prof. dr. W.H.M. Saris Project: 'A randomised, placebo controlled, double-blind, parallel group multicentre trial of the effect on maintenance of weight loss, of treatment with sibutramine in combination with a recommended diet and exercise programme'. Period: 1995 - 1998 - Ph.D. student under the guidance of Prof. dr. W.H.M. Saris, Prof. dr. K.R. Westerterp of the Department of Human Biology, Maastricht University and Prof. dr. C.E. Blanco of the Department of Paediatrics, University Hospital Maastricht Project: 'Metabolic aspects of childhood obesity'. Period: 1997 1999

- Resident in Paediatrics at the Academic Hospital Maastricht. Period: 1999 - 2005

External Stays: Children Exercise and Nutrition Centre, McMaster University, Hamilton, Ontario, Canada under the guidance of Prof. dr. O. BarOr. Period: January - October 1992. Project: 'Optimal Load Measurement in the Wingate Test in Children with Neuromuscular Diseases'. - GOVERNMENT OF CANADA AWARD 1992

Membership: European Childhood Obesity Group 
70 | 


\section{Publications}

\section{Journal Articles}

Optimization of force in the wingate test for children with a neuromuscular disease. E. van Mil, N. Schoeber, R.E. Calvert and O. Bar-Or. Med Sci Sports Exerc, 1996; 28: $1087-1092$

Muscle function of 11- to 17-year-old children of extremely low birthweight. $E$. Small, O. Bar-Or, E. van Mil, S. Saigal. Pediatric Exercise Science 1998; 10: 327-336

Debate: Physical activity and the prevention of childhood obesity - Europe versus the United States. E.G.A.H. van Mil, A.H.C. Goris, K.R. Westerterp. Int J Obes, 1999; 23: $541-44$

Energy expenditure at rest and during sleep in children with Prader-Willi syndrome is explained by body composition. E.G.A.H. van Mil, K.R. Westerterp, W.J.M. Gerver, LM.G. Curfs, C.T.R.M. Schrander-Stumpel, A.D.M. Kester, W.H.M. Saris. Am J Clin Nutr, 2000;71:752-756

Activity induced energy expenditure in children and adolescents with Prader-Willi syndrome. E.G.A.H. van Mil, K.R. Westerterp, A.D.M. Kester, L.M.G. Curfs, WJ.M. Gerver, C.T.R.M. Schrander-Stumpel, W.H.M. Saris. Int J Obes, 2000; 24: 429-434

Body composition in Prader-Willi syndrome compared with nonsyndromal obesity: Relationship to physical activity and growth hormone function. E.G.A.H. van Mil, K.R. Westerterp, W.J.M. Gerver, W.D. van Marken Lichtenbelt, A.D.M. Kester, L.M.G. Curfs, C.T.R.M. Schrander-Stumpel, G.A.K Heidendal, W.H.M. Saris. J Pediatr, accepted

Energy expenditure in adolescence: a multicenter analysis of the effect of gender and body composition. E.G.A.H. van Mil, K.R. Westerterp, A.D.M. Kester, W.H.M. Saris. Arch Dis Child, accepted

Sibutramine prevents the decrease in basal metabolic rate associated with restriction of energy intake in obese adolescents. E.G.A.H. van Mil, K.R. Westerterp, A.D.M. Kester, W.D. van Marken Lichtenbelt, W.J.M. Gerver, W.H.M. Saris. submitted 


\section{Abstracts}

Prediction of optimal braking force for the wingate test during arm cranking in children and adolescents with neuromuscular disabilities. E. van Mil, N. Schoeber, R. Calvert, O. Bar-Or. Pediatric Exercise Science, 1993; 5:481

Energy metabolism and body composition in Prader-Willi syndrome. G.A.H. van Mil, K.R. Westerterp, W.H.M. Saris, C.T.R.M. Schrander-Stumpel, L.M.G. Curfs. International Conference on Prader-Willi syndrome, Venice, Italy, 1997.

Sleeping metabolic rate adjusted for fat-free mass in Prader-Willi syndrome. G.A.H. van Mil, K.R. Westerterp, L.M.G. Curfs. C.T.R.M. Schrander-Stumpel, W.H.M. Saris. Int J Obes, 22, S3, P396, 1998

Relative expansion of extracellular water in children with Prader-Willi syndrome vs. obese controls. G.A.H. van Mil, W.D. van Marken-Lichtenbelt, K.R. Westerterp, L.M.G. Curfs, W.H.M. Saris. Int J Obes, 1998; 22: S12

Fat-free mass as a function of fat mass in children with Prader-Willi syndrome. G.A.H. van Mil, K.R. Westerterp, W.J.M. Gerver, L.M.G. Curfs, C.T.R.M. SchranderStumpel, W.H.M. Saris. Int J Obes, 1999; 23: 544

Determination of body water from bioimpedance spectroscopy. T.P. Gill, M.C.W. van Wijk, G.A.H. van Mil, M. Elia, G. Jennings, W.P.T. James, W.M. Saris. Int J Obes, 1999; 23: $\$ 107$

Drug treatment in obese adolescents. E.G.A.H. van Mil and D. Molnár. Int J Obes, accepted 



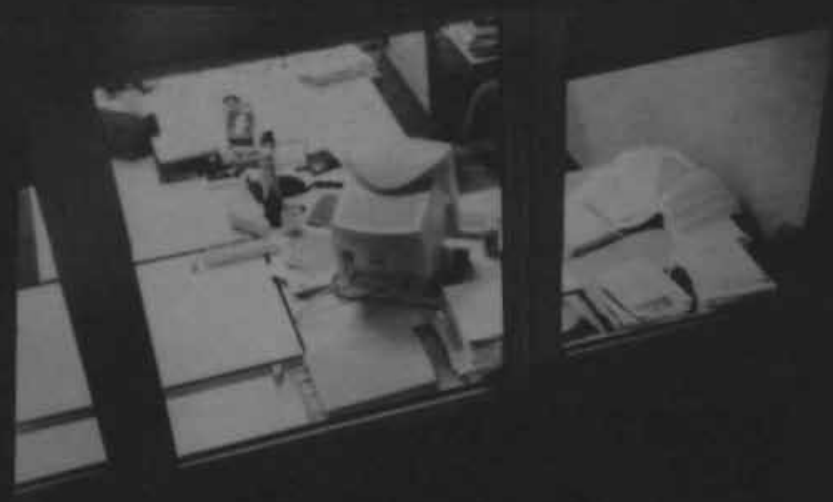

'The author's seat' 